University of San Diego

Digital USD

2011-05-01

\title{
What Do They Say? Students from a Private, Faith-Based, Four- Year University Share their Perspectives on College as a Mentoring Environment
}

Jeffrey Andrew Bolster EdD

University of San Diego

Follow this and additional works at: https://digital.sandiego.edu/dissertations

Part of the Leadership Studies Commons

\section{Digital USD Citation}

Bolster, Jeffrey Andrew EdD, "What Do They Say? Students from a Private, Faith-Based, Four-Year University Share their Perspectives on College as a Mentoring Environment" (2011). Dissertations. 821. https://digital.sandiego.edu/dissertations/821

This Dissertation: Open Access is brought to you for free and open access by the Theses and Dissertations at Digital USD. It has been accepted for inclusion in Dissertations by an authorized administrator of Digital USD. For more information, please contact digital@sandiego.edu. 


\title{
WHAT DO THEY SAY? \\ STUDENTS FROM A PRIVATE, FAITH-BASED, FOUR-YEAR UNIVERSITY SHARE THEIR PERSPECTIVES ON COLLEGE AS A MENTORING ENVIRONMENT
}

\author{
by \\ Jeffrey Andrew Bolster \\ A dissertation submitted in partial fulfillment \\ of the requirements for the degree of \\ Doctor of Education \\ University of San Diego
}

May 2011

Cheryl Getz Ed.D., Chair

Theresa Monroe Ph.D., Member

George Reed Ph.D., Member 
(C) Copyright by Jeff Bolster 2011

All rights reserved 


\begin{abstract}
Research indicates that the term mentor in the context of higher education currently has multiple definitions and is used to describe a variety of programs, efforts, and formal as well as informal activities. In recent years, interdisciplinary perspectives on traditional undergraduate students have been converging around the idea that the functions and characteristics of mentoring students could be shared across the institution, creating what Daloz Parks (2000) has called a mentoring environment. This sharing of responsibility has the possibility to address what Baxter Magolda (2009) has recently identified as missing in higher education, a "holistic, theoretical perspective to promote the learning and developing of the whole student" (p. 621). A review of the literature from psychology, sociology, and student affairs documents this attempt to consider a more integrated and collaborative approach to college as a mentoring environment.

The purpose of this research was to understand better how these students perceived, received, understood, and experienced one aspect of their college experience: mentoring. This qualitative study used thematic analysis to consider the input of 12 undergraduate students who have recently or will soon graduate from a private, four-year, faith-based liberal arts university in Southern California.

The study was guided by the following research questions: How do graduating seniors attending a private, traditional, faith-based, four-year liberal-arts university describe mentoring? How do the students describe the formal and/or informal mentoring they have received during their college years? What suggestions do the students have for improving the university's formal and informal mentoring efforts? Based on extensive data analysis, findings revealed that students spoke to the transformative nature of relational and participatory experiences with faculty, staff and administrators as well as
\end{abstract}


the value of opportunities to interact with several important adult mentors. Irrespective of efforts categorized as formal or informal mentoring, participants spoke more to the value of campus leaders showing an interest in their personal and professional development.

Recommendations are offered for faculty, staff and administrators regarding a more holistic and collaborative approach to college as a mentoring environment. Beyond this study, the recommendations discussed should be considered based on individual, institutional suitability. 


\section{Dedication}

This project is dedicated to my wife, Danielle. Throughout my four years of doctoral coursework, along with the final year of writing this dissertation, she has been supportive, encouraging, and loving. I am sure I would not have been able to finish this degree had it not been for her. I am grateful and humbled at her sacrifice that has us now across the finish line. 


\section{Acknowledgements}

Dr. Cheryl Getz. As my advisor, you have been consistent, fair, invested, and authentic since the day I rode the shuttle up the hill with you during orientation. As my committee chair, you have been supportive, available, and thorough. I look forward to continuing to take up good and important work with you in the years to come.

Dr. Terri Monroe. In the course of my time here at USD, you have helped to restore my faith in spirituality. When I began this program, I regularly downplayed the inner life. I end with a dissertation that attempts to integrate spirituality and higher education.

Dr. George Reed. In every class and interaction I have had with you, you listen, ask good questions, and call forth the best in academic rigor. And while feedback from you on my first couple of papers was shocking in volume and detail, I came to rely on and trust those standards. 


\section{Table of Contents}

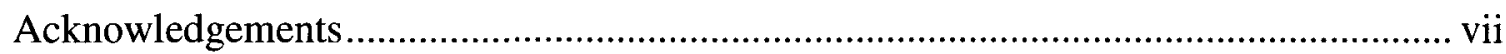

Table of Contents ..................................................................................................... viii

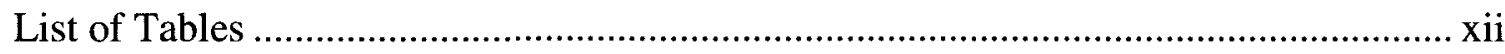

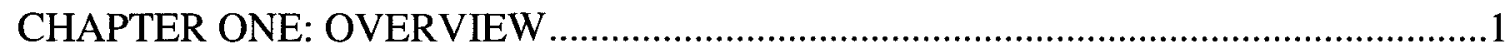

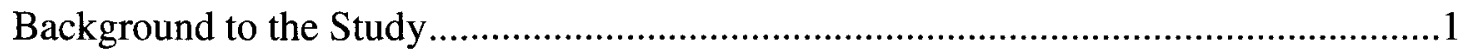

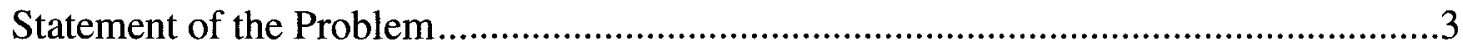

Purpose of the Study and Research Questions...........................................................

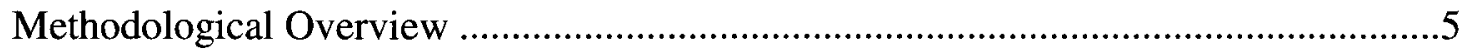

Limitations and Delimitations of the Study …………..............................................

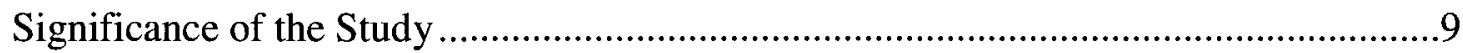

CHAPTER TWO: REVIEW OF THE LITERATURE .................................................11

Mentoring: A Problematic Concept ...........................................................................11

Mentoring and Higher Education.........................................................................11

College as a Mentoring Environment ...................................................................

Adult Development Theory and College as a Mentoring Environment .....................13

The Developmental Transition from Adolescence to Adulthood ................................14

Adult Development: Classic Stage Development Theories.......................................15

Recent Young Adult Development Literature: A New Fourth Stage? .......................16

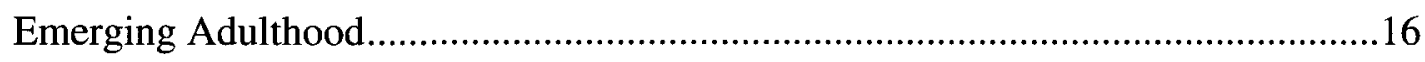

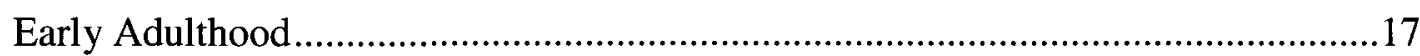

Making Meaning, Faith, and Young Adult Development .........................................18

Reasons for the Rise of a Fourth Stage of Adulthood ................................................19

Marriage and Parenthood ............................................................................... 19

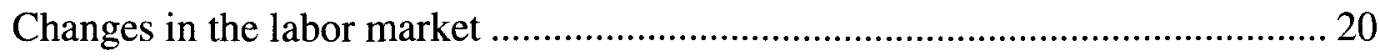


Higher education

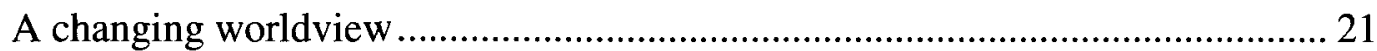

Generational Labeling and the College as a Mentoring Environment.......................22

College as a Mentoring Environment: Conditions, Practices, and Pedagogy.............24

Young Adult Development and Student Affairs.......................................................24

Conditions of College as a Mentoring Environment ………….................................25

Best Practices and College as a Mentoring Environment ..........................................28

Constructive Developmental Pedagogy and College as a Mentoring Environment..31

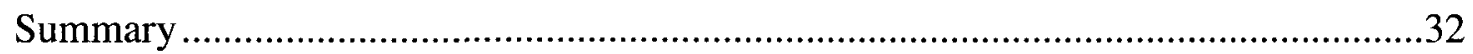

CHAPTER THREE: RESEARCH DESIGN AND METHODOLOGY …………..............34

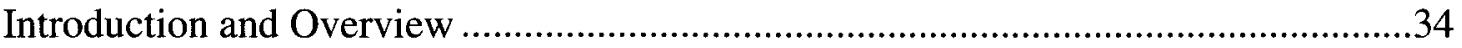

Research Site

Contact, Selection, and Scheduling ………………….........................................

Research Participants ...........................................................................................42

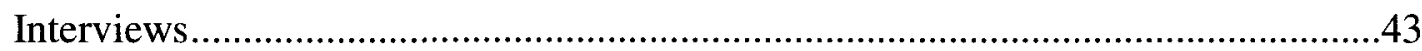

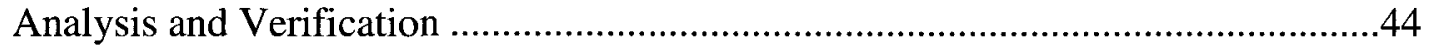

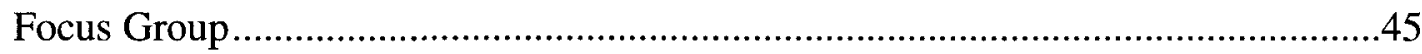

Collapsing of Broad Themes to Useable Categories ................................................46

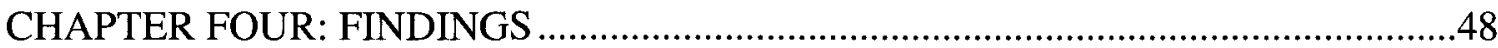

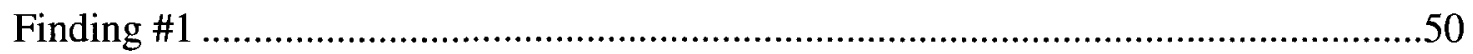

Relational and Participatory Experiences ...............................................................51

Relational and Participatory Experiences as Transformational ..................................57

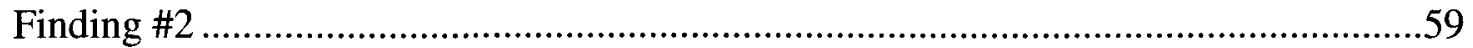

The Morrie Syndrome

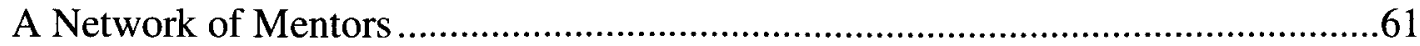




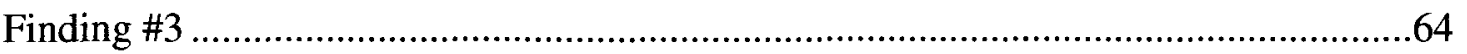

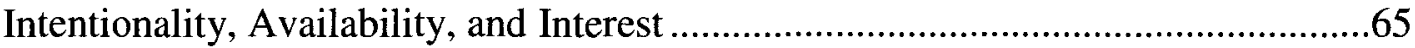

The Integration of Student Development Theory with Mentoring Efforts .................66

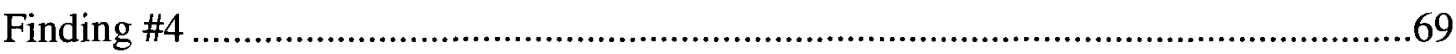

Formal Versus Informal ......................................................................................

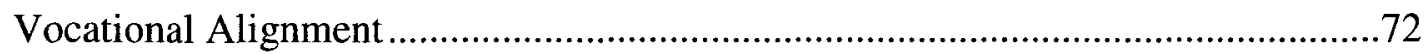

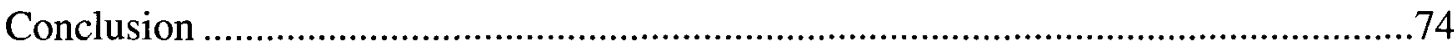

CHAPTER FIVE: CONCLUSIONS, DISCUSSION, AND SUGGESTIONS FOR

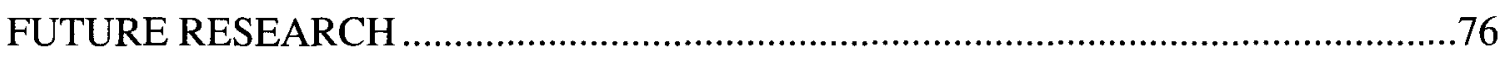

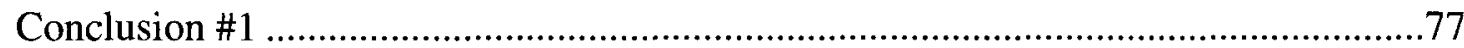

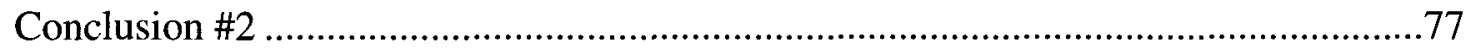

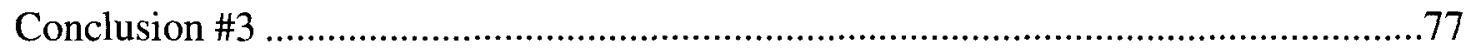

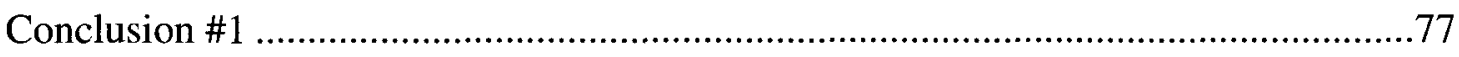

Looking for Significance as Part of Young Adult Development...............................78

Dismissive Labeling as Inhibitive to Holistic Development .....................................79

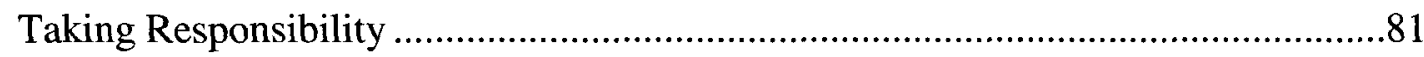

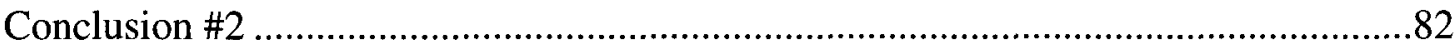

The Realities and Challenges of College Students ....................................................83

The Realities and Challenges of Staff, Faculty and Administrators............................83

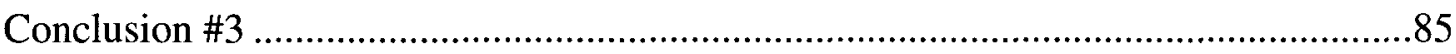

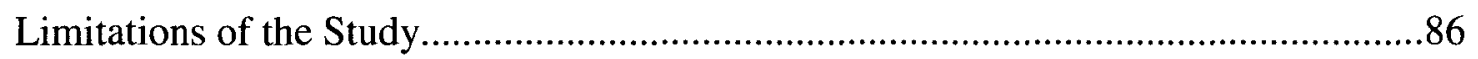

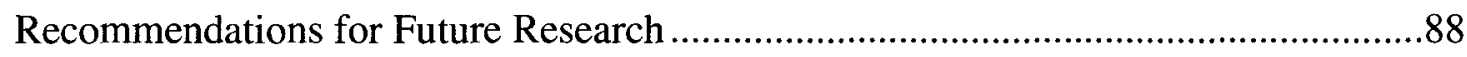

Access to Education and Mentoring Networks........................................................8

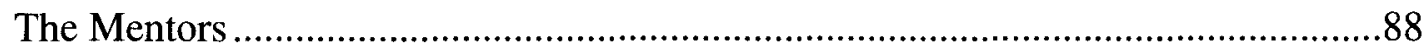

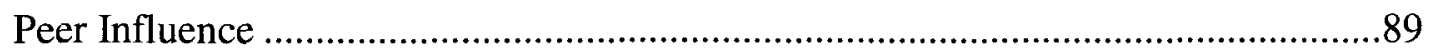


Conclusion .90

References .91

Appendix A: Original Interview Guide (Pre-Pilot Study) ..............................................101

Appendix B: Summary of Pilot Study …………………............................................103

Appendix C: Final Interview Guide ...........................................................................106

Appendix D: Table of Classic Three-Stage Adult Development Stages ...........................108

Appendix E: Table Comparison of the Three- and Four-Stage Models of Adult

Development

Appendix F: Summary of Contact, Selection, and Scheduling of Individual Interviews 112

Appendix G: Focus Group Participant Breakdown .......................................................114

Appendix H: Master List of Potential Themes .........................................................116

Appendix I: Coding Scheme Used to Transition Themes into Useable Categories ........120

Appendix J: Structural Framework .........................................................................122

Appendix K: Data Analysis Map .................................................................................124

Appendix L: Draft of Invitation Email (Not Used in Final Study).................................126

Appendix M: Research Participant Consent Form ..........................................................128

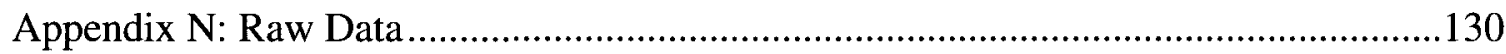




\section{List of Tables}

Table 1: Classic Three Stage Adult Development Stages 109

Table 2: Comparison of the Three- and Four-Stage Models of Adult Development ......111

Table 3: Summary of Contact, Selection and Scheduling of Individual Interviews........113

Table 4: Focus Group Breakdown .115 


\section{WHAT DO THEY SAY? \\ STUDENTS FROM A PRIVATE, FAITH-BASED, FOUR-YEAR UNIVERSITY \\ SHARE THEIR PERSPECTIVES ON COLLEGE AS A MENTORING ENVIRONMENT \\ CHAPTER ONE: OVERVIEW}

\section{Background to the Study}

The traditional four-year undergraduate college experience takes place at a key developmental time in the lives of young adults. As a result, institutional efforts to mentor college students are numerous and include strategies that are both formal and informal. Formal mentoring is most often seen in programs and relationships directed at high-risk, underrepresented, under-served, or underachieving college student populations (Astin, 1977; 1993; Carr, 1996; Erkut \& Mokros, 1984; Jacobi, 1991; Johnson, 2006; Kinzie, Schuh, Whitt, \& Kuh, 2005; Komives, Woodard Jr., \& Associates, 2003; Pascarella \& Terenzini, 1991, 2005; Reynolds, 2009; Van Puymbroeck \& Maryland Univ, 2001; Wallace \& Abel, 1997). Informal mentoring can be even more difficult to define and is attributed to relationships between students and faculty, supervising staff, and even peers (Fogg, 2009; Jacobi, 1991; Lasley, 1996). These varied approaches often make mentor an elusive term and a concept that is difficult to define or measure. In fact, the word mentor conjures up an enormous number of definitions, expectations, and interpretations across multiple sectors, including the academy, business, and the military (Erkut \& Mokros, 1984; Jacobi, 1991; Reed, Martin, Collins, \& Dial, 2002; Sorcinelli \& Yun, 2007).

As is true in other sectors of society, the term mentor in the context of higher education is associated with multiple definitions and a wide variety of programs and initiatives. A recent Educational Resource Information Center (ERIC) search of the two keywords undergraduate mentoring, limited to the last 10 years, yielded almost 3,000 
results. In her comprehensive and widely cited review of the literature of mentoring in higher education published by the American Educational Research Association's Review of Educational Research, Jacobi (1991) indicated two major problems with the concept of mentoring: the glaring absence of a widely accepted operational definition and a questionable link between mentoring and academic success.

One intriguing theory of mentoring in higher education focuses on college as a mentoring environment (Daloz Parks, 1986; 2000; Daloz Parks, Parks Daloz, Keen, \& Keen, 1996). From this perspective, the responsibility to care for the institutional environment is shared by all the stakeholders. In fact, when the literature on mentorship is limited to traditional undergraduate students attending four-year institutions, there is a perceptible convergence around the idea that faculty, staff, administrators, peers, and other aspects of the college experience can combine to create and enhance the environment where mentoring takes place (Astin \& Chang, 1995; Baxter-Magolda, 1992; Boyer, 1990; Calabrese, 1996; Kaye, 2000; McDonald, 2002; Nora \& Crisp, 2008; Daloz Parks, 2000, 2008; Sorcinelli \& Yun, 2007; Storrs, Putsche, \& Taylor, 2008; Van Puymbroeck, 2001; Willimon, 1997). Parks (1986, 2000, 2009) has clearly articulated this idea of college as a mentoring environment, contending that effective concepts and practices of mentoring should embrace and respect the classically understood and "venerable term" (2000, p. 127) of mentor while realizing "that a network of belonging that serves young adults as a mentoring environment may offer a powerful milieu and critical set of gifts in the formation of meaning, purpose, and faith" (p. 127).

Such conceptualizations and the studies that support them (Boyer, 1990; McDonald, 2002; Settersten Jr., Furstenberg Jr., \& Rumbaut, 2005) do not eliminate the classic notion of mentorship as a one-on-one relationship, but they expand the definition 
to include a collaborative view that has the capacity to hold numerous aspects of mentoring undergraduate students. In the literature, this collaborative view is referred to as the mentoring process (Calabrese, 1996), a shared responsibility (Storrs et al., 2008), a mentoring web (Van Puymbroeck, 2001), a mentoring constellation (Johnson, 2006), and mentoring networks (Sorcinelli \& Yun, 2007).

As this environmental view of mentoring gets defined and implemented on campuses throughout the country, researchers and practitioners have begun to call for and use student input to help shape and bring clarity to initiatives and policies designed to transform a college into a mentoring environment (Daloz Parks, 1986; Daloz Parks, 2009; King, 2009; Kuh, 2009; 2009; Nora \& Crisp, 2008).

\section{Statement of the Problem}

There is a need to understand better how students experience and make sense of mentoring efforts during their college years. Given that the college years represent a key period for young adult development along with the amount of resources that institutions invest into mentoring-type efforts, it seems clear that the recipients of mentoring efforts should help shape how the notion of college-as-a-mentoring-environment becomes operational in college campuses. The problem comes when students are not regularly asked about their perspectives on their educational environment. Programs and pedagogies that are not shaped with collaborative input from students are often flawed. Some of the preeminent researchers in the field of student affairs have called this work with students the co-creation of knowledge (Baxter Magolda, 2001; Baxter Magolda \& King, 2004) and suggested that undergraduate student experience and input should consistently inform all aspects of higher education, including this developing concept of college as a mentoring environment (Astin, 1993; Bliming, Whitt, \& Associates, 1999; 
Hoover, 2009; Levine \& Cureton, 1998; Lewis, 2006; Wallace \& Abel, 1997; Willimon, 1997; Wolfe, Retallick, Martin, \& Steiner, 2008).

Baxter Magolda (1992, 2001) captures data from a longitudinal study that she began with 101 first-year college students in 1986. In the opening of Making Their Own Way, Baxter Magolda says, "This book is about being better company for young adults on their journeys toward self-authorship, their journeys toward making meaning of their own lives" (p. xi). Both of these works model the positive potential for the use of qualitative interview data that is woven into the presentation of theoretical data, and Baxter Magolda's results from this and other endeavors are regularly cited in the leading journals of higher education and student affairs.

Using Baxter Magolda's idea of “better company" (2001), there is need for a deeper understanding of the developmental processes that impact undergraduate students. And, specifically related to my own field of higher education administration, there is a need for those of us who take up leadership in higher education to regularly seek and use input from students, who are key stakeholders in the educational environment. Such an approach provides additional information about who these students are and treats them as collaborators in their own educational experience. As will be discussed further in the literature review, this developmental approach of inquiry is taking place in many disciplines that overlap on young adult development, including sociology, psychology, and higher education. More and more researchers and practitioners from these discipline are considering the internal lives of young adults (Arnett, 2000; Astin, Astin, \& Lindholm, 2011; Chickering, 2010; Nash \& Murray, 2010; Palmer, Zajonc, \& Scribner, 2010 ; Settersten Jr., et al., 2005) as a key consideration of the college education. This approach of inquiry also opens institutions to the powerful ways in which students make 
meaning out of their own experiences. By engaging the student experience, we gain a better understanding of how undergraduate students attending traditional four-year universities describe the functions and characteristics of a campus community.

\section{Purpose of the Study and Research Questions}

The purpose of this qualitative study was to understand better how a group of 12 traditional undergraduate seniors attending a private, faith-based, traditional, four-year liberal-arts university in Southern California perceived, received, understood, and experienced one aspect of their college experience: mentoring. The study explored if and how they identify any experience of mentoring and was guided by the following research questions:

1. How do graduating seniors attending a private, traditional, faith-based, four-year liberal-arts university describe mentoring? What do they say about the function and characteristics of mentoring?

2. How do the students describe the formal and/or informal mentoring they have received during their college years?

3. What suggestions do the students have for improving the university's formal and informal mentoring efforts?

\section{Methodological Overview}

I conducted qualitative interviews with a total of 12 students who graduated in May 2010 or would graduate in May 2011 from my research site: a private, traditional, faith-based, four-year liberal-arts university in Southern California. After seven interviews, I conducted a focus group of 12 students. This focus group was made up of four students who had previously been interviewed and eight students who had been suggested as interview candidates by staff and faculty. I then proceeded with the 
remaining four interviews. At the outset of this study, I anticipated that approximately 12 - 15 interviews would provide robust data related to the topic. I also anticipated that after the focus group, I would be close to a saturation point; that is to say that the themes and ideas would be such that proceeding with more interviews would be redundant.

The use of qualitative methodology for this project is appropriate, necessary, and directly linked to the review of the literature, the stated problem, and the intended outcomes of the study. As Patton (2002) indicates, these kinds of interviews serve to "facilitate study of [these] issues in depth and detail" (p. 342). In the study, my intention was to model the very kind of programmatic and pedagogical approaches that are important in undergraduate higher education. All of these aspects of the project were connected to gathering student input on mentoring in order that efforts, ideas, and programs could be situated more closely in the realities of student experience. As Baxter Magolda (2001) stated, “Students perceive education as 'not made for them' when it does not acknowledge, respect, and connect to their experience and perspectives" (Baxter Magolda, 2001, p. 234).

All interviews used an interview guide that had already undergone a pilot study (see Appendix A for Interview Guide, Pre-Pilot Study; Appendix B for Summary of Pilot Study; and Appendix C for Final Interview Guide). Interviews were recorded. I personally transcribed each interview prior to initiating the coding process. Analysis of Research Question One "How do graduating seniors attending a private, traditional, faith-based, four-year liberal-arts university describe mentoring? What do they say about the function and characteristics of mentoring?" provided an opportunity for students to describe mentoring. The literature suggests two aspects of mentoring: the functions (more active) and characteristics (more passive) of mentoring (Bliming, Whitt, \& Associates, 
1999; Kinzie, et al., 2005; Komives, et al., 2003; McDonald, 2002; Pascarella \& Terenzini, 2005). Analysis of Research Question Two "How do the students describe the formal and/or informal mentoring they have received during their college years?" looked at similarities and variations of the students' personal experiences (or lack of experiences) with mentoring during college. Finally, analysis of Research Question Three “What suggestions do the students have for improving the university's formal and informal mentoring efforts?" considered suggestions these students had in terms of the research site's efforts at formal and informal mentoring. The purpose of this question was to explore what students perceive as institutional successes, gaps, or shortcomings in creating a mentoring environment.

\section{Limitations and Delimitations of the Study}

This is a qualitative study and was purposefully based, in part, on self-reported data from undergraduate students at only one institution. Other limitations with this study must be acknowledged as well. The number of interviews was relatively small, and all participants came from the same institution, a private, faith-based, liberal-arts institution. Tuition, room, and board for this institution costs more than $\$ 30,000$ annually, which limits access for a number of socio-economic groups.

As will be discussed later in this study, considerable efforts were made to attain interpretations of the data at a level of trustworthiness (Bloomberg \& Volpe, 2008; Lincoln \& Guba, 1985; Merriam, 2002; Patton, 2002). Limitations extended beyond external validity or generalizability to include internal validity limitations. To be sure, this study attempted to identify a variety of participants by use of convenience and judgment sampling. In the process, I hoped to represent a variety of student views. 
However, true representation of the student body (approximately 2,200 students) is beyond the scope of this project.

There is another potential limitation: I hold a position of formal authority at the research site. As dean of students, I am responsible for residential life and matters of student conduct. While all attempts were made to ensure students did not perceive any coercion, risk, or potential reward by participating or not participating in the study, the sought-after student input could have been skewed by the power differential involved. As is detailed in the Data Analysis Map (Appendix K), I made use of multiple qualitative research strategies to ensure maximum trustworthiness, validity and reliability while simultaneously minimizing the power differential and my own personal biases.

This included, among other components, triangulation of the data via member checks, the literature and peer review/examination. A majority of the participants in the study were nominated by colleagues and selection criteria were predetermined. These strategies were employed to minimize the impact of my position as researcher and a formal authority at the research institution.

This study did not set out to narrow or clarify the difficulty surrounding a definitional understanding of the term mentor. Rather, this study sought to explore the ambiguity along with the various interpretations of, and expectations surrounding, the term as constructed by a group of college students. Similarly, this study was not intended to consider solely or to measure the impact of programs that could be classified as "formal" mentoring (i.e. academic improvement, engagement, retention), though some students interviewed alluded to mentoring relationships or encounters that could be classified as formal. 
Also, it is important to state that I am aware that this environmental approach to mentoring and the experience of a four-year college student does not negate student effort and responsibility. Rather, it points to those conditions, programs, strategies, and relationships that assist a student in the challenging and complicated transition to young adulthood.

\section{Significance of the Study}

The transition to young adulthood is challenging. In higher education student affairs literature, it is said that college is a time for students to develop, a process that also has been called "making meaning" (Baxter Magolda, 1999; Baxter Magolda, 1992, 2001, 2009; Baxter Magolda \& King, 2004; Chickering, Dalton, \& Stamm, 2006; Cote, 2006; Daloz Parks, 2000). Colleges and universities that espouse a desire to create a holistic environment for this meaning making, that is, a place where the development of students is shared across institutional boundaries, would find valuable input from studies such as this one.

Also, with more studies like this, institutional assumptions about what students value can be cross-referenced against actual input from students. With administrators, faculty, and staff in mind, this study provides additional perspectives on the idea of college as a mentoring environment and new ideas to consider by those most likely to transform colleges into mentoring environments. This study yields a clearer understanding of how at least some undergraduate students at one institution describe their experiences of mentoring during the college years. In addition, at the site where the study is conducted, faculty, staff, and administrators were given input from importantone might even argue the most important—stakeholders in the college experience: the college students. Additionally, this particular institution will now be able to assess, in a 
limited way, how mentoring efforts and support are actually being received by students who have been a part of the educational community for a significant portion of time. 


\section{CHAPTER TWO: REVIEW OF THE LITERATURE}

\section{Mentoring: A Problematic Concept}

The word "mentor" conjures up numerous definitions, expectations, and interpretations across multiple sectors, including the academy, business, and the military (Erkut \& Mokros, 1984; Jacobi, 1991; Reed, Martin, Collins, \& Dial, 2002; Sorcinelli \& Yun, 2007). The original Mentor was a character in Homer's The Odyssey. When King Odysseus left to go to war, he entrusted his household to his friend Mentor. It was Mentor who cared for and tutored Telemachus, Odysseus's son (Mandelbaum, 1990; Reed, et al., 2002). In this traditional understanding, many people think of a mentor as a person, "usually older and more experienced, who is able and willing to help a protégé get where he or she wants to go" (Daloz Parks, 1986, p. 20).

\section{Mentoring and Higher Education}

As is true in the other sectors, the term "mentor" when used in the context of higher education is fraught with multiple definitions, programmatic concepts, and interpretations. As an example, a recent Educational Resource Information Center (ERIC) search of the two keywords undergraduate mentoring, limited to the last 10 years, yields almost 3,000 results. In her comprehensive and widely cited literature review for the American Educational Research Association Review of Educational Research, Jacobi (1991) indicated two major concerns with the concept of mentoring: first, the glaring absence of a widely accepted operational definition and second, a questionable link between mentoring and academic success.

Mentoring in higher education is frequently associated with formal programs and relationships directed at high-risk, underrepresented, underserved, or underachieving student populations (Astin, 1977; Astin, 1993; Carr, 1996; Erkut \& Mokros, 1984; 
Jacobi, 1991; Johnson, 2006; Kinzie, et al., 2005; Komives, et al., 2003; Pascarella \& Terenzini, 1991, 2005; Reynolds, 2009; Van Puymbroeck \& Maryland Univ, 2001; Wallace \& Abel, 1997). These and other studies indicate that many of these students do not receive adequate academic and social support that could positively impact their abilities to succeed during their enrollment in a higher education institution (Nora \& Crisp, 2008). The promise and challenge of these relationships and programs are further complicated when the realities of mentoring across perceived social fault lines (race, gender, age and other differences) are considered (Calabrese, 1996; Carr, 1996; Fogg, 2009; Jacobi, 1991; Johnson, 2006; Kaye, 2000; Storrs, Putsche, \& Taylor, 2008; Tuckman, 1996).

\section{College as a Mentoring Environment}

This review of the literature on mentorship is limited to traditional undergraduate students attending four-year institutions. Within that limited scope, there is a perceptible convergence around the idea that faculty, staff, administrators, peers, and other aspects of the college experience can combine to create a shared mentoring responsibility or “environment" (Daloz Parks, 2000, p. 148) of mentoring. Parks has clearly articulated this idea of college as a mentoring environment (1986; 2000, 2008, 2009; 1996), contending that effective concepts and practices of mentoring should embrace and respect the classically understood and "venerable term" (2000, p. 127) of mentor while realizing "that a network of belonging that serves young adults as a mentoring environment may offer a powerful milieu and critical set of gifts in the formation of meaning, purpose, and faith" (p. 127). Such efforts and studies (Boyer, 1990; McDonald, 2002) do not eliminate the classic one-on-one relationships but expand the definition to include a holistic view that has the capacity to hold numerous aspects of mentoring undergraduate students. This 
also is referred to as the mentoring process (Calabrese, 1996), a shared responsibility (Storrs, et al., 2008), a mentoring web (Van Puymbroeck \& Maryland Univ, 2001), a mentoring constellation (Johnson, 2006), and mentoring networks (Sorcinelli \& Yun, 2007). When this mentoring environment literature is seen in connection with the already established lack of definition and questionable link between mentoring and academic success (Jacobi, 1991), there is a significant question that emerges: What is actually happening in the young adult development of traditional college-age students who would enter the college mentoring environment?

\section{Adult Development Theory and College as a Mentoring Environment}

Before those in higher education can look to refining definitions of mentoring and emulating best practices, the adult development literature should be consulted. We should consider whether commonly used mentorship definitions and models are appropriate, considering the limited amount of understanding we have about the development of 18to 22-year-old college students (2004; Arnett, 2000; Arnett \& Lynn Tanner, 2006; Arnett \& Arnett Jensen, 2002; 1999; Baxter Magolda, 1992; Calabrese, 1996; Cherlin, 2005; Chickering, Dalton, \& Stamm, 2006; Cohen, Kasen, \& Henian, 2003; Cote \& Bynner, 2008; 2006; Erkut \& Mokros, 1984; Jacobi, 1991; Levine \& Cureton, 1998; Lewis, 2006; Nathan, 2005; Pascarella \& Terenzini, 1991, 2005; Storrs, et al., 2008; Willimon, 1997; Wolfe, Retallick, Martin, \& Steiner, 2008). This literature review seeks to identify and critique the most current and relevant developmental literature related to young adults, particularly those entering four-year colleges, and then to use that developmental foundation as a means to identify and explain the conditions and functions of college as a mentoring environment. 


\section{The Developmental Transition from Adolescence to Adulthood}

The transition from adolescence to adulthood is well documented as challenging (Arnett, 2004; Astin, 1977; Beaudoin, 1998; Calabrese, 1996; Cohen, et al., 2003; Erikson, 1987; Jaurigue, 1991; Kegan, 1982; Komives, et al., 2003; Nelson, Badger, \& Wu, 2004; Pascarella \& Terenzini, 1991, 2005). The fact that a college education (for an 18- to 22-year-old student) happens at the beginning of this significant developmental transition makes it all the more crucial for those in higher education to be developmentally informed: "Virtually all adolescents attend school and many receive support from youth organizations during early and middle teens. In the late teens, these supports begin to diverge and disappear altogether" (Settersten Jr., et al., 2005). The relationships one has during the college years, mentoring relationships included, fill an important developmental role in the lives of students (Carger, 1996; Lasley, 1996; Tuckman, 1996).

Those working in the college environment would benefit from a deeper understanding of what is actually happening within the lives of students. Both foundational adult development literature and recent young adult development literature serve as informants and are important in creating the college mentoring environment. The foundational-stage development work related to the challenges of the undergraduate years points to empirically based studies and programs designed around the effectiveness of classically understood mentoring/coaching/teaching/helping relationships (Astin, 1977; Baxter Magolda, 1992; Chickering, 1968; Erikson, 1987; Pascarella \& Terenzini, 1991, 2005; Perry, 1968), while the recent work in young adult development expands to include a broader understanding of the mentoring functions. 
In a recent article, Baxter Magolda (2009) cites Kneflekamp, Widick and Parker (1978), who "synthesized the student development research literature into five clusters, noting that they 'did not find, nor could we create, the comprehensive model of student development" (2009, p. 621). According to Baxter Magolda, the five clusters are: psychosocial theories, cognitive developmental theories, typology models, and personenvironment interaction models. As she argues, “Thus, higher education in general and student affairs in particular lack a holistic, theoretical perspective to promote the learning and development of the whole student. Constructing a holistic theoretical perspectives requires focusing on the intersections rather than separate constructs" $(2009$, p. 621). One intersection, both literally and figuratively, is the actual student. Those who hold positions of formal authority on college campuses cannot underestimate the power and potential of collaborating with students. Such collaboration, across programs and pedagogies, can provide significant data in the evolution of the college environment.

\section{Adult Development: Classic Stage Development Theories}

Erik Erikson's classic eight stages of development model proposed three stages of adulthood: young, middle, and late. Erikson considered adolescence to range from age 12 until age 18 and then young adulthood from age 18 until age 35 (Erikson, 1968; Erikson, 1987; Jaurigue, 1991). In this model, the traditional college experience begins in late adolescence and continues into early adulthood. Kegan (1982) presented three stages of adult development: interpersonal, institutional, and inter-individual. In his foundational work, Perry (1968) published Forms of Ethical and Intellectual Development in the College Years: A Scheme. Similarly to Erikson and Kegan, Perry proposed that young adults were in motion, developmentally transitioning from dualism to relativism to commitments. Perry's scheme ranged over a total of nine positions, with an 
understanding of deflections (temporizing, retreat, or escape) as a compromise of development (p. 11). Fowler (1981) introduced an analogous stage model for faith and meaning-making. He identified three adult stages: Individuate-Reflective Faith, Conjunctive Faith, and Universalizing Faith. All three of these classic developmental theories would locate the college experience late in the adolescent stage and into the first stage of adult development (see Appendix D for summary table).

These theories provide documentation involved in the complex navigation into young adulthood. Much of the mentoring literature and programs have evolved as faculty, staff, and administrators have seen students make these attempts with varying degrees of success and failure. The continued evolution of research has produced promising and insightful work on young adult development.

\section{Recent Young Adult Development Literature: A New Fourth Stage?}

Modern, interdisciplinary adult development theory is exploring the idea of a "new" fourth stage of adult development, one of emerging or young adulthood (Arnett, 2004; Arnett, 2000; Arnett \& Lynn Tanner, 2006; Arnett \& Arnett Jensen, 2002; Cohen, et al., 2003; Cote \& Bynner, 2008; Cote, 2006; Daloz Parks, 1986; Daloz Parks, 2000; Fowler, 1981; Settersten Jr., et al., 2005) that is positioned between adolescence and young adulthood and in some instances linked to the concept of college as a mentoring environment. These theories, especially those of emerging adulthood, build on classic stage development theory but advocate for acceptance of a new fourth stage of development.

\section{Emerging Adulthood}

Arnett $(2004 ; 2000 ; 2006 ; 2002)$ presented a new conception of development for the period of the late teens to early twenties, with a particular focus on 18- to 29-year- 
olds, citing five main features/norms of emerging adulthood. When considered in light of the college mentoring environment, they are informative. According to Arnett, this stage of emerging adulthood is an age of identity explorations, an age of instability, a selffocused age, an age of feeling in between, and an age of possibilities.

The ensuing critique and conversation have added a depth of understanding to each of five attributes. Continued longitudinal and interdisciplinary studies have found both variance and functional integrity within these five classifications (Cohen, et al., 2003; Cote \& Bynner, 2008; Cote, 2006; Nelson, et al., 2004; Nelson \& Barry, 2005; Padilla-Walker, Barry, Carroll, Madsen, \& Nelson, 2008; Reifman, Arnett, \& Colwell, 2003). The main critique of emerging adulthood continues to be that "many social scientists do not believe there is much to be gained by the use of the concept, and some prominent developmental psychologists do not accept that Arnett has presented sufficient evidence for his claim to have discovered a new developmental stage" (Cote \& Bynner, 2008, p. 264).

\section{Early Adulthood}

In a landmark effort for the John D. and Catherine T. MacArthur Foundation, the Research Network on Transitions to Adulthood and Public Policy was established in 1999 and funded for a three-year period beginning in 2000 (Settersten Jr., et al., 2005). The Network investigated large-scale, nationally representative surveys on young adults in the United States and indicated, "We wanted to describe the changes that had taken place over time and among subgroups of the population in the post-adolescent years that span roughly ages eighteen to thirty-four" (p. 8). The group worked with large data sets that included longitudinal or time series information. In the end, 14 data sets representing 11 countries, "arguably the best secondary sources available on this topic in the United 
States, Canada and Western Europe" (p. 8), were used. Among the many significant conclusions and policy recommendations summarized in the 2005 On the Frontier of Adulthood, one is connected directly with potential of college as a mentoring environment: that early adulthood is a distinct and socially recognizable stage of life.

Even the consideration of this idea requires those in positions of formal authority at colleges and universities to pause and consider the new reality of the student experience. Arguably, the transition to adulthood is more challenging, complicated, and ambiguous than ever before. If this is even potentially valid, then those who would take up leadership on college campuses must be actively seeking ways to connect and collaborate with students. What do students say about their development? What do students say about the programs and pedagogies they are experiencing and being subjected to? What do students say about becoming young adults?

\section{Making Meaning, Faith, and Young Adult Development}

Daloz Parks has published several qualitative research-based studies on the idea of a new stage of young adult development (Calabrese, 1996; Daloz Parks, 1986; Daloz Parks, 2000, 2000, 2008; Daloz Parks, et al., 1996). Framed in faith development language but related to the idea of a new, fourth stage, Daloz Parks (2000) states the following:

Current developmental theories (represented by Kegan and Fowler) continue to describe the movement to mature adult faith as a three-step process whereby conventional (or adolescent) meaning making develops into a critical-systematic faith (or order of consciousness) which then evolves into a mature adult faith that can hold both conviction and paradox. My own view is that the developmental journey is more adequately grasped as a four-step process. That is, I believe a distinctly young adult way of making meaning may be discerned in the often murky and overlooked territory between conventional faith and critical systemic faith. (p. 12) 
See Appendix E for a summary comparison of the three- and four-stage models of adult development.

\section{Reasons for the Rise of a Fourth Stage of Adulthood}

The idea that there has potentially been a rise of a new, fourth stage of young adult development is based also on broader historical/sociological analysis. Related to the college as a mentoring environment, this analysis is an opportunity for those in higher education to receive a broader perspective on those forces that have been acting upon the lives of 18- to 22-year-olds, which is indicated in the report from the Research Network on Transitions to Adulthood and Public Policy:

It is now commonly understood that economic and social conditions in tandem create categories such as childhood, adolescence, young adulthood, middle age and old age that are recognized and reified in popular discourse. Ideas about life periods are rooted in social structural changes that give rise to new behaviors. They come about as inventions or solutions to structural dilemmas created when social change renders old practices unworkable or, in common parlance, out of fashion. ... We believe that similar forces are at work today to make early adulthood a distinct and socially recognized stage of life. (Settersten Jr., et al., 2005, p. 3)

Reasons for the rise of a new developmental period or stage (Arnett, 2004; Baxter Magolda, 2001; Komives, et al., 2003; Mortimer \& Larson, 2002; Nelson, et al., 2004; Willimon, 1997) can be summarized into four main categories: (a) marriage and parenthood, (b) changes in the labor market and unstable job markets, (c) increase in the number of people attempting higher education, and (d) a changing worldview of young people. What follows is a brief summary of each category, with the understanding that those who argue for a fourth stage of development see the sum total force of these categories working together to shift the landscape of young adult development.

Marriage and Parenthood. The United States has seen a rise in typical ages of marriage and parenthood (Cherlin, 2005): “Today's emerging adults spend more years 
single and dating than young people in previous generations, but the great majority of them make their way to the altar" (Arnett, 2004, p. 97). In 1950, the median age of marriage was 20 for women and 22 for men, whereas in 2000 , the typical age of marriage was 25 for women and 27 for men. Age of parents at the birth of their first child has followed a similar trend: From the 1950 s to the 1970 s, most couples had a child in their very early twenties, while today most wait until their late twenties (Cherlin, 2005). The invention of the birth control pill alongside less stringent standards for sexual relationships since the sexual revolution of the 1960 s and 1970 s means that young people can engage in a prolonged period of dating and sexual relationship(s) before entering into marriage. What have been two of the pillars of entering adulthood (marriage and parenthood) are now taking place far later than ever in the life cycle. This space is being filled by a more explorative approach to relationships, career, and dating. As a result, an emerging adult is not as often faced with the immediate pressure of spousal and/or family responsibilities.

Changes in the labor market. Rarely do young adults now have the same opportunities for employment that their parents would have had at a comparative age (Sum, Mangum, \& Taggart, 2002). Along with the current economic crisis, researchers have referred to the youth labor market crash of the 1980s (Arnett, 2004; Cote, 2006) to explain that while in the 1950s and 1960s there was an abundant amount of well-paying manufacturing jobs available, that changed in the 1980s. Companies used new technology to reduce the required workforce, resulting in low-paying service-industry jobs becoming the default, readily available option. What was true then is also true now, that better-paying and more significant employment requires more education. Because work is another means of the exploration of identity for young adults (Lewis, 2006; 
Padilla-Walker, et al., 2008; Pascarella \& Terenzini, 1991, 2005; Settersten Jr., et al., 2005), higher education is becoming one of the most common ways to get there. As a complicating layer, after the tech-based job boom and bust of the last 15 years, more and more studies are also revealing that recent undergrads are not guaranteed better jobs just because they attain the baccalaureate degree (Jaurigue, 1991).

Higher education. According to The Chronicle of Higher Education (Education, November 22, 2009), full-time status at a four-year college is still the most popular enrollment choice for all racial groups. More than ever in the history of the United States, young adults are attempting some sort of higher education, with nearly $70 \%$ having obtained at least some college education by age 25 . Higher education serves an attractive dual role for young adults. It is a fertile setting to explore identity (Astin, 1977; Astin, 1993; Baxter Magolda \& King, 2004; Boyer, 1990; Calabrese, 1996; Daloz Parks, 2000; Erkut \& Mokros, 1984; Pascarella \& Terenzini, 1991, 2005; Reynolds, 2009) and is also a way to gain access to the skills and networks needed for a more significant job. In the current economic climate, issues of accessibility are paramount in two- and four-year institutions. Reasons for not completing an undergraduate degree in the U.S. are extremely varied, with finances ranking high on that list. However, there is also an issue that is less tangible but familiar to those who work with undergraduate students: a changing worldview of young adults — an outlook that, among other characteristics, values individual processes.

A changing worldview. There are less tangible social forces cited in the literature, including a very different view of the meaning and value of becoming an adult and entering the adult roles of spouse and parent. As Arnett states, "There has been a profound change in how young people view the meaning and value of becoming an adult, 
and entering the adult roles of spouse and parent" (2004, p. 6). What once were seen as adulthood achievements are now perils to be avoided for the time being (Arnett, 2000; Arnett \& Lynn Tanner, 2006; Nathan, 2005; Twenge, 2006). Emerging adults today have unprecedented freedom in terms of social expectations. This interactive force is dethroning the previous kings of adulthood. Young adults carry out most of their explorations in the arenas of work and relationships, especially romantic relationships. The identity exploration takes place, according to Cote (2006), in what he calls the contemporary moratorium, referring back to Erikson's psychosocial moratorium, but he extends the discussion by saying that "sociological circumstances associated with the transition to adulthood have changed over the 50 years since Erikson formulated his theory, in ways that have undoubtedly affected how the identity moratorium is experienced and adult identities are formed" (p. 88).

Cote argues that this is a postmodern version of the psychosocial moratorium, with fewer social norms and expectations placed on emerging adults as they explore their identities. For this and other reasons, the transition is taking far longer than in Erikson's day, prolonged into the late twenties for a significant portion of the population. But this is not to imply a diminished view of the process. Terms like prolonged adolescence can imply immaturity and laziness, and perpetuate other over-generalized, common misconceptions of emerging adults.

\section{Generational Labeling and the College as a Mentoring Environment}

Some researchers argue that the analysis of these sociological forces helps to give an account of college students from a developmental perspective. There is also the recent approach of generational labeling (Howe \& Strauss, 2000; 2006; Twenge, Konrath, Foster, Campbell, \& Bushman, 2008). The idea of emerging adulthood is different than 
the recent rise in generational studies, in the vein of Generation X, Y, Millennial, and so on. That literature seeks to profile each generation, bringing forth common characteristics, trends, and strategies as society looks to the mixing of the generations (Fogg, 2009; Hoover, 2009). Some researchers have done larger macro studies (Levine \& Cureton, 1998; Twenge, 2006) of raw sociological data over the last 100-plus years and come out with a rather negative (if not disheartening) perspective of today's young Americans. In particular, Twenge $(2006 ; 2009 ; 2008)$ used macro-sociological analysis to explicate a new generation of students as more narcissistic than ever before. Without careful consideration of this idea, it would be easy to miss the essence of the subtle and yet profound shift that the paradigm of emerging or young adulthood captures. While some of the statistical trends found in work like that of Twenge and others can be helpful, the perspective found among the researchers and practitioners of emerging adulthood counters that it not only captures the "birth" of emerging adulthood but helps to unlock the positive potential of the interchange between society and young adults.

The theory of a fourth stage of emerging adulthood would seek to establish a new developmental period, such that whatever generation is within the ages of 18 to 25 will be better understood. Generational characteristics can and will continue to change. But for at least the foreseeable future, the potential for a stage known as emerging adulthood is finding an established place of relevance. Whether one accepts emerging adulthood as a new stage or considers it merely valuable in that it helps to "bring attention to the prolonged transition to adulthood that adolescent psychology tends to ignore" (Cote \& Bynner, 2008, p. 263), the connection to mentoring environments is found in that faculty, staff, and administrators can be better equipped, good company on the pathway to selfauthorship and adulthood (Baxter Magolda, 1992, 2001; Baxter Magolda \& King, 2004). 


\section{College as a Mentoring Environment: Conditions, Practices, and Pedagogy}

As stated earlier, Parks $(2000,2009 ; 1996)$ articulated the idea of college as a mentoring environment, contending that effective concepts and practices of mentoring should embrace and respect the classically understood concept of mentor while realizing "that a network of belonging that serves young adults as a mentoring environment may offer a powerful milieu and critical set of gifts in the formation of meaning, purpose, and faith" (2000, p. 127). The gifts, according to Parks, are recognition, support, challenge, and inspiration. The gifts are connected in that they are founded on the classic and current young adult development theories detailed above. In this way, a broader definition of college as a mentoring environment endorses existing efforts while exploring new opportunities.

\section{Young Adult Development and Student Affairs}

With the classic and emerging theories of young adulthood used as a foundation for college as a mentoring environment, much of the relevant literature is found in what is considered student affairs (Astin, 1977; Astin, 1993; Astin \& Chang, 1995; Baxter Magolda, 1992, 2001; Kinzie, et al., 2005; McDonald, 2002; Nora \& Crisp, 2008;

Pascarella \& Terenzini, 1991, 2005; Reynolds, 2009) and is categorized as best practices, functions, and characteristics. Rather than muddying the waters, the concept of college as mentoring environment can clarify the purpose of higher education by uniting academicians and student affairs professionals as stewards of the academic environment. Put another way, there are "significant mismatches [that] exist between the emerging and varied pathways to adulthood that are now taken and the institutions and policies that affect young people. How might the patchwork of often outdated institutions and policies be rewoven to smooth entry into adult life?" (Settersten Jr., et al., 2005, p. 22). 
Noticeably, Chickering (1968) pioneered some of this original, foundational, and widely recognized work in the late 1960 s and early 1970 s by asserting the mission of colleges had changed from that of exclusive concentration on intellectual development to a more universal, thoughtful, informed, and dedicated effort and sustained attention to the total college environment (Carr, 1996). Astin (1993) also pointed out that

while the research suggested that the most effective undergraduate education is associated with such things as small institutional size, private control, a common curricular experience, living on campus, and full-time attendance, the policies that had guided expansion of the system favored larger and larger institutions, public control, and unstructured curricular experience (the "distributional system"), more commuter education, and more part time attendance. (p. xviii)

Considering college as a mentoring environment is one framework among many. Baxter Magolda (Baxter Magolda, 2009) said that

In arguing for a context and a holistic approach, I am not arguing for a grand narrative or theory. I am advocating exploring the intersections among multiple dimensions of development from multiple perspectives. Creating one grand theory of holistic development is not possible or desirable; however, placing theoretical frameworks in dialectic to inform a holistic view of development is necessary[.] (p. 633)

The mentoring environment framework is one that has capacity to carry this kind of context and holistic approach. As will be shown, the literature offers best conditions and practices that frame the holistic college education in an environment suitable for development and achievement.

\section{Conditions of College as a Mentoring Environment}

Student Success in College (2005) described policies, programs, and practices that a diverse set of institutions used to enhance student achievement. The research team attempted to identify colleges and universities that performed well in student engagement and graduation rates. A regression model was used to identify baccalaureate-granting institutions that had higher-than-predicted scores on the five clusters of effective 
educational practice used by the National Survey of Student Engagement (NSSE) and a second regression model to determine predicted graduation rates compared to their actual six-year graduation rate. Twenty institutions were then selected to represent diversity: 9 private and 11 public. Some were large and research-intensive, others small and undergraduate-focused. Size ranged from 700 to just more than 20,000 . The study was called DEEP (Documenting Effective Educational Practice).

The DEEP study relates to and informs the idea of college as mentoring environment with a differentiation between conditions and practice. The conditions of educationally effective colleges included living mission and lived educational philosophy, an unshakable focus on student learning, an environment adapted for educational enrichment, clear pathways to student success, an improvement-oriented ethos, and a shared responsibility for educational quality and student success.

Student Success (2005) also reported that "what students do during college counts more for what they learn and whether they will persist in college than who they are or even where they will go to college. Voluminous research on college student development shows that the time and energy students devote to educationally purposeful activities is the single best predictor of their learning and personal development" (p. 9).

In 1990, the Carnegie Foundation for the Advancement of Teaching published a significant report entitled Campus Life: In Search of Community (Boyer, 1990). Written by Ernest L. Boyer, Sr., who served as the president of the Foundation from 1979 to 1995 , the published report was based on a survey of 382 responding institutions in the National Survey of College and University Presidents and 355 responding institutions in the 1989 National Survey of Chief Student Affairs Officers. The result was a 157-page document summarized in six principles intended to define the kind of community "every 
college and university should strive to be" (p. 2). The principles were also intended for day-to-day decision-making on the campus as well. College and universities should be a purposeful community, an open community, a just community, a disciplined community, a caring community, and a celebrative community.

The report is thick with empirical data and concrete, accessible recommendations for administrators, faculty, and staff on key issues like alcohol abuse, crime, breakdown of civility, racial tensions, sex discrimination, and a diminishing commitment to teaching and learning. As a follow-up, Creating Campus Community (McDonald, 2002) was released. The book used a case-study approach and looked at community in higher education, community in large research institutions, moving beyond rhetoric into specific programs, and utilization of campus leadership (meaning formal positions in student affairs). The study used five institutions ranging in size and mission that have utilized the previously mentioned Campus Life (Boyer, 1990) report as a means to structure and inform campus programming. One noticeable and vital contribution of this work was data assessing students' perception of campus community using the College and University Community Inventory (CUCI) tool and results from a study of 445 students at 16 institutions nationwide (McDonald, 2002). There was overwhelming consistency around students expressing significant and positive benefits around issues of community during the college experience.

The move from adult development theory to the consideration of conditions that matter to collaborative practice is not easy, but it is arguably crucial in establishing a mentoring environment. Unfortunately, the literature reveals that there is little reward in today's universities for equipping students with knowledge and habits of mind that will 
make them wise and productive adults (Lewis, 2006). Recently, Astin (Astin, et al., 2011; Astin \& Chang, 1995) framed this problem this way:

Although American higher education can justifiably take pride in its capacity to develop the student's ability to manipulate the material world through its programs in science, medicine, technology and commerce, it has paid relatively little attention to the student's "inner" development - the sphere of values and beliefs, emotional maturity, moral development, spirituality and self understanding. (p. vii)

While it could be argued that the developmental landscape might not be as bleak as Astin's assessment, it is notable that this giant in the field of higher education is turning the academy's attention to the inner life and development of students.

\section{Best Practices and College as a Mentoring Environment}

The use of these types of terms (mentoring, environment, conditions) represent an ongoing challenge in higher education as they can come across as vague and easily cause division and misunderstanding between those in classic academic positions and those in student affairs positions. Theorists, researchers, and practitioners are converging around a call for higher education reform that gives priority back to the actual experience of the undergraduate student (Astin, 1977; 1993; Chickering, et al., 2006; Lewis, 2006). The result is more and more specific best-practice models and case studies that are collaborative in nature, building on the experience and research of student affairs with the desire for academic success in the academy.

Again, the Documenting Effective Educational Practice (DEEP) study (2005) also identified several effective practices that colleges and universities should consider. Unlike some literature, the easily accessible summary statements are backed by considerable empirical data, longitudinal studies as well as case studies of efforts that have succeeded and failed. The highlighted effective DEEP practices included academic 
challenge, active and collaborative learning, student-faculty interactions, enriching educational experiences, and a supportive campus environment.

In another example of a substantial collaborative effort, noted scholar practitioners Bliming and Whitt (1999) made a recommendation to both the American College Personnel Association (ACPA) and the National Association of Student Personnel Administrators (NASPA), organizations that sponsor the development of principles of good practice for student affairs. The result was a study group of notable individuals in the field who worked for more than a year and drafted preliminary principles prior to the 1997 ACPA/NASPA joint convention. Feedback was taken at the convention and revisions were made, and the resulting landmark and often-used Good Practice in Student Affairs (Bliming, et al., 1999) “demonstrates and reinforces the field's commitment to student learning and institutional effectiveness" (p. 14).

Grounded in compelling research on college students and a wealth of practical experience in student affairs work, the principles were intended to help create learningoriented student affairs divisions. Accordingly, good practice in student affairs engages students in active learning, helps students develop coherent values and ethical standards, sets and communicates high expectations for learning, uses systematic inquiry to improve student and institutional performance, uses resources effectively to achieve institutional missions and goals, forges educational partnerships that advance student learning, and builds supportive and inclusive communities.

The most obvious critique of the mentoring environment model is that if everything is mentoring at a college, then nothing is mentoring. In an isolated but related study (Wolfe, et al., 2008), the College of Agriculture and Life Sciences at Iowa State University explored the mentoring functions of faculty at the college. The review of the 
literature isolated six mentoring functions: informal contact, role modeling, direct assistance, demonstration, assistance with professional development plans, and observation/feedback. A questionnaire was used to measure the extent to which faculty practiced each mentoring function. The average faculty member primarily mentored undergraduate student employees and advisees, spending approximately nine hours interacting and five hours mentoring students per week. Findings indicated faculty often practiced the established mentoring functions (Wolfe et al.). The study is used as an example of a different way to consider mentoring in higher education: as something that many in higher education are already doing.

Potentially, college as a mentoring environment is a concept with more space to contain multiple efforts, research agendas, interactions, programs, and relationships. If "mentor" is a term that leads to multiple interpretations and misunderstandings, can the idea of a functioning college mentoring environment absorb those variations and create a wider, sanctioning umbrella? This expanded view of mentoring is seen in Daloz Parks's work:

A society becomes more complex, extended education becomes increasingly necessary to meet the needs of the workplace, and an informed, broad, multicultural perspective combined with the capacity for critical, connected, and contemplative thought becomes increasingly vital for the functioning of democratic societies. (Daloz Parks, 2008, p. 158)

According to Daloz Parks, the good mentor simply recognizes that the young adult is still dependent in substantial ways upon authority outside the self, while at the same time the mentor is a champion of the competence and potential the young life represents. This connects to Baxter Magolda's longitudinal work. If a mentoring environment is supportive, and if that support is aware of the competence and potential of the young 
adults, then there will be a noticeable reflection of that awareness manifested in the institutional pedagogy (Baxter Magolda, 1992, 2001; Baxter Magolda \& King, 2004).

\section{Constructive Developmental Pedagogy and College as a Mentoring Environment}

Widely cited in multiple disciplines and arenas of higher education is the work of Baxter Magolda (1992, 2001; Baxter Magolda \& King, 2004). She began one major study in 1986 with 101 first-year college students. Annual interviews were conducted with each student from age 18 to their early twenties. That work was described in detail in the (1992) Knowing and Reasoning in College: Gender-Related Patterns in Students' Intellectual Development. A key to Baxter Magolda's work, and an important aspect of college as a mentoring environment, is her idea of creating conditions that foster selfauthorship through a constructive-developmental pedagogy. This theory was initiated in Knowing and Reasoning (1992) and then fully developed in Creating Contexts for Learning and Self Authorship (1999). In Making Their Own Way (2001), Baxter Magolda continues her longitudinal study of young adult development, focusing on the 39 participants from Knowing and Reasoning who remained in the study through their twenties and thirties. In a significant work for higher education, she and Patricia M. King published Learning Partnerships: From Student Affairs to Collaboration (2004).

Referring to young adults, Baxter Magolda (2001) defined self-authorship as "the capacity to internally define their own beliefs, identity, and relationships. This selfauthorship, this internal capacity, is the necessary foundation for mutual, collaborative participation with others in adult life" (p. xvi). Her work also outlines three core assumptions that are significant when considering college as a mentoring environment: First, that knowledge is complex and socially constructed. Second, that self is central to 
knowledge construction. Third, that authority and expertise are shared in the mutual construction of knowledge among peers:

Thus, self-authorship, or the internal capacity to define one's beliefs, identity and relations with others, stands at the core of the contemporary college learning outcomes identified in national reform reports. Subsequently, a holistic approach to education for the $21^{\text {st }}$ century must focus on self-authorship as its central goal. (Baxter Magolda \& King, 2004, p. 188)

Her constructive-developmental pedagogy is apparent: one that sees students, faculty, staff, and administrators as co-creating knowledge in and out of the classroom. There are three principles she presents that connect educational practice to self authorship: validating learners as knowers, situating learning in the learner's experience, and beginning learning as mutually constructing meaning (Baxter Magolda \& King, 2004, pp. 190-192).

\section{Summary}

Given the challenging and problematic nature of a concept like mentoring in an undergraduate setting, it would seem counterintuitive to broaden the working definition to that of a mentoring environment. However, this review of the literature reveals and proposes such a concept of mentoring that is robust in its capacity for a holistic, developmentally informed and collaborative approach to traditional undergraduate education. With this, higher education leaders are potentially more grounded in the realities of the student experience (Baxter Magolda, 2009; Baxter Magolda \& King, 2004; Chickering, 2010; Daloz Parks, 2000; Kinzie, et al., 2005; Komives, et al., 2003). Leaders in higher education who choose to consider such an approach would be participating in the needed evolution in traditional four-year higher education: that of interdisciplinary collaborative work that uses adult development theories, student affairs best practices and conditions, along with relevant societal and sociological cues. This is a 
significant leadership issue in the context of higher education, and some have gone as far as to call these concepts "revolutionary" (Kezar, Carducci, \& Contreras-McGavin, 2006,

p. 71)

The application of new paradigms and theories in leadership research has resulted in the emergence of new leadership concepts: ethics and spirituality, collaboration and partnering, empowerment, social change, emotions, globalization, entrepreneurialism, and accountability. These concepts reflect a new societal context in which leadership occurs, a context described as postindustrial by Rost [1991] and postmodern by others [Palestini, 2003; Parry 1998] (Kezar, et al., 2006, p. 71).

This difficult synthesis on a shifting societal landscape could continue to give rise to institutional perspectives on college student development that are holistic and connected, leading to college as a mentoring environment. This study is offered as a contribution to that ongoing effort. 


\section{CHAPTER THREE: RESEARCH DESIGN AND METHODOLOGY}

\section{Introduction and Overview}

As is seen in the literature review for this project, there has been a considerable amount of quality, empirical, multi-disciplinary and longitudinal work done on the issue of young adult development within the context of traditional college education (Baxter Magolda, 1992; Chickering, 1968; Daloz Parks, 2008; Fowler, 1981; Kegan, 1982;

Kinzie, et al., 2005; Nash \& Murray, 2010; Pascarella \& Terenzini, 1991, 2005;

Settersten Jr., et al., 2005; Sorcinelli \& Yun, 2007; Taylor, 2008; Twenge, 2006;

Willimon, 1997). Having reviewed this literature in detail and set as foundational, and having been inspired by the insightful, qualitative research work of Baxter Magolda $(1999 ; 1992,2001,2009 ; 2004)$ and others, I decided on qualitative interviews as the appropriate methodology to explore, with traditional aged college students, the concept of college as a mentoring environment.

I conducted qualitative interviews with 12 students at a private, faith-based, liberal-arts university in Southern California (institutional pseudonym Southern California University and hereafter SCU). The contact, selection, and scheduling of the students will be discussed in detail below. Students selected for interviews graduated in May 2010 or would graduate in May 2011. After seven of the interviews were completed, I conducted a focus group made for the purposes of member checking and exploring the possibility of additional emerging themes. Upon completing that focus group, I proceeded with the remaining five interviews. Extensive data analysis was conducted (Appendix K), leading to the stated findings and recommendations. 


\section{Qualitative Interview Methodology}

The use of qualitative interviews for this project was appropriate, necessary, and directly linked to the review of the literature, the stated problem, and the intended outcomes of the study. Qualitative interviews with these undergraduates purposefully aligned with Baxter Magolda's $(1999 ; 2001 ; 2004)$ three principles for educational practice that link assumptions and development: validating learners as knowers, situating learning in the learner's experience, and defining learning as mutually constructing meaning (2001, pp. 190-191). Qualitative interviews, and specifically the structure of this study, afforded me the opportunity to validate the undergraduate student participants as the "knowers" on the topic of mentoring. Further, I situated the learning on this subject of mentoring in the experience of the participants in that my research questions and interview guide seek to find the personal experience and insight of each participant. Finally, the "learning", specifically the findings and recommendations about mentoring, were "mutually constructed" with the participants. By this I mean that the data and subsequent analysis are constructs of my interviews and then ongoing collaboration with them, the student participants, as well as my higher education colleagues. In-depth interviews allowed for the time, interaction, and personal exchange that is vital to this principle of mutually constructing meaning. In other words, I aimed to model this study after the kinds of programmatic and pedagogical approaches that are important in undergraduate higher education.

\section{Research Questions}

The purpose of this qualitative study was to understand better how these traditional undergraduate students perceived, received, understood, and experienced mentoring and/or a college mentoring environment. The study was guided by the 
following research questions that were formed out of the literature review, collaborative work with colleagues in the field of higher education, collaborative work with undergraduate students via a Pilot Study (Appendix B), and ongoing consultation with my committee chair:

1. How do graduating seniors attending this university describe mentoring? In other words, how do they describe the function and characteristics of mentoring?

2. How do the students describe the formal and/or informal mentoring they have received during their college years?

3. What suggestions would the students have for the university's formal and informal efforts at mentoring?

\section{Trustworthiness}

Qualitative and quantitative researchers utilize terms such as trustworthiness, reliability, validity and transferability in a variety of ways. In an ongoing debate, "current thinking has led some qualitative researchers to develop alternative terminology to better reflect the nature and distinction of qualitative research (Bloomberg \& Volpe, 2008, p. 77). Other qualitative researchers “... still feel comfortable borrowing terminology from quantitative research (p. 77). However,

Lincoln and Guba (1985) argue that sustaining the trustworthiness of a research report depends on the issues, quantitatively, discussed as validity and reliability. The idea of discovering truth through measures of reliability and validity is replaced by the idea of trustworthiness (Mishler, 2000), which is "defensible" (Johnson 1997, p. 282) and establishing confidence in the findings (Lincoln \& Guba, 1985). If the issues of reliability, validity, trustworthiness, quality and rigor are meant differentiating a 'good' from 'bad' research then testing and increasing the reliability, validity, trustworthiness, quality and rigor will be important to the research in any paradigm (Golafshani, 2003). 
For this study I will use this understanding of the term "trustworthiness". Based on Bloomberg and Volpe's (Bloomberg \& Volpe, 2008, pp. 77-78) discussion of trustworthiness, the criteria for evaluating trustworthiness for this study include:

Credibility: This criterion refers to whether participants perceptions match up with researchers portrayal of them. In other words, has the researcher accurately represented what the participants think, feel, and do?

Dependability: This criterion parallels reliability...[and] refers to whether an independent investigator could track the process and procedures used to collect and interpret data.

Transferability: Although qualitative researchers do not expect their findings to be generalizable to all other settings, it is likely that the lessons learned in one setting might be useful to others.

Each of these aspects is embedded and integrated in the discussion below. Within this study, a considerable effort has been put forth to implore methods of data collection, analysis and interpretation that ensure maximum trustworthiness and confidence in the findings. In order to conduct integral and ethically sound data gathering, analysis and verification in this qualitative study (see Appendix K), I consulted Merriman's (2002) strategies for promoting validity and reliability (pp. 22-31), using triangulation member checks, peer review and examination, an ongoing critical self-reflection of my own position and influence, adequate engagement in the data collection, maximum variation (even within the limited number of interviews), an audit trail, and a rich, thick description. Also, Appendix $\mathrm{N}$ offers the reader all of the raw data for this study: all 12 interviews transcribed in unedited format. 


\section{Research Site}

Although the research site for this study was selected partially as a matter of convenience (i.e., the site is the institution in which I work), the site selection process (and also the process used to select participants, which will be discussed in the next section) also reflected specific criteria that have already been described in Chapter Two, as optimal and/or effective for institutions of higher education (Astin \& Chang, 1995; Bliming, et al., 1999; Kinzie, et al., 2005; Komives, et al., 2003; Levine \& Cureton, 1998; Nathan, 2005; Willimon, 1997). Specifically, the selected site is a smaller, private, faith-based university with 2,200 undergraduate students, primarily residential (1,650 of the undergraduates live on campus). Based on my own working knowledge of the institution, it is of interest to note that on-campus living is mandatory for the first two years, and first year students are not allowed to bring cars. This is a policy reflective of a desire for students to engage fully in student life, as well as the realities of limited parking spaces.

The campus itself is set on the cliffs of the Pacific Ocean, scattered across almost 100 acres. There is a significant bio-diversity on the campus, a result of several previous entities committed to such ends prior to the current institution taking up residence here in the early 1970's. It is obvious that the community is committed to the aesthetics, as there is rich and lively landscaping all over the campus.

The residential environment is vibrant and supportive. There are nine different residence halls, each with a live in professional Resident Director. There are 65 student Resident Assistants campus-wide, along with student small group/Bible Study leaders and student Peer Educator/Wellness leaders in each hall. This leadership is connected to 
the Office of Student and Spiritual Development in programming, outreach, support and interventions.

There is a low student-to-teaching-faculty ratio (currently about 15:1), and a large majority of faculty are involved in full time teaching. Research and publications take place in the context of full teaching loads. And recently there has been a move for senior level faculty to teach entry level courses, giving first and second year students the opportunity to take classes from professors who normally would be teaching only upper division, major related courses. The average incoming GPA for freshman is 3.70 . Additionally, the mission statement (taken from the university website) is reflective of the nature of the institution:

[SCU] exists to provide higher education in a vital Christian community where minds are engaged and challenged, character is modeled and formed, and service becomes an expression of faith. Being of Wesleyan heritage, we aspire to be a learning community where grace is foundational, truth is pursued, and holiness is a way of life.

In a recent web publication to students transferring in for the spring 2011

semester, the Vice President for Student Development wrote to them:

You are joining a community that is deeply committed to your success. As a university, we value your intellectual growth; you will also discover multiple opportunities to grow spiritually, in relationships, emotionally, in leadership, and there will definitely be plenty of opportunities to have fun. You will be challenged here, and we commit to support your growth as a whole person.

Also of note is that this university has an Office of Student Development that is comparable to such offices at other institution. Somewhat unique is that there is an entire office dedicated to spiritual formation. The Office of Student Development oversees small group ministries, community volunteerism, international volunteerism, chaplaincy efforts, and other collaborative efforts around spiritual formation across campus. This includes mandatory chapel services that take place three days a week. 
Students are heavily involved in co-curricular and leadership opportunities. The annual "LEAD" week training for designated student leaders that takes place at the beginning of each fall semester has over 300 undergraduate participants. International volunteerism teams number over 350 students annually. Domestic and community based volunteerism sees close to 500 students participate annually.

When considering recent student publications, forums, requests for programming and other representative measures for student life, one can see SCU wrestling with issues of how to talk about various social and moral issues, such as alcohol consumption in the college environment while trying to hold to a position of abstinence. Students are also reconciling personal convictions and ideals about LGBT issues against that of the sponsoring denomination. Students express a considerable anxiety about the transition from college life to post-graduate young adulthood, and the institution hosts several formal and informal programs around this transition.

Noticeably, the institution's undergraduate student population is approximately 75\% white. Students of color and issues around diversity and inclusion are a high priority. Last year, the institution named the Associate Vice President for Student Development the Chief Diversity Officer. A presidentially initiated and sponsored Diversity Council has been meeting, programming and developing strategies around outreach, engagement and retention for students of color. Given the domestic, national and international volunteerism and service, there is considerable programming available that engages students in conversations about difference in all of its manifestations. The responses from several students in this study indicate that these conversations and experiences, especially with faculty impact them in positive ways. 
Issues of student conduct are similar to comparable institutions in quantity and issue, with the most common violation being underage drinking. The Student Handbook and the established student conduct responses are built on a restorative and developmental model, utilizing Residential Life staff and Wellness professionals to build out educational responses to student infractions rather than punitive measures.

Campus life, set in the context of Southern California is healthy, vibrant and involved. Based on strong turnout at campus events, athletic events, and other cocurricular offerings, the students, faculty and staff are engaged at a significant level. Finally, there is a "spirit" to the campus that one hears of quite often. Many times when students are questioned about a decision to attend, they reference the first time on campus and say something like, "There was just something about it. As soon as I drove on campus I knew I was supposed to be here." Given the highly selective and competitive process to be enrolled, one can sense a sense of pride, dedication and commitment alongside the usual and to-be-expected institutional frustrations, anxieties and challenges.

\section{Contact, Selection, and Scheduling}

All aspects of contact, selection, and scheduling were subject to Institutional Review Board (hereafter IRB) protocol for both the University of San Diego as well as the host institution. No research was initiated prior to IRB approval by the University of San Diego and the host institution. Upon receiving IRB approval, an initial email soliciting nominations for participants was sent to the host institution's Offices of Student Development and Spiritual Development. These two offices are made up of more than 50 staff and faculty across a wide range of the institution.

As an additional form of contact, I solicited participation via text, email and Facebook with several students I had encountered in my day-to-day responsibilities. 
These forms of contact briefly described the project and invited interested participants to respond. I also encountered potential interview candidates in my day-to-day responsibilities on the campus. When that happened I presented them with the verbal opportunity to participate. Any and all potential volunteers received a more detailed description of the project, along with a consent form (see Appendix M). That form both acknowledged my position of formal authority at the host site and assured potential volunteers that they could not be penalized institutionally for declining to participate, nor could they benefit institutionally from deciding to participate. As I received the nominations and responses from all these contact methods, respondents were screened for basic identifying information that ensured maximum variation. The actual participants were selected from the pool of volunteers that developed.

Then, in September 2010, having completed seven individual interviews, I met with my dissertation chair to review my interview progress. She raised and I shared a concern that participants so far had been referred only by staff or had participated at my invitation. As a result, an additional email was sent to the academic department chairs of the host institution to solicit more recommendations. In the end, a total of 12 students were interviewed. Four came from faculty recommendations, five came from staff recommendations, and three participated from my invitation.

\section{Research Participants}

Participants in the individual interviews included 12 students from the designated institution who graduated in the May 2010 semester or who would graduate in the May 2011 semester. Within the limits of this small sample size and these students, I sought a maximum variation in gender, declared major, declared race, and choices for cocurricular involvement. In the end, there were seven female and five male student 
interviewees (an attempt to show awareness that this university's current gender breakdown is about $60 \%$ female and $40 \%$ male). Declared race included one African American female, one Latino male. Co-curricular involvement was fairly diverse, with a noticeable mention of that particular option by four of the participants. One interviewee was a member of the men's basketball team. To a limited degree, I also used my own knowledge of the students, but mostly relied on suggestions from current faculty and staff, to identify potential participants. Preference was for students who spent three or more years living on campus, as research cited in the literature review indicated a residential setting as optimal for the undergraduate educational experience. Given that my target group was graduating seniors, age was a determining factor in that I desired to interview students who were within the range of what has been explained as "traditional," or in the 21- to 23-year-old range, a convenience sample.

\section{Interviews}

Within the qualitative interview framework explained above, I conducted one interview with each of the 12 different undergraduate students. Those interviews were recorded and lasted about 60 minutes. I used an interview guide (Appendix C) that was developed from the three research questions listed above. In order to refine the interview guide and to ensure maximum clarity and accessibility, I conducted a pilot study on March 23, 2010 at the University of San Diego (See Appendix B for description of pilot study and modifications made). This ensured consistency along with quality-the predetermined and relevant questions created room for the various responses. The guide contained open-ended questions intended to be clear and accessible to undergraduate students. 


\section{Analysis and Verification}

A data analysis map is provided (Appendix $\mathrm{K}$ ) that can be used as a reference for analysis and verification, beginning with the literature review and ending with the findings. Appendix $\mathrm{N}$ offers the reader all of the raw data for this study: all 12 interviews transcribed in unedited format. The approach detailed in this section was determined for two specific reasons: a commitment to best practices in qualitative research analysis and an ongoing awareness of my position of formal authority at the research site.

\section{Qualitative Analysis}

Prior to this analysis, certain categories and themes emerged from the literature and from the pilot study. Those included a strong delineation between formal mentoring and informal mentoring, familial and fraternal metaphors, negative and positive associations with formal mentoring, and ambiguity around the topic of peers as mentors. Most of the subsequent categories and themes, however, were developed out of the data analysis. After I conducted each individual interview, I listened to the recording at least three times. I then personally transcribed the interview. I read the transcript at least 3 times, and almost all have been read more than 10 times. Utilizing the qualitative analysis guidelines established for this study, the transcribed interview data was initially coded for broad themes and patterns related to the topic of undergraduate perceptions and experiences of mentoring.

This analysis included looking for "convergence, recurring regularities in the data" (Quinn Patton, p. 465), as well as "divergence, which includes the careful and thoughtful examination of data that doesn't seem to fit including deviant cases that don't fit the dominant identified patterns" (p. 466). The results of my coding efforts on the first eight interviews yielded nearly 100 broad themes (Appendix G) that I placed in 
categories based on responses to the seven interview guide questions. These were sent, electronically, to all interviewees as a means of member checking. Several of the participants responded electronically by affirming the themes as well as making substantive suggestions for additional themes. I used this member-checking approach several times throughout the study, asking the interviewees to evaluate the analysis for accuracy, accessibility, and clarity. As a means of inter-rater reliability, throughout the study I also sent sample sections of the transcribed interviews along with my draft of emerging thematic codes to several colleagues, some who work at SCU and some who work at other institutions of higher education.

\section{Focus Group}

I then took the interview guide and those 100-plus themes to the focus group and asked for their responses to the questions, along with analysis of the themes. I used a topical and thematic approach to the focus groups to ensure the privacy and confidentiality of the participants. The focus groups did not have access to the transcribed interviews. Rather, I brought questions, topics, and ideas that emerged from the interviews and asked them to comment on that data. This focus group contained four students who had participated in the preceding interviews, and eight additional students who had been nominated by faculty or staff members as potential interview candidates. Several additional themes and responses were noted and added from the focus group.

Based on this session and the feedback gathered, I proceeded with the remaining four interviews. Like the first round of interviews, the recordings of the remaining interviews were listened to at least three times, personally transcribed, and coded for the broad themes. Once all interviews and the focus group were completed, my data collection was completed. I again sent my codes and the growing list of themes to several 
higher education colleagues. I sent the themes to several interviewees. There were very few additions or suggestions at that point in the study. Based on the ongoing thematic analysis of the interviews, repeated member checking with participants, and consultation with my committee chair, it was determined that thematic saturation was reached after 12 interviews and the focus group. Thus it was determined that no further interviews or an additional focus group would be necessary or vital to the project.

\section{Collapsing of Broad Themes to Useable Categories}

The next step was to analyze the large thematic list and begin to collapse it into useable and refined categories. My commitment in this process was to remain connected to the language and descriptors that the students themselves had produced. To this end, my initial approach was to group the themes as they had emerged chronologically, first listing those from the initial round of interviews, then the focus group input, then the final round of interviews. Additionally, any input from higher education colleagues or interviewees was also clearly delineated. This chronological, more linear approach to the data analysis proved to be problematic and cumbersome because students were commenting across multiple themes and ideas. It became an unruly and counterproductive approach.

As a result, I took a step back in the analysis and, with assistance from my committee chair, restructured the analysis using the interview guide to build a Structural Framework (Appendix J). The interview guide had proven, in the interviews and focus group, to be effective, and it also lent itself as a solid tool for building the Structural Framework. Again, I met with my committee chair to share the proposed Structural Framework based on the considerable analysis already done. After additional editing, we agreed on the basic structure as a means to frame the project. With this, I began the initial 
collapse of themes into the major categories that would begin to reveal the interpretations as reported in the findings section.

The three categories that emerged from this process were: Significant Aspects of College, Descriptions of a Mentor/Mentoring, and Personal Experience. I used the refined codes (Appendix I) to place the 100-plus themes into useable categories. I also reread the transcripts, looking for undiscovered themes or data that would call for additional categories. As I analyzed, I made notes regarding other potential themes, categories, and sub-categories. As a means of inter-rater reliability and member checking, I also sent my categories and themes to several interview participants and to several higher education colleagues. I asked for input on the categories and subcategories. I typed each theme into a Word document, primarily using the tables function. To manage the data, I placed the themes into an Excel spreadsheet as a means to experiment with groupings and collapsing. Based on my experimental analysis, including a significant return to the literature, along with the ongoing, mostly electronic exchanges with several gracious interview participants and colleagues, I determined the final categories.

The next effort was to move from the categories to interpretation of findings. In moving to determining "substantive significance" (Quinn Patton, 2002, p. 469), I utilized Patton's suggested four questions (pp. 468-469) as an initial and guiding framework for establishing the findings: How solid, coherent, and consistent is the evidence in support of findings? To what extent and in what ways do the findings increase and deepen understanding of the phenomenon studied? To what extent are the findings consistent with other knowledge? To what extent are the findings useful for some intended purpose? These questions were helpful in that process, and the four significant findings are explored in the next chapter of this study. 


\section{CHAPTER FOUR: FINDINGS}

The purpose of this qualitative study was to use a thematic analysis approach to consider the thoughts about mentoring of 12 undergraduate students who had recently or would soon graduate from a private, faith-based, four-year, liberal-arts university. These students were asked about their perceptions and experiences of the various sorts of mentoring they received during their college years. Colleges and universities that espouse a desire to create a holistic educational environment, that is, a place where the development of students is shared across institutional boundaries, may find valuable input from studies such as this one.

This chapter presents the four key findings that emerged from the interviews and analysis described in Chapter Three. Those findings are:

Finding \#1: When asked to reflect on significant aspects of college, participants in this study consistently said that relational and participatory experiences with faculty, staff, and administrators were significant and transformative.

Finding \#2: When asked to describe their experiences with mentoring during college, 11 out of 12 participants indicated they had had the opportunity to interact with several important adult mentors, rather than one single, all-encompassing mentor.

Finding \#3: When asked to describe the functions and characteristics of mentoring, participants most often used language that described intentionality, availability, and interest.

Finding \#4: When asked to describe their mentoring experiences, participants rarely differentiated between functions and characteristics described in the literature as formal and informal. Rather, students described relationships and interactions that combined, overlapped, and interchanged these functions and characteristics. 
The following is a detailed discussion of these four findings. Each finding will be stated, followed by a discussion of the finding that uses representative direct quotations from the participants. This is connected to the purpose and intent of this study. I have endeavored to utilize and frame the explanation of the findings in the language of the students. In part, this is an attempt to give voice to students as part of addressing a holistic educational environment. But, more importantly, it is an attempt to honor the student participants as collaborators in the process of discovering what constitutes a mentoring environment. Where it is relevant to the finding, there is occasional mention and integration of a related theory drawn from the literature review for this project. Mostly, as Bloomberg and Volpe (2008) said, "the emphasis throughout is letting participants speak for themselves" (p. 111). And while this project was not intended to be ethnographic, the ideas of culture and language certainly emerged and can be seen in this chapter. Spradley (1979) indicated, "language is more than a means of communication about reality, it is a tool for constructing reality." And "if it is our serious purpose to understand the thoughts of a people the whole analysis of experience must be based upon their concepts, not ours" (1943:311) (p. 18). Because the point of the project was to discover what college students say about mentoring, I believe it is imperative to use their language in presenting and discussing the findings.

In some cases, numerical specificity is used (i.e. "seven out of 12 participants..."). Given the small sample size, such specificity is not intended to show statistical significance in the classically understood quantitative analysis approach. Rather, these ratios are used in a spirit of full disclosure of the data, in cases where it appeared important and relevant so that the reader can have a clear understanding of how many participants indicated such a response. 
The findings address the three original research questions:

1. How do graduating seniors attending this university describe mentoring? In other words, how do they describe the function and characteristics of mentoring?

2. How do the students describe the formal and/or informal mentoring they have received during their college years?

3. What suggestions would the students have for the university's formal and informal efforts at mentoring?

As was indicated in Chapter Three, the order of the findings is a result of considerable data analysis and an attempt to capture the convergence of themes from the interviews. In that, the findings are organized according to the research questions. The concluding remarks for each finding are intended as both a transition to the next as well as a highlight of the interconnectedness of the findings. All names used in this study are pseudonyms to protect the participants and those to whom they refer.

\section{Finding \#1}

\section{When asked to reflect on significant aspects of college, participants in this} study consistently said that relational and participatory experiences with faculty, staff, and administrators were significant and transformative.

This finding came primarily from the responses to the opening question for the interview guide. Initially, the intent of the opening question for the interview guide, "What have been some significant aspects of your college experience?" was to provide an icebreaker during the interview, a question that let the participant settle in, get comfortable, and talk freely about college. The question became one of the most engaging and insightful of all that were asked. In turn, this led to the most robust findings of this study: when asked about significant aspects of college, all interviewees said that 
relational and participatory experiences with faculty, staff, and administrators were some of the most significant and transformative in their college careers. I spoke with Justin, a graduating senior who had developed a relationship with two of the coaches in the Athletic department, initially out of a discovery that he had been using illegal drugs. Part of his follow-up to that incident was regular accountability meetings with these two men. According to him, he was resistant and reluctant at first, but over the course of a semester, and then on into his senior year, he went through significant change.

So, they both have got me into things and opened my eyes to things that I would never see myself doing before I came to this school. If it's mentoring other little kids, or helping out with that Rockin' at the Point event, where I helped him set that all up. Just the stuff that I am involved in and the things that I have done through them and then things that I have accomplished because of them is just I just step back and if you would have asked me two years ago if I would be doing this, I would laugh. There's no way I would be serving my community, or going to church, or praying with another person. It was really heavy at first, but it's been great.

It is important to note that the spectrum of experiences that were coded as relational and participatory ranged from a good conversation over a cup of coffee to a month-long study abroad trip in South Africa and many other possibilities in between. And not one interviewee indicated a preference between in-the-classroom and out-of-theclassroom relationships or experiences. It was quite the opposite as most indicated a mix of the traditional classroom with co-curricular or outside the classroom was important to them. In the following three sections a deeper and more rich description of question one is provided.

\section{Relational and Participatory Experiences}

The term "relational" is used broadly here and does not necessarily imply some sort of long-range and/or deeply personal relationship between a member of the faculty, 
staff, or administration and a student. Actually, only half of the participants described such people in their lives during college. Further, only one participant in my study described anything even close to what can be understood as a "classic" mentor, who he confided in about many different areas of his life ranging from personal to professional. It is also relevant to point out that all participants frequently referenced short-term relationships and encounters such as a professor for a one-semester class, or engaging in occasional or infrequent meetings and conversations, that were significant nonetheless.

The use of "participatory experiences" is a way to capture a large variety of experiences to which students referred, including service learning, study abroad, lab research, personal successes, and crisis. The participatory theme is my effort to summarize students describing people, again mostly faculty, administrators, and staff, who intentionally invited them to participate, be involved in, and co-create both in and out of the classroom. Significance was attributed to those people and experiences where there was an exchange of ideas, some sort of shared endeavor, and other kinds of engagement opportunities. Again, this ranged from truly open conversations in a classroom, to students engaged in major community- and academically based social change endeavors alongside faculty.

As an example, consider Haley, a female student who graduated in 2010 and now works for the International Rescue Committee. In answering this opening question about significant aspects of college, she referenced Student Ministries, which is a program at SCU that affords students the opportunity to participate as well as eventually lead volunteerism efforts within the local community. There are more than 35 different options for students each week. Haley participated in and then led several of the Homeless Ministries during her time as a student. Pam, the full-time staff person who 
runs the ministries, was someone Haley considered a mentor. It is clear that these opportunities overlapped with her academic journey as well, and that professors played a significant role in her overall development:

My involvement with Student Ministries definitely was very significant, and through that a lot of mentoring in the way the program is set up. And getting to know Pam. There were a couple of classes I took as electives that I ended up loving them: Globalization with Dr. Green and Sustainability with Dr. Smith. Those were two classes that I find are extremely applicable in my life right now, which is so good because I learned all this stuff in class and I am actually living it out right now, and it is amazing to see so many of the things I learned in my classes and talked about in discussions, and are so real right now.

This finding aligns with the seminal work of Baxter Magolda (2001) on self-authorship among young adults, which is detailed in Chapter Two of this study. She advocated for a constructive-developmental pedagogy: one that sees students, faculty, staff, and administrators as co-creating knowledge in and out of the classroom. In other words, the participants in this study found people and experiences that afforded them that opportunity to co-create their own educational experience. Haley discussed this very principle at work in her life:

I have been very grateful for my education lately. It's been really cool to see how it ties together, and mainly because of the professors' involvement. The content of the class was definitely interesting, but it was how the professors connect to things, encourage dialogue outside of class, and different projects. And so the professors were pretty much the driving force of my interest and involvement.

Casey, a music major who would graduate in May 2011, shared that one of the significant aspects of college for her came when she finally decided to change her major from pre-med to music. What struck me as interesting and remarkable about her decision was that it came out of an encounter with a professor in a required general education firstyear music course:

Ever since I was a kid, I planned to grow up and go to med school. And I had it all figured out. And then, I think just I had always done music since I was 5 and it was something that meant a lot to me. It was one of the first classes I took with 
Jim Swanlon, it was Intro to Listening, and it's just one of the "every freshman has to take it" as a music major, and he was so philosophical about it, what music is, why you do it, and how it affects people. So that just really changed my perspective on music. And so it was through that course that I did change my mind. It was mostly just seeing that my reasons for wanting to go to medical school were the same; I could accomplish all that with music; I wouldn't have to give anything up except for science.

Arguably, Casey found a faculty member who could accompany her in this change of major and give her the permission she needed to validate her own emerging internal voice as she searched for identity and purpose in music rather than medicine. Dr. Swanlon was passionate about his art, and he invited her into that experience. He never actually focused this attention on her specifically until much later in her career as a music major. Initially, it was how he was living his work in his class time.

\section{Challenging and Negative Experiences as Significant}

Participants also described challenging or negative experiences that were nonetheless significant and transformative. When I interviewed Tonya, young woman who graduated in May 2010, she explained how difficult it was to come to college, and that even at New Student Orientation (NSO) she had had a sense of isolation and marginalization. Throughout her time in college, she took on multiple leadership and outreach roles, eventually serving at a high level of student government. When I asked her about the significant aspects of her college experience, she spoke about that negative experience of being at New Student Orientation with her mom, and then seeing the gospel choir perform. She describes her meeting Dr. Flogan and making the decision to get involved:

I saw them perform at NSO and frankly ... well, I hated NSO. I did not have a good experience. It was hard. I felt like a lot of stuff was over my head, and my mom didn't really understand what was going on, so we were lost through the whole experience. Gospel choir was the first thing I saw, and I met Dr. Flogan after and that was the first connection, I think, to SCU that I had. I was like, "Oh, this is something that has been a part of my life all growing up." It was something 
I had done when I was little, and I had sang all those songs, and it was something that was important to me. And so that was the first time I felt like I could be connected to this community. I didn't know what other connections I would have, but I knew that was going to be one connection that I had. And Dr. Flogan was a big part of it, and has been, like, I guess a mentor type all four years.

Dr. Flogan is the Director of Academic Advising at SCU. Several years ago, she took on the role of Advisor and Conductor to the Gospel Choir. She is an African American female with a strong commitment to the choir as a place for all who want to be involved and be committed to a rigorous practice and performance schedule. The choir has grown to nearly 100 participants.

Similarly, other participants spoke specifically about their bad choices as points of learning, and entry points for significant people in their lives. I spoke with Anna, a senior graduating with a social work major and a Spanish minor. She described herself prior to coming to SCU...

In high school I never partied. I was against it, I thought it was wrong. Especially since I was in a leadership position in Neighborhood Ministries and we taught our kids not to drink and not to do these things. That was another reason I didn't and I just thought it was stupid. But then I came here, and it's supposed to be a Christian university. So if everyone else is doing it, then I didn't have to be an example for anyone. In high school I went to a public high school, and so for me, everyone knew I was a Christian and so I was being the example. But then to come to a Christian school, then in my mind I didn't have to be the example for anyone. Because everyone was supposed to be Christian, and the first weekend I was here my roommate took me to SDSU because her brother was in a frat. And I started dating a senior my freshman year and that was all they would do on the weekends is party. All the same group of people that party. So I didn't have my best friend Chelsea, who is usually the voice of reason in my head, and I just didn't have a ministry anymore to be an example to anyone. And if all these people are Christians, then I didn't have to be an example to anyone. For me, I didn't think about it happening, and it happened and I got swept up into it. That's just what we did every single weekend. That was our friends. The upper classmen guys are usually the ones that finds that group of freshman girls and they bring them up. And you can watch it every single year and they usually live in Rease. There are about 10 or 12 girls. It's always junior senior boys. That's what got me into it. 
She shared with me that she came as a freshman and spent much of her first year partying with upperclassmen, dating older guys, and living disconnected from the values she had established for herself before coming:

And so that was significant because that was the group I surrounded myself with and that affected ultimately all four years here because that is who I spent all my time with until I got back from study abroad. And that's when I stopped hanging out with them. I studied abroad the spring of my sophomore year. I hung out with that group freshman; beginning of sophomore year I didn't want to be in that group as much anymore, but it was too hard to pull away. That was all my friends. I still hung out with them, and then I studied abroad. And then when I came back, it just wasn't the same, so I stopped hanging out with them.

Her study abroad experience was with an organization called LASP (Latin American

Studies Program) that is known for a no-nonsense, cultural-immersion, high-expectation approach to international studies. It is competitive and demanding. Anna's time was disruptive and caused a significant amount of dissonance to her worldview, as well as to her choices regarding friends and partying. When taken in the context of her entire interview, there is vein that begins with her in high school, involved in a neighborhood tutoring ministry call Neighborhood House, then coming to SCU and making choices that were removed from her established values. When I asked her about what it was like to return to college, she explained the differences:

Then I came back to SCU, and then to have a place that is majority Caucasian, and I didn't want to go back and party anymore, and so, I went out one night when I got back to see everyone. And everyone was completely drunk, and I just sat there and thought, "I don't want to do this anymore." so I just stopped going. . .. I wasn't really close with anyone and I had friends, but I didn't really consider them my friends. So they noticed that I wasn't there, but that was about it. There was no effort. I would see them on campus, and they would say, "We went out last weekend," and that was all. And I couldn't even function; I hated it here; I didn't have any friends.

My experience and interpretation of these challenging, sometimes negative accounts in the lives of students is that there is need and room for good adult company. You can hear Anna and others trying to make better choices, trying to find the courage 
and motivation to get involved. Often, students find connections with a member of the faculty, staff, or administration during these in-between times in their lives. It is this kind of company that I argue can lead to some of the more transformational times in the life of a college student. Anna went to work for Melanie, a staff person in the Office of International Volunteerism. Melanie became a mentor figure to Anna, and played a key role in Anna's decisions to get involved.

\section{Relational and Participatory Experiences as Transformational}

Along these lines, one of the more profound interviews of the entire project was with Kate, a young woman who would graduate from the math department in May 2011. She came to school with a host of challenges that she disclosed, including a highly dysfunctional family, a serious cutting problem, low self-esteem, and a strong sense of not fitting in.

Coming here from the home environment I did was really rough. Immediately I was in culture shock, a lot of shock, because I had never been in a faith environment, and because nothing was wrong, and I was even more confused because I was expecting it to be, and therefore it was weird. Why is everyone so nice? They are either fake, or crazy. How are you not pissed at the world? I hated it.

One of her early involvements was with the Residential Life staff, then an international volunteer team where Shelly and John, the staff leaders took up significant leadership in her life.

I went on LoveWorks to Dominica. It worked out because of my leaders on that trip, Shelly and John. John told me straight up he was scarred for me to go on the trip because I was young and he thought I might get crazy. Looking back, I love that he was that honest with me, but then through that trip, instead of saying you're crazy, they listened and that was something I never had in my life. John and Shelly simply listened to my life and told me it wasn't my fault and nothing I had ever heard. It was freeing. I was shocked, sitting on the beach where the Caribbean meets the Atlantic, and Shelly said, "It's not your fault" and I said, "No, my mom tells me every day that it's my fault". So that was so freeing. The next week, John asked me to preach. "I'll work with you". I did it and he said it's the best preaching anyone did that trip, including the pastor and him. And 
long story short, that relationship, Shelly being older and wiser, and being a psych major, and living and working in the city where I grew up, it felt God given to me. The first time I felt like God had a role of bringing someone into my life in that sense.

Kate then entered into a counseling relationship in the university's Wellness

Center that continues currently. She described one particular breakthrough when she

returned to SCU as a sophomore. She had been going to counseling regularly, was

establishing a peer group, and several of her professors were paying attention to her. She

described that time:

And something happened to me, the middle of my sophomore year, in physics. I had been going to counseling for five months, and everything was good with friends. I can't explain what happened. I was sitting at a physics test and had serious test anxiety. I knew how to do it, but couldn't prove it, and get angry and freeze up and freak out. But I was looking at the physics test and just pretended that it was just a homework problem, I looked at it and said, "It doesn't matter, this doesn't matter, in the scope of all things, it's just a test." The weight was gone, and I just started laughing, straight up laughing, and I said, "It doesn't matter," worked it out. The week before I got a 60 on the test. Nine days later, turned it in. Dr. Puttney emailed me the next day and said, "Your test is better than my answer key, how did you think of this? You got 102\%." That same semester, after [mathematics professor] Dr. Rowe saying these things to me, I started getting As on my midterms, stats, probability. He said, "I don't know what happened to you, but you caught fire and no one can contain you, maybe not even yourself, so be careful. I am just letting you know, you caught fire, and I think it's going to stay," and he shook my hand and said, "Good job, I am proud of you."

I do not think that we can underestimate the significance of these kinds of relational and participatory experiences. I must emphasize again that the adults who impacted these students did so very much in their own context: an advisor, a professor, and a choir director who reached out to students who were literally in front of them. Often as I discuss this study and this idea with colleagues, I hear and sense their hesitation. Very few of us, I find, have a self-proclaimed, confident sense of wanting to mentor young people. It conjures up images of being the wise, all-knowing sage who can impart wisdom in any situation. The idea can create pressure, anxiety, and a lack of willingness 
to engage students. The next finding in this study, however, speaks to the value of mentoring done in the context of a mentoring community. In other words, faculty, staff, and administration all work together, reaching out and working with those students they are most often with. All but one of the students in this study described significant encounters with several members of the faculty, staff, and/or administration during their college experience.

\section{Finding \#2}

When asked to describe their experiences with mentoring during college, a majority of participants indicated they had had the opportunity to interact with several important adult mentors, rather than one single, all-encompassing mentor.

In my preparation for this study, I found considerable discussion in the literature around differences between a classically understood mentor and the idea of college as a mentoring environment or network, where students experience valuable and meaningful interactions with multiple members of the college community. That literature is covered extensively in Chapter Two of this study, indicating the difficulty associated with a student finding that one person, as well as with members of the academic community being that one person. In the next section, I describe how the students experience and made sense of their networks of relationships.

\section{The Morrie Syndrome}

I found it noteworthy that several interviewees actually referenced Tuesdays with Morrie, a 1997 book that was eventually made into a movie. The book and the film explore a very intimate mentoring relationship between two men, one older and one younger. They meet weekly to discuss life. The discussion with four participants was almost verbatim for each: They would say, "Well, I don't really have a Morrie, you 
know, that one person? But, I do have ..." and they would continue on and describe for me two, three, or sometimes even more members of the faculty, staff, or administration whom they met with, talked with, traveled with, took classes from, and so on. They described a mentoring network, one in which multiple members of the community take up the work of developing its young people (Chickering, et al., 2006; Daloz Parks, 2000; Jacobi, 1991; Kinzie, et al., 2005; Nash \& Murray, 2010; Settersten Jr., et al., 2005). Their descriptions were very consistent with the literature in what has been called a mentoring network. I asked Erin, a senior who would graduate in May 2011, about her thoughts on mentoring:

I don't think I have one specific that we meet on a weekly basis. But I have always had the desire for that. I have wanted that before. I think I have had snippets of it before. Conversations with Cam Neilson. And I just finished Tuesdays with Morrie today, so my image is of that. Marion Teeter is a friend, too. Someone I knew before I came. I have good conversations. In my major of social work, good conversations with Becky, but I don't have one specific person. But if that was there, I feel like it would be a huge gift. It's definitely an interest and has been on my mind. ... So finishing that book, and then having that I feel like I try to find avenues, which is a different thing than I guess a mentor relationship when you meet one-on-one once a week, but feel like I am still getting snippets of wisdom by interacting with people who are older than me and through interacting through hearing stories.

Erin was one of three students I spoke with who would conceptualize "Morrie" as something possibly better than what she currently had. It is interesting to consider the richness of three or four adults who are regularly available to her as coming up short compared to the possibility of finding that one special person.

For the purpose of this study, I am calling this the "Morrie Syndrome": the idea that your Morrie is out there. The literature and my experience would indicate that most in the academy would resist being Morrie (Calabrese, 1996; Carr, 1996; Daloz Parks, 2009; Johnson, 2006; Kaye, 2000; Lasley, 1996; Reed, et al., 2002; Van Puymbroeck \& Maryland Univ, 2001). I propose within this finding that the idea of a mentoring network 
is often more sustainable, as the work of being with students is shared across the institution.

\section{A Network of Mentors}

An example of this idea of a network of mentors came out of my time with Justin, a fifth-year senior who transferred in to play baseball three years ago. Early on in that first year at SCU, he had tested positive for illegal drugs and was put through the athletic department's conduct process. Through that, as was stated earlier, he met regularly with two coaches and occasionally with the athletic director. He described his relationship with those three men:

I went to a junior college that was pretty liberal and open ... do what you want. Lived my life a certain way, and I thought morally I was on the right track. I came here and really struggled. My first semester here, it was like it wasn't what I thought; it was overwhelming. I felt like I was constantly in trouble; I couldn't be me. In the classroom, on the baseball field, with everything. I was almost to the point where I thought this was too much, and then I got in trouble. And I came in here and I sat down with Peter Hathtan and Coach Blather, and they kind of pushed me toward Coach Filmore as well, and they started to make me realize everything that I had to lose, and everything I had done to get to this point, and really just the fact that they didn't give up on me right when I had got in trouble, and we spun that whole thing so that it had been the worst thing that has happened to me, and it was probably the best thing that could have happened to me. It opened my eyes, and the way they handled it, and the way they stuck with me.

Justin's thoughts led me to Arthur Chickering's (2010) recently published article advocating for higher education to accept the responsibility of moral and civic education along with intellectual development. He recounts from a personal perspective what he has seen emphasized in higher education from the 1950s until the present time. Early on, it was what he calls "meritocratic orientation," educating the best and the brightest, cultivating the intellect. He cites the tumultuous times of the " 60 s and '70s as creating pressure on higher education to consider a shared effort at moral and ethical development of the student, but well into the ' $80 \mathrm{~s}$, it was still rare. In the closing of this article, he 
states, "In my now 51 years of work in higher education, arguing for greater attention to 'the effective domain' for helping students address issues of purpose and meaning, integrity and identity, and spiritual growth, I have never felt as strong a sense of urgency about this values orientation as I do now" (p. 5).

Certainly our world is no less complex, and our young adults need every possible opportunity and positive, ethical, integrative development. Justin further reflected on the effects of his relationships with the three men in his life at SCU. It is clear that there are positive, transformational effects that are a direct result of the efforts of these three men in his life:

I have built relationships with Coach Blather and Coach Filmore. I still talk to Coach Filmore maybe once or twice a week, Peter Hathtan, every time I see him. Those are three men that were unreal in turning my life around, and it wasn't just because "you're my pitcher and we need you." It was more because they were invested in who I am as an individual, and I can tell because now my baseball career is over, and I still talk to those guys as if I was still playing baseball and as if nothing has changed. So my relationship with them I guess would have never happened had I not gotten in trouble. I kind of look at that as a God thing, I guess. Totally turned everything around; I don't know if you want to call it scared straight or just surrounded by the right people or what, but it was pretty major. It was two years ago this Christmas break and was a complete 180. And now I love this place. The place I was cussing out and cursing, you know; now if anyone ever asks me about SCU, whenever Blather has a recruit in to talk about, or if they have question marks, he sends them to me, because I bought into the fact that it's a process.

To offer our students multiple people who are accessible on the path to young adulthood seems an amazing and empowering institutional gift. It also seems to be a worthy investment into the future of our society. These young people are in a place of deciding a major and finding some sort of orientation for the place they will take up in the world. It is a key, formational time for the individual student as well as the future society.

When I asked Kate about her experience with mentoring, she talked about the different relationships she had with her math professors, a group of people she called a 
"network of support and encouragement." When I asked her about them as mentors, she replied:

Any professor in the math department. I still have this sense, I just thought I worked hard and didn't think I was smart, but they took me. I wasn't getting As, I was failing calculus. And Dr. Smith sat down, and instead of saying, "What don't you get it? How can I help?" said, "What is going on? What are you doing this Christmas break?" I don't know. And he asked, "Are you scared about it?" And somehow without knowing it, I didn't know it then, pretty sure that the reason I couldn't succeed in math was because I had way too many other stresses going on. And for him to not count me as stupid, and to see the way my brain worked in class, and my performance on tests, I am so thankful that he saw the correlation, truly sat down and said, what's going on at home because this is affecting you. And, for a professor to sit down and let me share that yeah, I am paying half my mom's mortgage, and paying for my schooling, and these little things. And then all of a sudden I got math scholarships, and wasn't worried about school. So now I work 10 hours a week instead of 30 , and that's something so small and it was the world to me. I didn't know anyone had money to do that, and he didn't I don't know where it came from. That was the moment where I thought, these people believe in me, and it made me want to work, not to gain approval and appreciation like I always did with my mom and it never came, but because I felt like I could be something.

In a recent issue of About Campus, Shushok and Hulme discuss how faculty and staff can equip students for this kind of success that Kate experiences: "The primary goal of higher education is not merely the successful completion of college degrees. It is the formation of a generation of people that clearly understand their contribution and genuinely desire to use this uniqueness for the common good" (Shuchok \& Hulme, 2010, p. 4). This is that holistic development of students that has been discussed. It requires a willingness on the part of our colleges and universities to recognize the value of this kind of engagement with students. It requires a priority on effort that is at times difficult to measure tangibly. This is, in part, a motivation for this study. As is seen in Finding \#3, students in this study have been positively affected by these kinds of efforts. 


\section{Finding \#3}

\section{When asked to describe the functions and characteristics of mentoring,} participants most often used language that described intentionality, availability, and

\section{interest.}

As was described in detail in the Literature Review for this project, researcher Marcia Baxter Magolda, working from a 25-plus-year longitudinal project that began with more than 100 first-year students, indicates that what college students need during these formative years is members of the faculty, staff, and administration to be "good company" in the developmental work of moving into young adulthood (Baxter Magolda, 1999; Baxter Magolda, 1992, 2001, 2009; Baxter Magolda \& King, 2004). Likewise, the important works of Arnett (2004; 2000; 2006; 2002), Settersten (2005), Daloz Parks (1986; 2000, 2008, 2009; 1996), and recent works from Astin and Lindholm (2011), Chickering (2010; 2006), and Palmer (2010) would indicate that the social complexities, developmental tasks, and shifting globalized landscape make this good company all the more crucial as students attend college and begin to take up this kind of work. So it was all the more striking to me that when I asked these 12 students to describe the functions and characteristics of mentoring, they talked about people who were intentional, available, and interested in them. While this finding could easily be reduced to common sense, I would offer that listening to the way the students articulated the impact of faculty, staff, and administrators only validated the kind of vigorous and important research cited above. Particularly, what will be highlighted below is these students describing the presence of adults as they make their way through vocational decisions, relationships, and challenging life circumstances. 


\section{Intentionality, Availability, and Interest}

When I asked Mark, a senior philosophy and theology major, to describe the functions or characteristics of a mentor, he talked about his relationship with his college pastor, a man who also worked on the campus in another department:

Persistence, frequency of interaction. The ability to listen only because the most impressive things Tim has said to me have come after some statement I have made about whatever. But he can't respond to me unless he has listened. So it's not a prescribed this is what I need to teach you, but what has been so powerful about Tim is that it has been tied to certain situations, moments in my life that the lesson isn't divorced from my life. I would add accessibility and ability to listen. Deep trust. If that's not there, you aren't going to get anywhere. Maybe a better way to say persistent is to say being committed. Out of your commitment comes persistence. I am going to hope that someone who is 30 has better perceptive skills than I do, to say that someone who has been in a career or a church or whatever for 10 years longer than I have can meet me and in the first month say, "I see some things that are good but they need to be grown" and at that point say, "Whether this person likes it or not, I am committed." And maybe it flops and in two months you get to know the person down the road and it's not what you thought. But if there isn't an initial commitment on the side of the mentor, then you can't expect someone who has never been mentored to know what to ask for.

When I asked the same question to Anna, the young woman who had participated in the challenging Latin American study abroad experience and then returned to the States, she described her relationship with one of the staff members she met with and then began to work for. As was explained earlier, Anna was nearly in crisis when she returned from study abroad. Her experience there had reframed her values, and she desired to leave her friends who were partying and begin to make choices more in line with her desire to serve in the community, use her fledgling Spanish, and find people who cared about the same kinds of things she cared about. But she repeatedly felt lost, alone, and isolated. She met a staff person who ran volunteer opportunities in Mexico, and connected quickly. Here she describes that staff person, Melanie:

For me, finding someone that has the same heart, the way she lives her life. The things that she loves to do are the same things that I love to do. That part was good, and just having someone to listen to me. She understood how I was feeling, 
taking the time out to pay attention and listen to me. I didn't feel like I could talk to a lot of people about it, because it doesn't register. To my old friends, talking about my study abroad experience has no meaning, because they have never really experienced anything and they don't really care. But for Melanie, having her be there for me and seeing the way she lives is somehow, that is how I want to be.

It is significant to consider that "being there" for a student as something that is received and perceived as quite intentional. Also, Anna indicated she could see the way that Melanie lived her life, implying they had spent enough time together for this to happen. These are just some of the ways that the ideas of interest, availability and intentionality play out on the day to day interactions.

\section{The Integration of Student Development Theory with Mentoring Efforts}

Student development theory over the last three decades has produced crucial tools for the academy to engage students more holistically. Interestingly, part of the developmental nature of this age is a sometimes conflicted relationship with authority figures, especially related to parental influence. The wide range of experiences, positive and negative, requires skill, patience, and intuition on the part of the faculty, staff, and administrators who attempt to be good company. As was indicated earlier in this study, those working in the college environment would benefit from a deeper understanding of what is actually happening developmentally within the lives of students. College student development theory creates a backdrop to understanding choices that otherwise make little if any sense to the onlooker.

It is easy to approach college students with a traditional understanding of adulthood, and much of that psycho-social information is still very relevant. Too many times in my own work, I have been in a conversation with a colleague where the most common point of reference is summarized in the statement "Well, when I was in college. 
..." This is a good reference point for anyone, regardless of the nature of his or her own college experience. However, the dangers and risks when it is the only point of reference are multiple. Similar to triangulating data, interacting with college students and making interpretations or intervention needs other points, including solid young adult development theory. There can also be crucial emerging information, often deeply lodged within the work of student affairs professionals operating in the trenches of college campuses: residence halls, student unions, clubs and organization advisors.

With this in mind, what is needed is the integration of these experiential and intuitive approaches with sound young adult development literature, so that the result is holistic work with students, important to all who would be involved in creating the college mentoring environment. The responses of these interviewees align with recent work in young adult development that expands to include a broader sociological and understanding of the mentoring functions in the new, complex realities of becoming a young adult.

When I interviewed Alex, a May 2010 graduate now working as a nurse, she said that she couldn't identify anyone who really acted as a mentor during her college experience. When I specifically asked her to discuss functions or characteristics of a mentor, she said:

Umm ... I think first someone who is not my parents. Someone I can, I guess it depends on your parents. But I can tell my mom something, but she always has to give me advice or tell me what to do with it. What to think about it. Sometimes I just want to share my feelings with you, and you say, "That is really hard." For me, with a mentor it is someone who will listen to you and give you feedback, and maybe share an experience that they had. Just to remind you that you are not on your own. College is all about finding who you are, your beliefs and realizing your life, and I think that would be good in a mentor. Someone to bounce questions and ideas off of. And I don't know if you need to hang out with them necessarily, maybe more of a professional friend. I think you can share more with someone you are not super close to. 
When asked why she called certain professors mentors, Haley, the May 2010 graduate

working for the International Rescue Committee, said:

For me, a mentor is someone who provides guidance. And is also a friendship as well, so I don't feel like I have had an "official" mentor but their mentoring has come alongside the friendship that has developed through the involvements. So I consider Tami a mentor because of her willingness to talk through issues, or also offer her perspective from her experiences, which has been very helpful. She's experienced pretty much everything we're encountering in our ministries. She offers that developed perspective. And a mentor offers perspective, has the time to invest in you and what you are doing. Is aware of where you are at and that more checking in here and there.

She then shifted and began to talk about one of the faculty members she worked with as an undergraduate, and continues to do so:

With Kevin, he gets me to think about different issues. He more has the power of suggestion in what he is talking about. Think about these things, or in different ways. Like the project we're working on now, it's to advocate to redesign Friendship Park at the border. And so in working on that project and hearing his perspectives on immigration issues and my just beginning knowledge of everything, too, and coming along and just learning from him and his work and his passion. When I think of a good mentor, I think of someone who exemplifies a life of passion, dedication to what they are involved in or what they are saying in class is reflected in their life. Like he's on sabbatical right now, and he's working on this project. It's cool to see that side of it.

The journey metaphor that Parks $(2000 ; 1996)$ uses was a strong part of Tonya's response to this question. She is the female student who graduated in May 2010 and struggled upon entering the university. Her insight reflected the need for safety within the context of the relationship:

Someone who is willing to ... who recognizes your journey and is volunteering their time and their energy to not only walk with you through that, but kind of have that hindsight to know which questions to ask you; they know how to give you advice. I think in our Christian context, it's someone who is able to have, who can look at your life, and look at what you are going through, who can look at these next four years, and be able to show you which ways, show you the ways God is working in your life. And that can be how God is working in you finding your vocation, or it could be in any circumstance. It's someone who has a bird's eye view of your situation, of your life, and is willing to guide you. I don't think it has to be. It can be formal or informal, I guess. It can be something, someone who meets with your regularly; it can also be someone who not very frequently meets 
with you. You can feel safe with them. I think safety is a huge thing. You feel safe with that person.

What is important to see in the responses of these students is their sense of making it through some of these developmental markers, difficult experiences, significant decisions, and initiation of vocational paths. In one way or another, all 12 participants attributed developmental success to the faculty, staff, or administrator who walked alongside them. Personal and professional outcomes were altered, arguably for the betterment of the individual involved and the context she or he was in.

\section{Finding \#4}

When asked to describe their mentoring experiences, participants rarely differentiated between functions and characteristics described in the literature as formal and informal. Rather, students described relationships and interactions that combined, overlapped, and interchanged the functions and characteristics.

Part of the purpose of this study was to explore a debate I discovered in the literature and am engaged in as part of my ongoing professional work, that of formal versus informal, established versus organic. Some practitioners argue that for mentoring programs to succeed, it is crucial for those programs to be more organic and grassroots, so that natural relationships can occur (Boyer, 1990; Calabrese, 1996; Daloz, 1986; Fogg, 2009; Hoover, 2009; Jacobi, 1991; Storrs, et al., 2008; Sum, et al., 2002; Taylor, 2008; Tuckman, 1996; Wolfe, et al., 2008). On the other side of this spectrum is the multitude of formal mentoring programs that can be seen on college campuses across the United States. The merits and risks of these formal programs, ones that are usually sponsored, funded, and supported by the institution, are also heavily discussed and debated in the literature (Johnson, 2006; Kaye, 2000; Kinzie, et al., 2005; Knefelkamp, et al., 1978; Komives, et al., 2003; Lasley, 1996; Reynolds, 2009; Schreiner, 2010; Settersten Jr., et 
al., 2005; Shuchok \& Hulme, 2010; Sorcinelli \& Yun, 2007; Stewart, 2009; Van

Puymbroeck \& Maryland Univ, 2001; Willimon, 1997).

\section{Formal Versus Informal}

As I entered this project, I found myself quite curious and caught up in this debate and wondered what the students would say. I believe that my line of inquiry ended up revealing a bias, that I assumed my participants would discuss a preference for the informal, grassroots type of mentoring relationships, ones that would seem more natural and thereby more significant. What I found was, quite simply, that it didn't matter to them. All participants discussed experiences with both formal and informal types of mentoring relationships. Categorically, 7 out of 12 put their academic advisors in the formal category, but the functions that those advisors played in their lives all bordered on or crossed into what could be considered personal or developmental, that is, beyond the function of advising which classes to take.

All described relationships that would be considered informal in the mentoring literature. Meetings were irregular, taking place in offices, homes, or restaurants, and the same discussion would range from the progress of a professional internship to inquiry on family members, dating relationships, or emotional health. In other words, the lines between formal and informal, at least for these participants, overlapped. As related to Finding \#3, the participants in this study did not necessarily have a preference for formal or informal, but for adults who were intentional, available, and interested. Participants often discussed formal mentoring relationships such as those associated with academic, career, and vocational advising or coaching, while discussing informal mentoring relationships when speaking of personal development. 
My attempt in dealing with this finding is to convey the ambiguity, subtle differences, and multiple definitions around mentoring. After closely listening and analyzing the language and descriptors of the interviewees and participants, I found an interesting comfort that they have with the somewhat indefinable and varying nature of their relationships with the faculty and staff they interact with on campus. When I spoke with Randy, a senior basketball player who would graduate in May 2011, he delineated between two mentors in his life, his coach and his academic advisor:

Immediately, I think of my advisor Rugler. I think of my coach. Them having been through what you are going through. Knowing that they are going to try and do what is in your best interest and being able to trust that. And I feel like here you can get that a lot more than the other places I have been. And just knowing that, well, Rugler is an outstanding guy. I trust what he is going to say, and I know that he is going to do what is best for me and get me going in the right direction. That's what I consider mentoring, and just knowing that that is there for me is great.

When I asked him to speak about those relationships, including the differences and similarities, he explained:

Rug first. Rug is the relationship isn't as intimate as the one with coach. It's more professional as to where I am trying to get to a certain point, but he's not an everyday basis, here we'll talk about my family and stuff . . . it's strictly careerfocused and centered. I can go in there. Right now I am doing an internship at a chiropractic office, and he set the whole thing up. I'll go in there, and we'll talk about it. I got into class and he asked me, "How's your rotation going?" That support system and he's there. Whereas Coach Hamilton, I see him every day and he invites us over to his house, we'll eat, we know his family, he knows my family, it's a deeper level, and I think that, not taking anything away from Rug, just the time we've spent together as a basketball team and my parents are at the games, you can develop that deeper relationship. We'll have devotionals on Friday, and he'll invite some people in, but most of the time he does them, and so one time he even brought his wife in and they got deep into their relationship and talked about relationships. Having that, and seeing who he is, you can connect on a more personal level and just knowing that.

Then there was Matt, a fifth-year philosophy major. I asked if he had anyone he considered a mentor during his times at SCU. He replied by describing a positive but at times conflicting relationship with one of the philosophy professors. There are formal and 
informal paternal elements brought into the relationship, and contact that at one time was weekly was then discontinued for close to a year. This typifies the challenging nature of working with students:

John, because he is the philosophy guy. When I first transferred here, he took me under his wing. Because he knows my dad, and they used to teach together at USU. So it was cool, but it also led to problems because he has this preconception of me as this kid who he once knew. And I am trying to find my own way. Many times, he'd belittle what I was trying to do. I'd say, I want to do this project, and he'd say, "Are you sure you can handle it?" Kind of skeptical at times, and it really bothered me some days. Because, it's your mentor, you trust him. Even if it was, if it was someone I wasn't so attached to, I think they would have been required to be optimistic. But, I guess he felt more connected, so he felt like he could be more honest. Which, I don't know if it was good or bad. Some days, I didn't like it at all, and once I went a whole semester without talking to him. It's weird how you fluctuate out. Maybe it was a whole year; all last year I didn't talk to him as much and I treated him more like a professor, not like a friend. Maybe philosophy and theology are special like that, you are used to it, you want to build togetherness, but you are trying to be colleagues and trying to be intellectual. I think that line is blurred, and it's an interesting hurdle.

\section{Vocational Alignment}

I discovered that a significant part of the blurred overlap seems to come when the student and the mentor(s) share some sort of vocational alignment. In this way, the professional or academic pursuits intersect with the personal passions, interests, and explorations. Henry, a Latino student who would graduate in May 2011, spoke to this when he talked about his relationship with his supervisor that evolved out of his decision to volunteer on one of her trips to Mexico:

What got me interested was that Tucker did it. But the more I thought about it, the more time I spent here, I felt I wanted to be a missionary somewhere. This would be a good way to experience that. And then I talked to Tucker about it and she said, "Yeah." So we had good conversations, and she was always the person I would come to for any advice, and I still do. She's been a mentor and a person that I look to for guidance. That's what I would define it as . . . a person you look to for guidance.

When I inquired about this overlap and effects in his life, he went on to say: 
[Y]es, with the ministry and stuff, I feel like I can contribute a lot. I was in the foster care system, and I can somewhat relate to them. It's different, and it is my culture. So coming back from YouthWorks, and I told Tucker I have been praying about it and this is something I am supposed to help, I feel like I could help out. You work in Mexico, I am from Mexico, I could help. There is culture barriers, and no matter how experienced you are in the culture, there will always be this collapse somewhere. So I am fluent in Spanish, I can connect with a lot of Mexicans, it feels natural.

Like Henry's, Tonya's discussion of her academic advisor contained a remarkable and subtle reference she made that exemplifies this formal and informal overlap. She is the student who struggled upon entering and then went on to take up multiple leadership roles. A significant part of her experience was being a biology major. I asked her to describe in more detail the mentors she had named. One was a college pastor, one was a staff person, and one was her faculty advisor. This is how she described her faculty advisor:

Dr Halk. Has followed me since my first advising meeting. Followed me going through deciding if I was going to be pre-med, supported me when I decided I didn't want to go to medical school, into public health. Supported me to run for student government ... supported me to do LoveWorks. A lot of different things. That was the most formal type of relationship because I had to meet with him twice a semester. If I wasn't meeting with him in person, I was emailing him. We emailed a lot. Was a good soundboard, mostly listened, validated how I was feeling, especially when I wasn't sure vocationally what I was going to do. I think he's probably been the only person that has seemed like my family. That has seen the evolution of my vocational goals and has supported me and questioned things, supporting me in not doing the conventional route of a biology major. He's always given me insight.

Consider how she calls him the "most formal" and at the same time indicates he is the only person who "seemed like family." It is also apparent with Casey, the young woman who graduated in May 2010 from the music department. She also described the overlap of formal and informal when she talked about two of her professors in the music department. Not only does she mix the formal and informal roles they played in her life, she intertwines her description of the roles that they played in her life: 
Dr. Plenyon. I studied private piano with him while I was here. Musically, it's always been a musical mentor. And then there were some big family situations that happened my junior year that he, I had to tell him about. I explained it to him. He never tried to step in and fix anything, or be anything to me that I might have needed; he made it very clear that I was okay. It's okay. Still if practicing doesn't work the way you want it to, it's okay, and he was very encouraging through that whole thing. Even if he didn't know all the details or anything, it was just he knew something big was going on, and he was there to support it. He's been very good through all of that. Just in general, maybe I felt like I made the wrong decision, with being in music, or I am not good enough, he'd always come back with these life-coaching speeches, why it is important, how it is a spiritual thing as well, so he was one. . . . Yes, I have learned a lot about the career I want to go into, from Dr. Plenyon especially, and observing how he does all of it, what works, what doesn't work, and I try the things he says don't work, and he ends up being right. He's taught me a lot about that. Joe [another professor in the music department] was always more the "you are great just the way you are" person, always encouraging me in that way. Whereas Dr. Plenyon, you can be better, push yourself, a lot of times I need that, I like having a challenge to get better at something. So that worked, from him. And then I did an honors project my senior year, and Joe Clemmons was my mentor for that. With her it was more work, I guess, or more academic, but at the same time she would always throw in these things of like, about life in general, more than just the project.

This finding revealed and challenged a bias I had going into the study. My assumption was that students would have a strong preference for informal efforts at mentoring, and a strong disdain for more formalized or institutional efforts. What emerged was an obvious and consistent finding for the functions and characteristics of the relationship, regardless if it was classified as formal, informal or both.

\section{Conclusion}

There was a subtle thread throughout the interviews that is relevant to this conclusion of this Findings chapter. At least half of the participants expressed some sort of surprise at the efforts shown toward them that have been described. Haley was a good example of this when she spoke about her student ministry supervisor and one of her faculty members:

I was surprised. I didn't expect her to take so much time. She's busy, all over the place, family, school. And I don't know how she does it. So definitely felt like a 
privilege to have that kind of guidance. I think it's expected from professors, but many of them come and take the time with students outside the classroom, not even about school stuff, just what's going on in your life kind of stuff. That's incredible to experience. ... One thing I have noticed about Dr. Smith is that since the subject matter we cover in class can be really heavy material, he's really good at getting your personal response to a world issue and having you explore what a personal response is and what to do with all these things that you feel, and every class ends with what is our theological, spiritual response look like? What is our calling? And he takes it to the next level.

This element of surprise was all the more noticeable to me given the institutional context of these interviews. The host institution has an undergraduate population of about 2,000 . It is easy to see in the stated values and mission of the institution that there is a high priority on students. These kinds of caring, intentional relationships are in many ways part of the ethos of the campus. Even so, students express surprise when faculty, staff, and administrators go the perceived "extra mile" or take the time. 


\section{CHAPTER FIVE: CONCLUSIONS, DISCUSSION, AND SUGGESTIONS FOR FUTURE RESEARCH}

The purpose of this qualitative study was to use a thematic analysis approach to consider the thoughts of undergraduate students who had recently or would soon graduate from a private, four-year, liberal-arts university in Southern California. These students were asked about their perceptions of and experiences with the various sorts of mentoring they received during their college years. Those who are in or who will take on leadership roles in traditional higher education settings can use this study to further conceptualize a college education in terms of a holistic environment, that is, a place where the development of students is shared across institutional boundaries. The study was based on the following three research questions:

1. How do graduating seniors attending this university describe mentoring? In other words, how do they describe the function and characteristics of mentoring?

2. How do the students describe the formal and/or informal mentoring they have received during their college years?

3. What suggestions would the students have for the university's formal and informal efforts at mentoring?

These three research questions were addressed by the findings presented in Chapter Four. The most significant finding from this study came from the first question asked of the participants and it was initially intended as an opening icebreaker. That question asked participants to reflect on significant aspects of college. They most often described experiences that were relational and participatory. Similarly, when asked to discuss personal experiences with mentoring in college, all participants but one described 
multiple people of influence in their lives, as opposed to one mentor. As a result, when asked to describe the functions and characteristics of mentoring, participants most often used language that described intentionality, availability, and interest. And finally participants rarely differentiated between functions and characteristics described in the literature as formal and informal. Rather, students described relationships and interactions that combined, overlapped, and interchanged these categorical differences. This chapter offers three conclusion, each intended to be considered by those who are in leadership positions in institutions of traditional higher education. Each conclusion is supported and discussed, and when it is relevant, there are direct quotations from the participants, integration of theory, or both. The conclusions to be discussed are:

Conclusion \#1: Traditional undergraduate education is optimal when all stakeholders, including students, are participating in a holistic educational experience.

Conclusion \#2: Positive efforts around mentoring traditional undergraduate students are optimal as a shared endeavor; that is to say when done in the context of a mentoring environment.

Conclusion \#3: Leaders in the field of traditional undergraduate education would benefit from an awareness of the difficulties, challenges, and potential involved as college students navigate into young adulthood.

Following the discussion of these three conclusions, there will be suggestions for future research related to this project.

Conclusion \#1: Traditional undergraduate education is optimal when all stakeholders, including students, are participating in a holistic educational experience.

Participants in this study consistently said that relational and participatory experiences with faculty, staff, and administrators were significant and transformative. I 
believe that this is because the adults referred to by the students in this study understand at some level that among the many facets of a college education, paying attention to the inner life (Astin, et al., 2011) and engaging in the development of college students produces deep learning (Chickering, et al., 2006). Originally intended as a simple conversational kick-start, in every interview the question about what was significant in college produced considerable reflection on the part of the participants. Why? This study would indicate that college is arguably one of the more challenging, important, and developmentally significant times of life.

Based on this study, company of some sort is valued by a young adult attempting to maneuver these challenges, be it a guide, a mentor, or someone who has some lived experience and is willing to listen and share. As will be discussed in the upcoming sections, working with young adults is challenging, and many aspects of their development, including but not limited to the nature of their decision-making, processing, and life planning, can be easily misunderstood and interpreted negatively. Based on participant responses SCU's espoused values, commitments and ethos are impacting students. Participants reference faculty, staff and administrators who work at a holistic level, caring for and paying attention to the critical aspects of the inner life of students.

\section{Looking for Significance as Part of Young Adult Development}

Research cited earlier in this study would affirm that college students are less inclined to jump quickly on the traditional spectrum of life choices for young adults. This pause, while often infuriating to parents and college personnel, is part of a developmental period that some are calling a fourth stage of development (Arnett, 2000; Baxter Magolda, 2009; Daloz Parks, 2000; Settersten Jr., et al., 2005). More often, college students are holding off on traditional choices of marriage and career and attempting to 
explore lives of significance, while looking for faculty, staff, and administrators who will model and share that kind of life with them. Tonya, the African American female who graduated in 2010, described her relationship with Dr. Woo, a history/political science professor for one of her general elective classes her sophomore year:

Dr. Woo ... I had him sophomore year for World Civ[ilizations] and would just talk to him after class. It started with us being mean to each other, being sarcastic. ... I am a really sarcastic person. And it started from there. We would meet in the cafe a lot. I learned more about his life. I asked questions about his life and things he's gone through, and last semester we went to a conference. I took him to a conference on racial reconciliation, and I had emailed it to all the history professors and all the sociology professors. He knew it was something that I strongly valued, especially with [a recent racial crime at UCSD] and how I wrote the article for the student newspaper. He knew that it was something that I deeply valued, and when we went, we drove there and back together and just had lots of good conversations. He's always been someone who has taken interest, not just my well being as a leader on campus, or a student, but as a person. And has expressed that he wants to continue that after college.

Recently a national surf company has developed a new branding statement, "Live the Search." I think this is an entirely appropriate summary of the life of a college student. It is a search for meaning, purpose, vocation, friendship, success, and differentiation. Within this search, there are many ways to misinterpret, minimize or dismiss the deep value of student efforts.

\section{Dismissive Labeling as Inhibitive to Holistic Development}

Many times as I listen to colleagues discuss their students, I cringe at some of the most frequent and easily accessible labeling schemes. The less positive interpretation of this searching time of life is that these kinds of choices are a form of delayed adolescence and that more affluent, seemingly entitled students are delaying adulthood. Participants in this study could be put into such a grouping. On the surface, the setting of this private, liberal-arts, faith-based institution must be considered. Arguably, students who arrive here have competed for their place. Annual expenses are more than $\$ 35,000$. As is often 
the case in the literature, these students are considered privileged and entitled, with their college career one additional rung in their privileged development. I wrestled with this vein of literature in Chapter Two, citing considerable frustration with this view of college students. The initial wave of generational labeling literature $-X, Y$, Millenials, and so on (Howe \& Strauss, 2000) — was novel and seemingly helpful in establishing a sociological basis for students entering college.

Other researchers like Twenge $(2006 ; 2009 ; 2008)$, however, who focus on issues of narcissism and entitlement, picked up on this work and, in my opinion, cast an unnecessarily darker shadow on the potential, outlook, motivation, and life skills of young adults. These kinds of attitudes were not prevalent in the participants I interviewed. More often, I experienced students who were humble, intelligent, grateful, and reflective of faculty, staff, and administrators who took time to be good company (1999; Baxter Magolda, 1992, 2001) to them during their college career. This aligns with another body of literature and research in higher education that deals with the inner life of the college student.

\section{A New Reckoning with the Inner Lives of College Students}

When one simply considers the external choices of a student (changes in major, seemingly random choices for friends or romantic interests, travel), there are multiple ways to interpret the choices negatively. But recent literature would say that for those taking up leadership in the traditional college environment, there must be a reckoning with the inner lives of college students. As an example, during the duration of this study, several important and helpful works were released. Astin, Astin, and Lindholm (2011) wrote Cultivating the Spirit: How College Can Enhance Students' Inner Lives, a 
culmination of a seven-year study out of UCLA's Higher Education Research Institute.

Early in their work, they state:

Our primary reason for undertaking this study has been our shared belief that spirituality is fundamental to students' lives. The "big questions" that preoccupy students are essentially spiritual questions: Who am I? What are my most deeply felt values? Do I have a mission or purpose in my life? What am I in college? What kind of person do I want to become? What sort of world do I want to help create? When we speak of students' "spiritual quest" we are essentially speaking of their efforts to seek answers to such questions. (p. 1)

In other words, the way in which all 12 participants in this study described the transformative and significant nature of their relationships with faculty, staff, and administrators could be connected to the considerable amount of inner development that is taking place during these years. With this, one would hope for a guide, for good company, beyond one's own peers. This conclusion speaks to the kinds of experiences and relationships articulated in this study and being explored in the literature. It is not dismissive of the academic experience, but rather a calling for a purposeful, holistic college educational experience. Nash and Murray recently co-wrote Helping College Students Find Purpose: The Campus Guide to Meaning Making (2010). Nash is a faculty member and Murray a student-affairs vice president. In the preface to their book, they write:

We believe strongly that when it comes to teaching for meaning-making, no single group in the academy own the meaning making or purpose-driven life. Nor does any single group on campus own the intellectual life. Education, when done well, is cross-disciplinary, collaborative, and student-centered. Faculty and administrators need one another as active, knowledgeable, passionate collaborators if we are to be successful in helping our students to discover, and to create, in Frankl's (Frankl, 1979) words, a "meaning to live for."

\section{Taking Responsibility}

The easiest way to misunderstand this literature is to view the approach to college students as a "blank check" approach to the college years and several years after. There is 
an image of the college student that, I think, is the fear of parents and educators: The student changes majors multiple times, has one or more alcohol-infused study abroad experiences, graduates and moves home only to work a low-paying job while mooching off parents, saving up for occasional travel and leisure with friends, and only taking up some sort of meaningful work and place in society in the later part of her or his twenties. In reality, the kind of approach I have argued for here is quite the opposite. Taking a holistic approach to a college education, being intentional with students, and recognizing the depth of development taking place is exactly the kind of work that presents a student with the opportunity to take personal responsibility for his or her education and life choices. I would argue that buying into the dismissive and hopeless labeling is often a quick and easy off-ramp for faculty, staff, and administrators, leaving our young people to do the best they can in a period of life when they need and want good company. College and university personnel have a unique opportunity to speak truth, accountability, and responsibility into the lives of their students, but, as has been conveyed in this study, it must be done in the context of relationships, intentionality, and interaction. This is a realm of respect for the experience of the student and requires the kind of awareness that is quite possible, especially when done in the context of other colleagues in the effort of supporting students.

Conclusion \#2: Efforts around mentoring traditional undergraduate students are optimal as a shared endeavor; that is to say when done in the context of a mentoring environment.

This shared endeavor is optimal for creating a holistic educational environment. As was stated in the previous chapter, out of the students I interviewed, only one affirmed the presence of a classically understood mentor in his life. The rest discussed several people whose combined influence was helpful and transformative. As was discussed in 
Chapter Two, there is a perceptible convergence in the literature around this idea that faculty, staff, administrators, peers, and other aspects of the college experience can combine to create a shared mentoring responsibility or environment of mentoring The Realities and Challenges of College Students

The results of this study would indicate that institutions would do well to realize the somewhat transient nature of working with college students. Schedules change each semester. A student you might see three days a week this fall, you might not see once during the following semester. Not to mention that finding, establishing, and nurturing this kind of intimate, one-on-one relationship is difficult, rare, and not able to be forced. When it happens, or if it happens, it can be celebrated. But the seemingly more common, sustainable, and reasonable expectation would be that faculty, staff, and administrators look to those students who are immediately before them and take an intentional approach there. As was discussed in Chapter Four, this kind of approach will require formal programs and informal relationships. Regardless, there must be an elevated value on the act of willfully and intentionally participating in students' experiences.

\section{The Realities and Challenges of Staff, Faculty and Administrators}

To work with students in the ways that are being espoused in this study requires a shared endeavor at any institution. If any one person or department were to be held responsible, it would be daunting and impossible. The conclusion here is that all can make these efforts in their context and with their students. Academics and student affairs professionals both bring valuable opportunities to the institution, but that kind of collaborative work is challenging, frustrating, difficult, and many times derailed by schedules, personalities, committees, and the ever-filling Outlook inbox. Along this line of thought, Chickering (2006) says: 
Almost all content areas that typically characterize college and university curricula have potential for helping students address issues of spiritual growth, authenticity, purpose and meaning ... realizing the potential of any particular content area requires integrating pertinent pedagogy, experiential learning, and human interactions. Simply presenting relevant readings and lectures and asking students to memorize the content and feed it back may occasionally trigger some reflection and growth, but for most persons the material remains inert, devoid of lasting contribution. Similarly, pedagogical technique, in the absence of judiciously chosen, well-organized resource materials and without rich experiential encounters won't have much impact. (p. 113)

As awkward, frustrating, and difficult it can be to make these curricula shifts, pedagogical reforms, committee restructures, and any other number of institutional reforms, the evidence indicates it is a worthwhile endeavor. Such efforts go beyond customer service, to the very experience of students and families within our institutions. As our students take their places in our classrooms, assume leadership positions on our campuses, and maneuver the transition to adulthood, they are also taking their place in the complex and shifting landscape of our world. We are co-creating our future.

As one who has been in higher education for 15 years, I am grounded in the realities of student life. What I know to be true is that no matter how rich the holistic educational environment, the power of choice is the most significant aspect of a student's education. I believe the temptation is to miss the integrated and reciprocal nature of this networked approach. But a student who may be upset at me for a very difficult situation we have had to deal with can walk across campus to a trusted faculty member and continue to deal with the frustration and the situation in that context.

We often consider such an approach in terms of student success, which is an outcome that is easy to affirm. As will be discussed in Conclusion \#3, however, this study has created a heightened awareness for me of the realities of the student experience. I was surprised at the kinds of ways that these successful, intelligent, and motivated young 
people described their experiences, which included loneliness, isolation, and marginalization.

Conclusion \#3: Leaders in the field of traditional undergraduate education would benefit from an awareness of the difficulties, challenges, and potential involved as college students navigate into young adulthood.

One aspect of this study that I did not anticipate was the consistency of participants in articulating feelings or emotions of marginalization, isolation, loneliness, and significant challenge. Out of curiosity, I went back and analyzed their profile characteristics, involvements, and co-curricular activities. By common standards, at least eight of these participants would be considered student leaders on most traditional university campuses in the United States. And if those eight students are considered student leaders, part of that leadership role at SCU is direct access on a regular basis to motivated and committed faculty, staff, and administrators. There is built-in support, and as has already been shown, the relationships were active and for the most part positive, and they resulted in significant growth.

Even so, a majority still experienced significant feelings and periods of isolation. In light of the consistency of the students' responses, I returned to the developmental literature and was again reminded of the challenging nature of this time of life. These kinds of periods, emotions, and experiences are part of the transition to adulthood. This is all the more reason that colleges and universities be committed to providing students with as much support, encouragement, mentorship, and availability as possible. As an example, I asked Henry, who is president of one of the student clubs, if he had a mentor while at SCU:

No. I came with a high expectation. Always heard it's a small school and you can have good relationships, and I heard people made good relationships with their 
professors. When I was here, I didn't feel that or see anybody. Class ... out of class. It was powerful when a professor prayed in class, but it never went beyond that. I never really had . . . it didn't feel like anyone had an interest. I understand that they have a busy life, but it was disappointing. You hear about people doing dinner at their houses and stuff. Where are all these great professors I was hearing about? A lot of my friends from last year have that. I feel like they put the effort talking to professors, and I feel like that is probably my fault.

As someone who knows Henry, and based on his previous responses in the interview describing a strong relationship with a staff person, his response came as a surprise to me. And it served as a caution not to assume that a particular student has the necessary support or connections at that particular time. Campus mentorship requires an ongoing practice of awareness on behalf of our students. This was an important outcome of this study for me. As one who attempts to be aware of my own biases, projections, and assumptions about students, I was genuinely surprised and realized that I have additional work to do.

\section{Limitations of the Study}

As was indicated earlier, this is a qualitative study and was purposefully based, in part, on self-reported data from 12 undergraduate students at only one institution, a private, faith-based, liberal-arts institution. Tuition, room, and board for this institution costs more than $\$ 30,000$ annually, which limits access for a number of socio-economic groups. And while considerable efforts were made to attain interpretations of the data at a level of trustworthiness (Bloomberg \& Volpe, 2008; Lincoln \& Guba, 1985; Merriam, 2002; Patton, 2002), limitations extended beyond external validity or generalizability to include internal validity limitations.

To be sure, this study attempted to identify a variety of participants by use of convenience and judgment sampling. In the process, I hoped to represent a variety of student views. However, true representation of the student body (approximately 2,200 
students) is beyond the scope of this project. And while a majority of the participants in the study were nominated by colleagues and selection criteria were predetermined and followed closely, the methods use for selection of participants cannot completely eliminate bias in the nomination or selection process.

There is another potential limitation: I hold a position of formal authority at the research site. As dean of students, I am responsible for residential life and matters of student conduct. While all attempts were made to ensure students did not perceive any coercion, risk, or potential reward by participating or not participating in the study, the sought-after student input could have been skewed by the power differential involved. As is detailed in the Data Analysis Map (Appendix K), I made use of multiple qualitative research strategies to ensure maximum trustworthiness, validity and reliability while simultaneously minimizing the power differential of and my own personal biases. As has been discussed, this included, among other components, triangulation of the data via member checks, the literature and peer review/examination. These strategies were employed to minimize the impact of my position as researcher and a formal authority at the research institution.

This study did not set out to narrow or clarify the difficulty surrounding a definitional understanding of the term mentor. Rather, this study sought to explore the ambiguity along with the various interpretations of, and expectations surrounding, the term as constructed by a group of college students. Similarly, this study was not intended to consider solely or to measure the impact of programs that could be classified as "formal" mentoring (i.e. academic improvement, engagement, retention), though some students interviewed alluded to mentoring relationships or encounters that could be classified as formal. 


\section{Recommendations for Future Research}

\section{Access to Education and Mentoring Networks}

Education is a powerful tool in the life of a young person. According to the most recent U.S. census data, 28\% of Americans 25 and older hold bachelor's degrees (Richards, 2011). While this number has and continues to grow, access to quality, affordable, and meaningful education is still a challenge in the United States and around the world for a significant majority of the population. Stating this in the context of this study is a recommendation for future research and at the same time an acknowledgement that regardless of the educational situation of a young person, the need for good company is real and critical. Relatively speaking, very few have access to the traditional university experience and the network of support potentially provided there.

\section{The Mentors}

One immediate area of further interest resulting from this project would be to hear the perspectives of the faculty, staff, and administrators mentioned in this study on mentoring and the role they serve at the institution. This entire study could be done again, but from the perspective of the mentors. Initially, the analysis of intent would be of interest. Did the faculty, staff or administrator "intend" to mentor the student? This connects to the institutional norms, espoused values and practices. One study showed faculty that students indicated as mentors did not see themselves as mentors (Wolfe, et al., 2008) until the institution reflected back to them that much of their ongoing work with students was at least perceived as mentoring. In the literature, there is indication of widespread hesitancy on the part of campus leadership to accept the role of mentor (Boyer, 1990; Calabrese, 1996; Carger, 1996; Jaurigue, 1991; Johnson, 2006; Kaye, 2000; Sorcinelli \& Yun, 2007; Storrs, et al., 2008; Tuckman, 1996; Van Puymbroeck \& 
Maryland Univ, 2001) but much of that hesitancy is based on a perception (or misperception) of what they think students would need or want. The advantage of this current study is clear data from students that could potentially be taken up and worked on by those who could be in the mentoring role.

\section{Peer Influence}

During the course of my research for this project, I came into contact with literature on peer culture on the college campus. This has to do with how peers influence peers, for good or for bad. One theory emerging for me is that if a college desires to maximize its ability to support students, then the peer-to-peer culture must be utilized in a positive way. One of the immediate access points in such a culture is the pool of motivated student leaders who have self-selected or been chosen from the student body. This group of students spends more time with faculty, staff, and administrators than the general population. I would speculate that more can be done in leadership development programs so that the supportive and mentoring efforts directed at student leaders can have a ripple effect to the general student body. Certainly, the peer-to-peer relationships are valuable, needed, and vital to the college experience. Dalton and Crosby (2010) recently published an article on peer culture, saying that "college peer culture is perhaps the single most important influence on student learning, values, and behavior on the college environment and yet it remains one of the least studied and understood aspects of higher education" (p. 1). My experience as an educator and a researcher resonates deeply with this statement.

It is because of this that I believe quality relationships with faculty, staff, and administrators are important. Not all students at a given college or university will naturally, formally or informally, find a mentor or a mentoring network. Some, if not 
many, wander through the college experience, primarily encountering and interacting with peers.

If institutions were to take seriously those naturally forming relationships as beginning points, centers of influence on the greater peer culture, the "ripple effect" of quality relationships could extend far beyond students directly connected to faculty, staff, or administrators. Part of a mentoring network is a realization of the far-reaching potential of influencing a peer culture.

\section{Conclusion}

For leaders on the college campus, it is important to acknowledge that the young people in our institutions will transition to young adulthood with or without us. This study demonstrates that the opportunity to join them in their transitional work in the context of a holistic educational environment is challenging, complicated, and profoundly important. 


\section{References}

Arnett, Jeffrey Jensen. (2004). Emerging Adulthood The Winding Road from the Late Teens through the Twenties New York: Oxford University Press.

Arnett, Jeffrey Jensen (2000). Emerging Adulthood A Theory of Development From the Late Teens Through the Twenties. American Psychologist, 55(5), 469-480.

Arnett, Jeffrey Jensen , \& Lynn Tanner, Jennifer (Eds.). (2006). Emerging Adults in America. Coming of Age in the 21st Century. Washington, DC: American Psychological Association.

Arnett, Jeffrey Jensen, \& Arnett Jensen, Lene (2002). A Congregation of One:

Individualized Religious Beliefs Among Emerging Adults. Journal of Adolescent Research, 17(5).

Astin, Alexander W , Astin, Helen S, \& Lindholm, Jennifer (2011). Cultivating the Spirit. How College Can Enhance Students' Inner Lives San Francisco: JosseyBass

Astin, Alexander W. (1977). Four Critical Years. Effects of College on Beliefs, Attitudes, and Knowledge.

Astin, Alexander W. . (1993). What Matters in College...Four Critical Years Revisited. San Francisco: Jossey-Bass.

Astin, Alexander W., \& Chang, Mitchell J. (1995). Colleges That Emphasize Research and Teaching: Can You Have Your Cake and Eat It Too? Change, 27(5), 44-49.

Baxter Magolda, Marcia B. (1999). Creating Contexts for Learning and Self-Authorship. Nashville: Vanderbilt. 
Baxter Magolda, Marcia B. . (1992). Knowing and Reasoning in College: GenderRelated Patterns in Students' Intellectual Development. San Francisco: Jossey Bass.

Baxter Magolda, Marcia B. . (2001). Making Their Own Way. Sterling: Stylus Publishing LLC.

Baxter Magolda, Marcia B. . (2009). The Activity of Meaning Making: A Holistic Perspective on College Student Development. The Journal of College Student Development 50(6).

Baxter Magolda, Marcia B. , \& King, Patricia (2004). Learning Partnerships: Theory and Models of Practice to Educate for Self-Authorship. Sterling: Stylus Publishing LLC.

Beaudoin, Tom (1998). Virtual Faith. San Francisco: Jossey-Bass.

Bliming, Gregory S. , Whitt, Elizabeth J., \& Associates (Eds.). (1999). Good Practices in Student Affairs. San Francisco: Jossey-Bass.

Bloomberg, Linda Dale, \& Volpe, Marie. (2008). Completing Your Qualitative Dissertation A Roadmaps from Beginning to End Thousand Oaks Sage Publications Inc. .

Boyer, Ernest L. . (1990). Campus Life. In Search of Community. A Special Report. (pp. 157). Princeton: Carnegie Foundation for the Advancement of Teaching Calabrese, Raymond L. (1996). Friends Along the Journey. Peabody Journal of Education, 71(1), 44-56.

Carger, Chris Liska. (1996). The Two Bills: Reflecting on the Gift of Mentorship. Peabody Journal of Education, 71(1), 22-29. 
Carr, Jeffrey. (1996). An Investigation of the Influence of Mentoring on the Collegiate Success of the Undergraduate African American Students at the University of San Francisco. Dissertation University of San Francisco San Francisco.

Cherlin, Andrew J. (2005). American Marriage in the Early Twenty-First Century. The Future of Children, 15(2), 33-55.

Chickering, Arthur W. (1968). The Young Adult. A Conceptual Framework. .

Chickering, Arthur W. (2010). A Retrospect on Higher Education's Committment to Moral and Civic Education Journal of College and Character, 11(3).

Chickering, Arthur W. , Dalton, Jon C. , \& Stamm, Liesa (2006). Encouraging Authenticity and Spirituality in HIgher Education. San Francisco: Jossey Bass.

Chickering, Arthur W. , Dalton, Jon C. , \& Stamm, Liesa (2006). Encouraging Authenticity and Spirituality in Higher Education. San Francisco: Jossey-Bass. Cohen, Patricia, Kasen, Stephanie, \& Henian, Chen. (2003). Variations in Patterns of Developmental Transitions in the Emerging Adult Period. Developmental Psychology, 39(4), 657-669.

Cote, James, \& Bynner, John M. (2008). Changes in the Transition to Adulthood in the UK and Canada: The Role of Structure and Agency in Emerging Adulthood. Journal of Youth Studies, 11(3), 251-268.

Cote, James E. . (2006). Emerging Adulthood as an Institutionlized Moratorium: Risks and Benefits to Identity Formation. In J. J. Arnett \& J. L. Tanner (Eds.), Emerging Adults in America Coming of Age in the 21st Century (pp. 85-116). Washington DC: American Psychological Association.

Daloz, Laurent A. . (1986). Effective Teaching and Mentoring. San Francisco: Jossey Bass. 
Daloz Parks, Sharon. (1986). The Critical Years: Young Adults and the Search for Meaning, Faith and Commitment. San Francisco: HarperSanFrancisco.

Daloz Parks, Sharon (2000). Big Questions Worthy Dreams. San Francisco: Jossey Bass.

Daloz Parks, Sharon (2000). Big Questions, Worthy Dreams: Mentoring Young Adults in Their Search for Meaning, Purpose, and Faith. San Francisco: Jossey-Bass.

Daloz Parks, Sharon (2008). Leadership, Spirituality and the College as a Mentoring Environment. Journal of College and Character, $X(2)$.

Daloz Parks, Sharon (2009, September 10). Mentoring, Leadership and the College as a Mentoring Environment

San Diego.

Daloz Parks, Sharon, Parks Daloz, Laurent A. , Keen, Cheryl H. , \& Keen, James P (1996). Common Fire. Boston: Beacon Press.

Dalton, Jon C. , \& Crosby, Pamela C (2010). College Peer Culture: Taming the "Monster Within the Gates Journal of College and Character, 11(4).

Education, Chronicle of Higher. (November 22, 2009). Data Points: Postsecondary Enrollment by Race and Type of Institution, Fall 2008

Chronicle of Higher Education. Retrieved from

Erikson, Erik H. (1968). Youth and Crisis (4th ed.): W.W. Norton and Company.

Erikson, Erik H. (Ed.). (1987). A Way of Looking at Things: Selected Papers. New York: W.W. Norton and Company.

Erkut, Sumru, \& Mokros, Janice R. (1984). Professors as Models and Mentors for College Students. American Educational Research Journal, 21(2), 399-417.

Fogg, Piper. (2009). When Generations Collide. Education Digest: Essential Readings Condensed for Quick Review, 74(6), 25-30. 
Fowler, James (1981). Stages of Faith. San Francisco Harper

Golafshani, Nahid (2003). Understanding Reliability and Validity in Qualitative Research. The Qualitative Report, 8(4).

Hoover, Eric. (2009). The Millennial Muddle. The Chronicle of Higher Education.

Howe, Neil , \& Strauss, William (2000). Millenials Rising: The Next Great Generation New York: Vintage

Jacobi, Maryann. (1991). Mentoring and Undergraduate Academic Success: A Literature Review. Review of Educational Research, 61(4), 505-532.

Jaurigue, Rebecca. (1991). I Feel Like an Armadillo: A Look at College Seniors and Recent Graduates Using Erik Erikson's Model of "Identity Versus RoleDiffusion.".

Johnson, Brad W. (2006). On Being a Mentor: A Guide for Higher Education Faculty: Lawrence Erlbaum Associates.

Kaye, Harvey J. . (2000). One Professor's Dialectic of Mentoring. The Chronicle of Higher Education. Retrieved from

Kegan, Robert (1982). The Evolving Self. Cambridge: Harvard University PRess.

Kezar, Adrianna j., Carducci, Rozana, \& Contreras-McGavin, Contreras. (2006).

Rethinking the "L" Word in Higher Education: The Revolution in Research on

Leadership. In A. f. t. S. o. H. Education (Ed.), The ASHE Higher Education

Report Series (Vol. 31). Hoboken: Wiley Periodicals

King, Patricia M. (2009). Principle of Development and Development Change

Underlying Theories of Cognitive and Moral Development Journal of College

Student Development, 50(6), 597 - 620. 
Kinzie, Jillian, Schuh, John H , Whitt, Elizabeth J., \& Kuh, George D. (2005). Student Success in College. San Francisco Jossey-Bass.

Knefelkamp, L, Widick, C, \& Parker, C.A. (Eds.). (1978). Applying new developmental findings. New Directions for Student Services (Vol. 4). San Francisco JosseyBass.

Komives, Susa R., Woodard Jr., Dudley B., \& Associates. (2003). Student Services: A Handbook for the Profession. San Francisco: Jossey-Bass.

Kuh, George D. (2009). What Student Affairs Professionals Need to Know About Student Engagement Journal of College Student Development, 50(6), 683 - 706.

Lasley, Thomas J. (1996). Mentors: They Simply Believe. Peabody Journal of Education, 71(1), 64-70.

Levine, Arthur, \& Cureton, Jeanette S. . (1998). When Hope and Fear Collide: A Portrait of Today's College Student. San Francisco: Josey-Bass.

Lewis, Harry R. . (2006). Excellence Without a Soul Does Liberal Arts Have a Future? New York: PublicAffairs.

Lincoln, Y.S., \& Guba, E.G. (1985). Naturalistic Inquiry Beverly Hills: Sage. Magolda, Marcia B. Baxter. (2009). The Activity of Meaning Making: A Holistic Perspective on College Student Development. The Journal of College Student Development 50(6), 621-639.

Mandelbaum, Allen (1990). The Odysey of Homer: A New Verse Translation McDonald, William M. (2002). Creating Campus Community: In Search of Ernest Boyer's Legacy. The Jossey-Bass Higher and Adult Education Series. San Francisco Jossey-Bass.

Merriam, Sharan B.and Associates (2002). Qualitative Research and Practice 
Examples for Discussion and Analysis San Francisco Jossey-Bass.

Mortimer, Jeylan T., \& Larson, Reed W. (2002). The Changing Adolescent Experience: Societal Trends and the Transition to Adulthood.

Nash, Robert J., \& Murray, Michelle C. . (2010). Helping College Students Find Purpose The Campus Guide to Meaning Making San Francisco: Jossey Bass

Nathan, Rebekah (2005). My Freshman Year What a Professor Learned by Becoming a Student. Ithica: Cornell University Press.

Nelson, Larry J., Badger, Sarah, \& Wu, Bo. (2004). The Influence of Culture in Emerging Adulthood: Perspectives of Chinese College Students. International Journal of Behavioral Development, 28(1), 26-36.

Nelson, Larry J., \& Barry, Carolyn McNamara. (2005). Distinguishing Features of Emerging Adulthood: The Role of Self-Classification as an Adult. Journal of Adolescent Research, 20(2), 242-262.

Nora, Amaury, \& Crisp, Gloria. (2008). Mentoring Students: Conceptualizing and Validating the Multi-Dimensions of a Support System. Journal of College Student Retention: Research, Theory \& Practice, 9(3), 337-356.

Padilla-Walker, Laura M., Barry, Carolyn McNamara, Carroll, Jason S., Madsen, Stephanie D., \& Nelson, Larry J. (2008). Looking on the Bright Side: The Role of Identity Status and Gender on Positive Orientations during Emerging Adulthood. Journal of Adolescence, 31(4), 451-467.

Palmer, Parker J. , Zajonc, Arthur , \& Scribner, Megan (2010). The Heart of Higher Education: A Call to Renewal. San Francisco Jossey Bass

Parks Daloz, Laurent A., Keen, Cheryl H., Keen, James P., \& Daloz Parks, Sharon. (1996). Common Fire. Boston. Beacon Press. 
Pascarella, Ernest T. , \& Terenzini, Patrick T. . (1991). How College Affects Students. San Francisco: Jossey-Bass.

Pascarella, Ernest T. , \& Terenzini, Patrick T. . (2005). How College Affects Students (Vol. 2). San Francisco: Josey-Bass.

Patton, Michael (2002). Qualitative Research and Evaluation Methods (3 ed.). Thousand Oaks Sage Publications.

Perry, William G. (1968). Forms of Ethical and Intellectual Development in the College Years A Scheme San Francisco: Jossey-Bass.

Quinn Patton, Michael (2002). Qualitative Research and Evaluation Methods (3 ed.). Thousand Oaks Sage Publications.

Reed, George E. , Martin, Gregg F. , Collins, Ruth B. , \& Dial, Cortez K. . (2002). The Road to Mentoring: Paved with Good Intentions. Parameters, 32( ).

Reifman, A., Arnett, J.J., \& Colwell, M.J. . (2003). The IDEA: Inventory of the Dimensions of Emerging Adulthood.

Reynolds, Amy L. . (2009). Helping College Students. San Francisco: Jossey-Bass.

Richards, Alex. (2011). Census Data Show Rise in College Degrees, but Also in Racial Gaps in Education. The Chronicle of Higher Education. Retrieved from http://chronicle.com website:

Schreiner, Laurie A. (2010). Thriving in Community About Campus, 15(4).

Settersten Jr., Richard A. , Furstenberg Jr., Frank F. , \& Rumbaut, Ruben G. (Eds.). (2005). On the Frontier of Adulthood: Theory Research and Public Policy. Chicago: University of Chicago Press.

Shuchok, Frank Jr. , \& Hulme, Eileen (2010). What's Right With You. About Campus, $11(4)$. 
Sorcinelli, Mary Deane, \& Yun, Jung. (2007). From Mentor to Mentoring Networks: Mentoring in the New Academy. Change: The Magazine of Higher Learning, 39, 58-61.

Spradley, James P. . (1979). The Ethnographic Interview Belmont Wadsworth Group/Thomson Learning

Stewart, Kenneth. (2009). Lessons from Teaching Millennials. College Teaching, 57(2), 111-118.

Storrs, Debbie, Putsche, Laura, \& Taylor, Amy. (2008). Mentoring Expectations and Realities: An Analysis of Metaphorical Thinking among Female Undergraduate Proteges and Their Mentors in a University Mentoring Programme. Mentoring \& Tutoring: Partnership in Learning, 16(2), 175-187.

Sum, Andrew, Mangum, Garth, \& Taggart, Robert. (2002). The Young, the Restless and the Jobless: The Case for a National Jobs Stimulus Program Targeted on America's Young Adults. Public Policy Issues Monograph.

Taylor, Kari B. (2008). Mapping the Intricacies of Young Adults' Developmental Journey from Socially Prescribed to Internally Defined Identities, Relationships, and Beliefs. Journal of College Student Development, 49(3), 215-234.

Tuckman, Bruce W. (1996). My Mentor: Robert M. Gagne. Peabody Journal of Education, 71(1), 3-11.

Twenge, Jean M. . (2006). Generation Me. New York: Simon and Schuster.

Twenge, Jean M. , \& Campbell, W. Keith. (2009). The Narcissism Epidemic: Living in the Age of Entitlement. New York: Free Press (Division of Simon and Schuester, Inc). 
Twenge, Jean M., Konrath, Sara, Foster, Joshua D., Campbell, W. Keith, \& Bushman, Brad J. (2008). Further evidence of an increase in narcissism among college students. Journal of Personality, 76(4), 919-928. doi: 10.1111/j.14676494.2008.00509.x

Van Puymbroeck, Christina M., \& Maryland Univ, College Park Counseling Center. (2001). The Mentoring Web: A Model To Increase Retention of Lesbian, Gay, and Bisexual Undergraduates.

Wallace, Dawn, \& Abel, Ronald. (1997). Clearing a Path for Success: Deconstructing Borders in Higher Education through Undergraduate Mentoring. ASHE Annual Meeting Paper.

Willimon, William H. (1997). Has Higher Education Abandoned Its Students? About Campus, 2(4), 4-9.

Wolfe, Ashley J., Retallick, Michael S., Martin, Robert, \& Steiner, Charles. (2008). Mentoring Functions Practiced by Undergraduate Faculty in Agriculture. Journal of Agricultural Education, 49(3), 99-108. 
Appendix A: Original Interview Guide (Pre-Pilot Study) 


\section{Appendix A}

\section{Original Interview Guide (Pre-Pilot Study)}

1. How would you describe mentoring?

2. In your opinion, what is the difference between formal mentoring and informal mentoring?

3. In your time here at this university, have you been mentored in any way? If so, can you describe that for me? If not, why do you think this did not happen?

4. Do you think it is valuable for college students to be mentored? Why or why not?

5. What suggestions do you have for this university regarding mentoring? 
Appendix B: Summary of Pilot Study 


\section{Appendix B}

\section{Summary of Pilot Study}

On Tuesday, March 23, 2010 I served as the guest instructor in the EDLD 351: Leadership Seminar at the University of San Diego's School of Leadership and Education Sciences. As described by the instructor, "this is the capstone course for the Leadership Minor that is meant to help students integrate their learning about leadership, solidify their personal philosophy of leadership, and help them take responsibility for their own learning about leadership." As part of that class, I asked the 13 students present the questions listed above in the interview guide. My intent was to utilize their responses to the questions as well as their critique of the questions as a source of revision for the interview guide.

The class is highly self-directed. Upon entering the classroom and meeting the students, I explained my project and desire for their input. The instructor had informed me that the class had additional in-class work to do. I offered them the choice of doing their work or pilot-studying my questions, and they chose to do the pilot study first. I asked each question and took notes on their answers. As a brief summary of that time, there was considerable dialogue about the preference for what can be called informal or natural mentoring relationships over formal mentorship programs. There was also a significant amount of discussion around peers as mentors, specifically referring to "big brother" or "big sister" relationships.

After the students finished answering the questions, I went back through and asked about the quality, accessibility, and understandability of each question. The class made the following suggestions: Questions 1,2,3, and 5 should be kept and utilized. 
Question 4 was deemed ineffective. Their suggestion was to replace it with the following: What would you want to get out of a mentoring relationship? 
Appendix C: Final Interview Guide 


\section{Appendix C}

Final Interview Guide

1. What have been some significant aspects of your college experience?

2. Tell me about your experience here with mentoring?

and/or

3. How would you describe mentoring?

4. In your opinion, what is the difference between formal mentoring and informal mentoring?

5. In your time here at this university, have you been mentored in any way? If so, can you describe that for me? If not, why do you think this did not happen?

6. What would you want to get out of a mentoring relationship?

7. What suggestions do you have for this university regarding mentoring? 
Appendix D: Table of Classic Three-Stage Adult Development Stages 


\section{Appendix D}

Table of Classic Three-Stage Adult Development Stages

Table 1

Classic three-stage adult development stages.

\begin{tabular}{|l|l|l|l|}
\hline Author & \multicolumn{3}{|c|}{ Adult development stages } \\
\hline Erikson & Young Adulthood & Middle Adulthood & Late Adulthood \\
\hline Kegan & Interpersonal & Institutional & \\
\hline Fowler & Individuate-reflective & Conjunctive faith & Inter-individual \\
\hline Perry & Daith & & \\
\hline
\end{tabular}


Appendix E: Table Comparison of the Three- and Four-Stage Models of Adult Development 


\section{Appendix E}

Table Comparison of the Three- and Four-Stage Models of Adult Development Table 2

Comparison of the three- and four-stage models of adult development.

\begin{tabular}{|l|l|l|l|l|}
\hline Author & \multicolumn{5}{|c|}{ Adult development stages } \\
\hline Erikson & Young adulthood & Middle adulthood & Late adulthood \\
\hline Kegan & Interpersonal & Institutional & Inter-individual \\
\hline Fowler & Individuate-reflective & Conjunctive faith & Universalizing faith \\
& faith & Dualism & Relativism/commitments & Commitments \\
\hline Perry & Adolescence & Emerging & Young & Adulthood \\
\hline Arnett & adulthood & adulthood & \\
\hline Parks & Adolescence & Young adulthood & Adulthood & Late adulthood \\
\hline Research & Adolescence & Early adulthood & Adulthood & Late adulthood \\
\hline
\end{tabular}


Appendix F: Summary of Contact, Selection, and Scheduling of Individual Interviews 


\section{Appendix F}

Summary of Contact, Selection, and Scheduling of Individual Interviews

Table 3

Summary of contact, selection, and scheduling of individual interviews.

\begin{tabular}{|c|c|c|c|c|c|c|}
\hline Date & $\begin{array}{l}\text { Interviewee } \\
\text { (coded name) }\end{array}$ & Time & Location & Gender & $\begin{array}{c}\text { Referral } \\
\text { Source }\end{array}$ & $\begin{array}{l}\text { Grad } \\
\text { Year }\end{array}$ \\
\hline $7 / 20 / 10$ & Tonya & 2:00 p.m. & My office & $\mathrm{F}$ & $\mathrm{Me}$ & 2011 \\
\hline $7 / 27 / 10$ & Randy & 11:00 a.m. & My office & M & Staff & 2010 \\
\hline 7/29/10 & \multicolumn{6}{|c|}{$\begin{array}{l}\text { Email to Offices of Student and Spiritual Development soliciting interviewee } \\
\text { candidates }\end{array}$} \\
\hline $8 / 4 / 10$ & Alex & 3:30 p.m. & My office & $\mathrm{F}$ & $\mathrm{Me}$ & 2010 \\
\hline $8 / 30 / 10$ & Mark & 11:45 a.m. & My office & M & $\mathrm{Me}$ & 2011 \\
\hline $9 / 2 / 10$ & Anna & $12: 30$ p.m. & My office & F & Staff & 2011 \\
\hline $9 / 14 / 10$ & Henry & 1:00 p.m. & My office & M & Staff & 2011 \\
\hline $9 / 16 / 10$ & \multicolumn{6}{|c|}{ Meeting with dissertation chair } \\
\hline $9 / 16 / 10$ & Erin & 3:00 p.m. & My office & $\mathrm{F}$ & Staff & 11 \\
\hline $10 / 5 / 10$ & \multicolumn{6}{|c|}{$\begin{array}{l}\text { Email to Academic Department Chairs, VP of Student Development, and } \\
\text { Provost soliciting interviewee candidates }\end{array}$} \\
\hline 10/11/10 & \multicolumn{6}{|l|}{ Focus Group } \\
\hline $10 / 12 / 10$ & Justin & 11:00 a.m. & My office & $\mathbf{M}$ & Staff & 2011 \\
\hline $10 / 13 / 10$ & Haley & $8: 30$ a.m. & My office & $\mathrm{F}$ & Faculty & 2010 \\
\hline $10 / 13 / 10$ & Kate & 1:00 p.m. & My office & $\mathrm{F}$ & Faculty & 2010 \\
\hline 10/14/10 & \multicolumn{6}{|c|}{ Meeting with dissertation chair } \\
\hline $10 / 14 / 10$ & Matt & 1:30 p.m. & My office & M & Faculty & 2011 \\
\hline 10/19/10 & Casey & 1:00 p.m. & My office & $\mathrm{F}$ & Faculty & 2010 \\
\hline
\end{tabular}


Appendix G: Focus Group Participant Breakdown 
Appendix G

Focus Group Participant Breakdown

Table 4

Focus group participant breakdown.

\begin{tabular}{|c|c|c|c|}
\hline Participant & Gender & Referral Source & Grad Year \\
\hline Randy & M & Staff & 2011 \\
\hline Henry & M & Staff & 2011 \\
\hline Erin & F & Staff & 2011 \\
\hline Alex & F & Me & 2010 \\
\hline Anna & F & Staff & 2011 \\
\hline Mark & M & Me & 2011 \\
\hline FG7 & M & Faculty & 2010 \\
\hline FG8 & M & Staff & 2011 \\
\hline FG9 & F & Faculty & 2011 \\
\hline FG10 & F & Staff & 2011 \\
\hline FG11 & F & Faculty & 2011 \\
\hline FG12 & F & Staff & 2011 \\
\hline
\end{tabular}


Appendix H: Master List of Potential Themes 


\section{Appendix H}

Master List of Potential Themes

\begin{tabular}{|c|c|}
\hline Significant Aspects of College & Descriptions of a Mentor \\
\hline Friends & Someone I could talk to \\
\hline Co-curricular activities (YouthWorks, & She understood me \\
\hline eWorks, clubs, etc) & Someone who recognizes your journey \\
\hline Participation in athletics & Volunteers time and energy \\
\hline $\begin{array}{l}\text { Anything that helped me interact outside } \\
\text { of my regular circle }\end{array}$ & $\begin{array}{l}\text { Has hindsight to know which questions to } \\
\text { ask you }\end{array}$ \\
\hline $\begin{array}{l}\text { Discovering students of similar } \\
\text { interestand background }\end{array}$ & $\begin{array}{l}\text { Walked with me in the evolution of my } \\
\text { vocational goals }\end{array}$ \\
\hline Roommate relationships & Helped me to recognize and to ask good \\
\hline Relationship with a staff person as a & questions \\
\hline mentor & They have been through what I am going \\
\hline Study Abroad & through \\
\hline ion to PLNU & They do what is in your best interest \\
\hline $\begin{array}{l}\text { Leadership roles } \\
\text { A loss of childhood }\end{array}$ & $\begin{array}{l}\text { Can show you the ways that God is working } \\
\text { in vour life }\end{array}$ \\
\hline $\begin{array}{l}\text { The taking on of adult tasks } \\
\text { Internships }\end{array}$ & $\begin{array}{l}\text { Someone who has a bird's-eye view of your } \\
\text { situation }\end{array}$ \\
\hline Dating & I don't know what it is, or how you get one, \\
\hline A time to discover passions & or how it gets set up \\
\hline $\begin{array}{l}\text { Positive and negative experiences with } \\
\text { roommates }\end{array}$ & $\begin{array}{l}\text { Get me going in the right direction } \\
\text { Career focused and centered }\end{array}$ \\
\hline The transition to PLNU as culture shock & She was the person I could come to for \\
\hline $\begin{array}{l}\text { The power of co-curricular experiences } \\
\text { Experiences }\end{array}$ & $\begin{array}{l}\text { advice and guidance } \\
\text { Someone who confronts and supports }\end{array}$ \\
\hline Departmental characteristics and & Not my parents \\
\hline experiences & Doesn't always have to give me advice or \\
\hline The specialness of my major & tell me what to do \\
\hline Involvement & Someone I can share my feelings with \\
\hline Elective courses & Someone who will listen and give you \\
\hline Major courses & feedback \\
\hline How the professors connect to things & Someone to bounce ideas and questions off of \\
\hline Residential living & Someone who understands your field of \\
\hline Entering the PLNU community as & study \\
\hline negative and disorienting & The ability to listen \\
\hline Feeling on the margin & Persistence \\
\hline Feeling lonely & Someone who is open \\
\hline Entering PLNU as overwhelming & Someone who pursues and is persistent \\
\hline Being in trouble as an experience & A discipleship relationship \\
\hline Encountering faith at PLNU & Someone who shares my interests or career \\
\hline & \\
\hline The desire to belong & Takes the time to pay attention \\
\hline
\end{tabular}




\begin{tabular}{|c|c|}
\hline $\begin{array}{l}\text { An older male } \\
\text { Non-judgmental } \\
\text { Honesty } \\
\text { Someone who listens } \\
\text { One who invites you to something } \\
\text { A God-given person in your life } \\
\text { Someone who sees something in you } \\
\text { Sees potential } \\
\text { Affirmation } \\
\text { Keeps the future in mind } \\
\text { Cultivates } \\
\text { Values } \\
\text { Cares and asks questions } \\
\text { Believes in me } \\
\text { I have connections with them } \\
\text { Required to be optimistic } \\
\text { Gives advice } \\
\text { Intentionality } \\
\text { Good conversations } \\
\text { Being heard } \\
\text { Being understood } \\
\text { Being acknowledged by someone who is } \\
\text { older } \\
\text { Advisor } \\
\text { Gives guidance } \\
\text { Friendship } \\
\text { Willingness to talk through issues } \\
\text { Offer her perspective } \\
\text { She helped me develop perspectives } \\
\text { Invests in you } \\
\text { Aware of where you are at } \\
\text { Checking in here and there } \\
\text { Gets me to think about different issues } \\
\text { Exemplifies a life of passion and } \\
\text { dedication } \\
\text { Helps with personal responses to world issues } \\
\text { Spiritual guidance } \\
\text { Encouraging } \\
\text { Someone older and wiser } \\
\text { Faithful } \\
\text { Someone who offers resources } \\
\text { Getaway for a few minutes } \\
\text { Long conversations } \\
\text { Validation }\end{array}$ & $\begin{array}{l}\text { Personal Experiences with Mentor/ } \\
\text { Mentoring } \\
\text { A willingness or desire to take up a similar } \\
\text { role in the lives of younger students } \\
\text { Experiences that serve as a wake-up call } \\
\text { Mentorship as secular discipleship } \\
\text { It didn't happen until I was ready } \\
\text { Can students mentor students? } \\
\text { PLNU does a good job of encouraging } \\
\text { involvement and making friends, but should } \\
\text { also encourage students to seek out faculty } \\
\text { and staff as mentors outside the classroom } \\
\text { It takes more than offering office hours } \\
\text { Transition from faculty/student interaction } \\
\text { to conversations outside the classroom } \\
\text { (classroom as gateway relationship) } \\
\text { Feeling lonely } \\
\text { I didn't have a mentor here (PLNU) because } \\
\text { I didn't make the effort } \\
\text { He sees something in me that is worth } \\
\text { developing. } \\
\text { How do you get a mentor? } \\
\text { Getting a mentor is intimidating } \\
\text { Peers cannot be mentors } \\
\text { On demand mentoring } \\
\text { A little bit from several people instead of } \\
\text { Tuesdays with Morrie } \\
\text { The need for an adult mentor when } \\
\text { transitioning out of a negative friend group } \\
\text { or situation } \\
\text { Positive associates with parents } \\
\text { Negative association with parents } \\
\text { Faith communities } \\
\text { A mentor that leads to therapy } \\
\text { Therapist as a mentor } \\
\text { Conflicted/Emulation/Parental issues } \\
\text { Like a cool uncle who finally screws up } \\
\text { after enough time } \\
\text { Expectations on the relationship } \\
\text { I don't think I have one ideal mentor } \\
\text { Loneliness } \\
\text { Needs to be mutual } \\
\text { The imaging of the mentor } \\
\text { The desire for a mentor } \\
\text { Post-graduate outcomes }\end{array}$ \\
\hline
\end{tabular}


Personal Experiences, cont.

Post-graduate continuing relationships I don't have one specific person

The desire for it

Snippets

Why not me? Why don't I have this?

Formal associated with professional

Someone you admire

Informal associated with personal

Organic

I don't think I have had an "official" mentor

Close door, but made us feel comfortable to drop in anytime

Casual or as needed

Would drop what she was doing if she

dropped in

Breakfast or lunch once a week

I have been to his house and I know his

family. I see who he is

Emulation

The potential transition from

mentor/mentee

to friends and/or colleagues

We're not interacting with people older than us

We're segregated by age and it's magnified at PLNU

What happens when the mentor fails you?

Dealing with the humanity of the mentor

Outgrowing your mentor

We put these images on them 
Appendix I: Coding Scheme Used to Transition Themes into Useable Categories 


\section{Appendix I}

Coding Scheme Used to Transition Themes into Useable Categories

Significant Aspects of College (SIG)

SIGEXP (referring to experiences)

SIGREL (referring to relationships)

SIGACA (referring to academics)

SIGDEV (referring to development)

Descriptions of a Mentor/Mentoring (MENT)

MENTFOR (referring to career or vocational mentoring)

MENTINF (referring to informal or personal development)

MENTNET (referring to a mentoring network)

FUNCTMENT (referring to functions of a mentor)

MENTINTER (referring to interaction or exchange in the mentoring relationship)

Personal Experience (PEXP)

EXPSTRUG (referring to struggling with the failure of a mentor)

EXPISOL (referring to feeling lonely, isolated, marginalized during college)

EXPSURP (referring to feeling surprised at the effort or intentionality of a mentor)

Suggestions for the University (SUG)

SUGSTRUG (referring to the struggle to answer or engage this question)

SUGFIND (the university should encourage students to find mentors)

Other:

MENTSTRUG (referring to struggling with the failure of a mentor) ISOL (referring to feeling lonely, isolated, marginalized during college) MENTSURP (referring to feeling surprised at the effort or intentionality of a mentor 
Appendix J: Structural Framework 


\section{Appendix J}

Structural Framework

Significant Aspects of College

Relationships with peers

Relationships with adults

Development

Academic endeavors

Experiential learning

Descriptions of a Mentor/Mentoring

Formal mentoring functions most associated with academic major and or career goals

Informal mentoring functions associated with personal development and

relationships

Formal relationships as gateway to informal relationships

Multiple mentoring relationships or mentoring network rather than an ongoing

$1 / 1$

Most referred to functions are those of intentionality and presence

Suggestions for the university

Students struggled to answer this question

Encourage students to seek out faculty and staff

Other Strong Themes

Focus group: dealing with the failure and humanity of a mentor

Feeling isolated, lonely or marginalized

The uniqueness of the academic major 
Appendix K: Data Analysis Map 


\section{Appendix K}

\section{Data Analysıs Map}
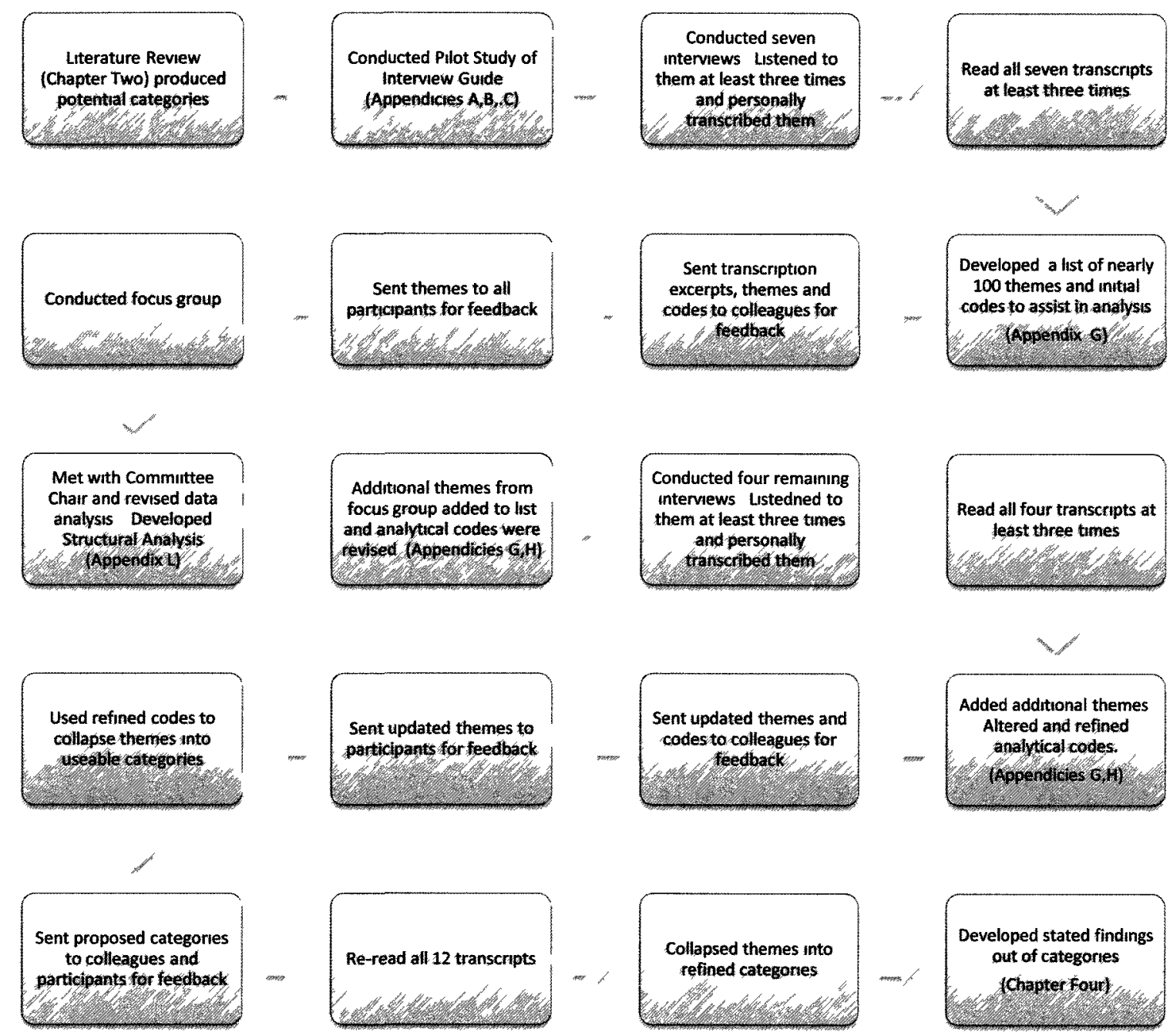
Appendix L: Draft of Invitation Email (Not Used in Final Study) 


\section{Appendix L}

Draft of Invitation Email (Not Used in Final Study)

Dear student:

This email is to invite you to participate in a study on mentoring. I believe that there is a need to better understand how students experience and make sense of mentoring efforts during their college years.

As part of my dissertation, I would like to interview you and find out about your experiences (or lack of experiences) with mentoring while at PLNU.

Mentoring means a lot of things to a lot of people. It's a tough word to define and that's also part of my study.

If you would be able to sit with me for about 60 minutes sometime this summer, I would greatly appreciate it. Please reply to this email to let me know you are interested, or if you have any questions.

I look forward to talking with you about mentoring and your time at PLNU. Thanks for your consideration.

Jeff Bolster

PLNU Dean of Students

619-849-2480

jeffbolster@pointloma.edu 
Appendix M: Research Participant Consent Form 


\section{Appendix M}

\section{Research Participant Consent Form}

\section{Student Perspectives on Mentoring}

Jeff Bolster is a doctoral student in Department of Leadership Studies at the School of Leadership and Education Sciences at the University of San Diego. You are invited to participate in a research project he is conducting for the purpose of exploring undergraduate student perspectives on mentoring.

The project will involve one interview and with a follow-up focus group. Both of these times will be to ask questions about your perspectives on mentoring. The interview will last about 60 minutes. The focus groups will also last about 60 minutes. These times will include some questions about you, such as the kinds of mentoring you have or have not experienced. The interview and focus group will take place at a time and place convenient for you.

Participation is entirely voluntary and you can refuse to answer any question and/or quit at any time. Should you choose to quit, no one will be upset with you and your information will be destroyed right away. If you decide to quit, nothing will change about your student status.

The information you give will be analyzed and studied in a manner that protects your identity. That means that a code number will be used and that your real name will not appear on any of the study materials. All information you provide will remain confidential and locked in a file cabinet in the researcher's office for a minimum of five years before being destroyed.

There may be a risk that participating in the interviews: may make you feel tired. Also, sometimes people feel anxious or sad when talking or reflecting on the things you will be asked about. If you would like to talk to someone about your feelings, you can call the San Diego Mental Health Hotline at 1-800-479-3339. Remember, you can stop the interview at any time you feel tired or for any other reason.

The benefit to participating will be in knowing that you helped educators, psychologists learn how to better understand what undergraduate students think about mentoring. If you complete the study, you will receive a $\$ 5$ gift card to Peet's Coffee. If you have any questions about this research, please contact Jeff Bolster at 619-855-2363 or Dr. Cheryl Getz at the University of San Diego 619-240-4289.

I have read and understand this form, and consent to the research it describes to me. I have received a copy of this consent form for my records.

Signature of Participant

\section{Date}

Name of Participant (Printed)

Signature of Principal Investigator

Date 
Appendix N: Raw Data 


\section{Appendix N: Raw Data \\ (interview transcripts presented in chronological order)}

All names are pseudonyms

Text not corrected/edited for grammar, etc.

Interview with "Tonya"

Graduated May 2010

Biology Major

\section{Interview date: July 20, 2010}

J: Now that you are done, looking back, what would you say are some of the more significant aspects of your time here? Just in general...

T: I think...classroom most definitely. I value education, but I think anything that I did outside the classroom whether that was following up with a professor or my advisor. I got really close to my advisor. Or anything else that I did outside. I did Cov Group, LoveWorks was a big part of my time here, ASB of course, Gospel Choir, clubs, Black Student Union, anything that I did outside that helped me interact with people that I probably wouldn't have. Especially being a biology major and in a major where a lot of students don't interact outside of that department. Early on I found that was important for me to not get sucked into Rohr Science and try to find other outlets.

J: Where did that motivation come from? You just listed LoveWorks, you went on two. After your sophomore year. Listed involvements.

T: I did stuff in the department. Lab assistant, TA

J: That's a lot. Bio major. Minor?

T: No. Let's be real (laughs)

$\mathrm{J}$ : Freshman year, what was one of the first things you did that was co-curricluar?

T: Gospel Choir and that was the longest thing I have done consecutively. All four years. $\mathrm{J}$ : What prompted that? 
T: I saw them perform at NSO and frankly that was like...I hated NSO. I did not have a good experience. It was hard, I felt (I think they have changed some things not) I think that they realized you have $15-20 \%$ of the students who are first generation college students and that was me. I felt like a lot of stuff was over my head and my mom didn't really understand what was going on so we were lost through the whole experience. Gospel choir was the first, I saw them and I met Dr. Flogan after and that was the first connection, I think, to SCU that I had. I was like, "oh this is something that has been a part of my life all growing up, been something that is a part" It was something I had done when I was little, and I had sang all those songs and it was something that was important to me. And so that was the first time I felt like I could be connected to this community. I didn't know what other connections I would have, but I knew that was going to be one connection that I had. And Dr. Flogan was a big part of it, and has been, like, I guess a mentor type all four years.

J: Do you have people that, looking back, you would say are mentors to you while you were here?

T: I was thinking about that while I was driving here. I do, but I don't really know what a mentor is, or how you get a mentor, or how does that set up, do you ask someone to mentor you, I don't really know what that looks like. But I know what natural relationships look like. Someone who is older than me, and who has experienced different things that I might go through, and has volunteered their time and their space, and their life to walk with me through different things, whether it be personal problems, exploration of vocational goals, or whatever that person is there. So I know who those people are during my time at SCU but it's always. Whenever I hear people and I think it's older generation talk about "my mentor" or "I mentored this person" I was like, I 
never could exactly pinpoint what that means or how that happens. I think that is something that I wish was more clear, especially during college, I know the importance of it, especially in the church...the importance of discipleship and stuff. But I don't think that it's ever articulated. How do you get a mentor. I feel like adults are always talking about getting a mentor, and the importance of it, but, like, it's kind of intimidating to ask..how do you ask someone, "can you mentor me?" you know, and what are your expectations of that?

J: How would you define, explain, or understand it? What do you think it is?

T: Someone who is willing to...who recognizes your journey and is volunteering their time and their energy to not only walk with you through that, but kind of have that hindsight to know which questions to ask you, they know how to give you advice, I think in our Christian context it's someone who is able to have, who can look at your life, and look at what you are going through, who can look at these next four years, and be able to show you which ways, show you the ways God is working in your life. And that can be how God is working in you finding your vocation, or it could be in any circumstance. It's someone who has a birdseye view of your situation, of your life, and is willing to guide you. I don't think it has to be. It can be formal or informal, I guess. It can be something, someone who meets with your regularly, is can also be someone not very frequently meets with you. You can feel safe with them. I think safety is a huge thing. You feel safe with that person.

J: who would those people be for you. Did you have those people here and describe those relationships.

T: Dr. Flogan. I guess she, now that I think about it, just different conversations that we had, right before I graduated, I think I realize now that she did reach out to me. Not only 
because I am a black woman, and on this campus she takes that sort of initiative. So I think she did sort of reach out to me at NSO.

My advisor, Dr. Halk. Has been someone for sure. Vocationally, that's been the biggest aspect.

Rug. LoveWorks. Dr. Woo. In random ways has. Most recently, the Purgenans. I guess them this whole last year.

$\mathrm{J}$ : Would you mind, if you could, doing a breakdown of where, how often, what? Walk through them and describe that mentoring was like.

T: Dr Flogan. I would see her every week for practice. It was the least formal. Mostly I knew that I we have shared, similar situations. It's been struggles with family, or just different life things. She had a sense of knowing when something was off with me. Or, when I wasn't well. And so that was important. That's been conversations that we have had through choir. I was also in leadership through choir, so I would meet with her semiregularly through the semester. But, she had a very intuitive character about her, I think. I guess more of a spiritual and wellness type of person. Dr Halk. Has followed me since my first advising meeting. Followed me going through deciding if I was going to be premed, supported me when I decided I didn't want to go to medical school, into public health. Supported me to run for Student Government...supported me to do LoveWorks. A lot of different things. That was the most formal type of relationship because I had to meet with him twice a semester. If I wasn't meeting with him in person, I was emailing him. We emailed a lot. Was a good sound board, mostly listened, validated how I was feeling, especially when I wasn't sure vocationally what I was going to do. I think he's probably been the only person that has seemed like my family. That has seen the evolution of my vocational goals and has supported me and questioned things, supporting 
me in not doing the conventional route of a Biology major. He's always given me insight.

Dr. Woo. I don't know what...he's a person. I had him sophomore year for World Civ and would just talk to him after class. It started with us being mean to each other, being sarcastic...I am a really sarcastic person. And it started from there. We would meet in the caf a lot. I learned more about his life. I asked questins about his life and things he's gone through and last semester we went to a conference. I took him to a conference on racial reconciliation and I had emailed it to all the history porfessors and all the sociology professors. He knew it was something that I strongly valued, especially with what happened at UCSD and how I wrote the article for the Point Weekly. He knew that it was something that I deeply valued and when we went, we drove there and back together and just had lots of good conversations. He's always been someone who has taken interest, not just my well being as a leader on campus, or a student, but as a person. And has expressed that he wants to continue that after SCU.

Rug. Was my LoveWorks leader went we went to Liberia. And, has our LoveWorks team was pretty unique. We still met regularly after Liberia. We would all take initiative to meet. Lot's of good people on that team and we weren't close before. Even at the end of the semester, all of us that were still here. The last three will have graduated. Through those meetings. He was someone who took interest. He went to Ryan's wedding, he married them. He's just that type of person. I knew was interested and he made time for our whole team.

The Smiths. Jeff made it real...I think I was surprised at how forward he was at starting a friendships. Our paths have crossed many times before we knew each other. But, he invited me to go to his Sunday School class last summer, and so I was consistent with 
that all summer through last year. He has been someone who has shown me a lot of what it means to be hospitable. What it means to ask good questions. Think critically about my faith. What it means to think about vocation. And he and I share...we come from hard family backgrounds and I think we have that commonality, too. And so he and Meredith and his home in general, has been home for me. There have been times I couldn't handle going home or whatever, I knew that space was always open. That has been pretty important to me. I think just showing me what it means to think critically about my faith and what I believe and what our tradition believes, what hospitality is. He's helped me think a lot and ask good questions, which I don't think a lot of people are forward enough to do. He showed me, I didn't know, I was having trouble after graduation figuring out what happens to those relationships..do people just cycle every four years and then email or Facebook occasionally but that's kind of it? That kind of sucks. So he made some really good points about using him and other people as resources. And so I think that, when I think about mentorship I think about resources. When I think about mentorship as a college graduate, as I won't be able to go to the caf with Dr. Woo, or I won't be able to come to Dr. Flogan's office, using these people as resources even when I am far away, or as I continue...maybe those resources will change maybe they will develop less of a hierarchy and more of a friendship I don't know. But using those people as resources.

$\mathrm{J}$ : Talk about the difference between formal and informal mentoring that you are referring to. If I am hearing you right, you would classify most of what you have experienced in the informal category and what has been your experience of those.

$\mathrm{T}$ : I don't really know the difference, and I might just perceive a difference between someone. Maybe I feel like a formal mentor is more exclusive. Maybe an informal 
mentorship is more..this person is a resource to a lot of people and it's less exclusive...I am a mentor to this person. That might be in my mind, the differentiation. Seasons, too. There are seasons in friendships and there are seasons here...people will come in and out and I think an informal mentor will be like, I am here, but there are seasons where we are more closely connected or more direction is needed. And there are seasons where there is not.

J: Your list... would you classify any of them as a formal relationship? T: No.

J: Do you know anyone who has had a formal mentor?

T: I do. And I think, I didn't even know people did that. I feel like Todd and Jeff. It's a pretty formal. Established...Jovonne. Dr. Flogan was her mentor and $\mathrm{J}$ : What would you want to get out of a mentoring relationship. What did you need or want out of these relationships?

I think a certain level of wisdom that is just different than a parental relationship. No matter how much older these people are...they cover a wide range of ages. It's not, here is what I think, this is what you need to do. It's, well, this is what I hear you saying and these are some options. It's more someone willing to explore things with me. Kind of a safety of a parent/child relationship brings but not that. I think that is something I want and will continue to want.

$\mathrm{J}$ : What advice would you have for the institution in terms of mentoring?

T: At SCU, it emphasized to get close to your peers, and I think that is a really good thing. ResLife and others do a good job of telling you to get invested in this place. But, I don't think we really talk about, "Get to know people that are older than you, get to know people that are around you and teaching your classes, leading you in extra-curricular 
activities. Get to know them, develop a relationship with them, gain wisdom from them. I know I do this all the time, I turn to my friends, people that are $21,21,22$ for life advice and I see seniors (us) doing that a lot, asking each other, when we're all not really sure what we're doing. And I thought, this is kind of dumb. So that's not really emphasized, I guess. If you connect it to the church, you see a majority of people going to really young churches, going to the Flood, the Rock, only going small groups. We're not interacting with people that are older than us. And I find that as a problem. That's not something that is talked about.

J: Do incoming freshman need permission to enter into those relationships, or a pushing to do that.

T: I think permission, I don't think people do that any more. You hear famous people and you hear of their mentors. Like Dr. King's mentor, you hear of all these people's mentors, but I don't think my generation realizes that people are still doing that. People have mentors, still. We're so segregated by our age, it's even magnified at SCU, at college, since we don't have many non-traditional students and it's magnified on the weekend, at church, because we're only sitting with our peers, our pastor is only a couple years older than us, it's not, I don't know what our institution can do, I just maybe it's a universal problem and a new direction our generation is going in. My life would not be as rich leaving SCU if I didn't develop relationships with the people I listed. Our lives intersected and went through things, I guess permission to do that...I don't know. I know with some majors it happens more naturally, like with my friends who did research. And that can turn into more of a mentoring relationship...that can turn into. But, that's when you are a junior or a senior. If you are an advisor, is that part of your role. I think I was lucky to have Dr. Halk and the believed that was part of his role. Not 
just clearing me to register for classes. Maybe we look at how we structure advising. That 15 minutes is such a unique time. Might as well make it worth it.

\section{Randy \\ Senior (Transfer student) \\ Major: Pre-Chiropractic \\ Interview: July 27, 2010}

\section{J: How was your first year here last year?}

R: I loved it. I am so glad I came down here. It was the happiest I have been. Out of the three places I have been. It's great down here. This will be my senior year. I am prechiropractic right now, and then I will have a year of Physics and O Chem to take when I graduate. I'll do those, take a year off, do clinical hours, and then hopefully head to chiropractic school the year after. I'll start applying next fall and see what happens. $\mathrm{J}$ : What have been highlights or significant parts of you being in school?

R: The thing I have noticed the most, through athletics, you get thrown in and immediately you have 12 friends. I went to Concordia, and I didn't get along with my coaches at Concordia or Questa, but I had the bond on the team. Here, I get someone like Hamilton and just unbelievable guy, and then having that and being able to hang out with those guys every day because you are in practice. That's the thing I Have noticed most, having that close knit group you can depend on.

$\mathrm{J}$ : what was the difference with the other two coaches and now having coach Hamilton? R: I would say personality mostly. His approach is that he wants to win, with quality guys. HE doesn't want to sacrifice having quality people on his team to win. Where those guys, I am not bagging on their mentality, but their willing to sacrifice character and integrity to get the win. That's not the kind of person I am. I don't agree with that, I 
want to win I want to keep certain standards. They would bring in certain guys, who were sketchy, and kind of ruin the chemistry of the team. Here, he has built, it's taken him a couple of years, there isn't a guy on the team I wouldn't take a bullet for.

Everybody is brothers, pretty much it's great. I came down here and everyone embraced me pretty much within the first week. Just having that is great.

$\mathrm{J}$ : When you hear mentoring what does it make you think of?

R: Immediately, I think of my advisor Rugler. I think of my coach. Them having been through what you are going through. Knowing that they are going to try and do what is in your best interest and being able to trust that. And I feel like here you can get that a lot more than the other places I have been. And just knowing that, well Rugler is an outstanding guy. I trust what he is going to say and I know that he is going to do what is best for me and get me going in the right direction. That's what I consider mentoring, and just knowing that that is there for me is great.

$\mathrm{J}$ : So you are with him for once a semester for the little 15 minute session.

R: And then I have him for maybe two or three classes a year, too.

J: Let's talk about those two relationships. Tell me about your relationship with Rug and then your relationship with coach. It sounds like you would call them mentors, so what does that look like?

R: Rug first. Rug is the relationship isn't as intimate as the one with coach. It's more professional as to where I am trying to get to a certain point but he's not an every day basis here we'll talk about my family and stuff...it's strictly career focused and centered. I can go in there. Right now I am doing an internship at a chiropracting office and he set the whole thing up. I'll go in there and we'll talk about it, I got into class and he asked me how's your rotation going? That support system and he's there. Whereas a coach 
Hamilton, I see him every day and he invites us over to his house, we'll eat, we know his family, he knows my family, it's a deeper level and I think that not taking anything away from Rug, just the time we've spent together as a basketball team and my parents are at the games, you can develop that deeper relationship. We'1l have devotionals on Friday, and he'll invite some people in, but most of the time he does them and so one time he even brought his wife in and they got deep into their relationship and talked about relationships. Having that, and seeing who he is, you can connect on a more personal level and just knowing that ... I have always, I grew up the youngest of 5 and have always been able to look at people and learn from them. I learned from an early age. I could see what they did wrong and just pick and choose and I think that makes me, I have a lot easier time being mentored, whereas other people want to make their own mistakes. I would say that has a big impact on it.

J: Would you say you were looking for that when you came here? As a college student, 5 years of college and three schools, did you want that in your life or was it more when you got here, oh man, this guy is telling me about his life, talking to me about his marriage, etc.

R: I wouldn't say I was looking for it like in the athletic department. But through Rugler, just cause I this is my family I have nobody in the medical field or anything. Their all teachers, and so I was definitely looking for that and when Rug provided it that was great and I responded really well to it. And then whereas I wasn't really expecting that with coach, but just having it and seeing it. He came up through Point Loma, and just having someone who has been in the same situation. So there is that credit you can give them. He's been there, he knows what is going on. Let's listen to him. 
J: Guys on the team, etc. College students. Do you think college students are looking for a professional or personal mentor and so they find it, or do you think they get to a place like this and go, "there are good people here" and it opens them up to the idea of hanging out with someone who is older.

R: You will notice that on the team. You look up to the seniors coming in and they set the example and the precedent. Looking around campus. I got lucky since I was on a sports team, and being at a smaller institution you can get plugged in and have that mentor. Whereas certain kids just want to get in and get out and they don't take the opportunity to get plugged in and they never have the chance to have that mentor. Or they will just be going through the motions and never take the opportunity to meet people. And so I think that maybe their chance of getting a mentor is less and they might look into a student or something like that and just try to find it in their friends. Which I think is a disadvantage. Just because of what I have experienced.

$\mathrm{J}$ : It is different for athletes. Do athletes face more challenges, do you need a mentor more or less?

R: Personally, just the way I was brought up and taught, I don't need someone telling me cause athletes are in a spotlight obviously. At a smaller school, people come to the games, they're gonna know you. We're held, don't get me wrong we get a lot of benefits, we get a lot more advantages of normal students. But the first time we meet they say, "ok you are going to be in the spotlight, you are going to be held to a higher standard, don't screw up." We're held to a higher standard, but also we're given a lot of advantages. Knowing we represent the whole basketball team, knowing that what we do reflects badly on the athletic department. We have to keep it in check. Just knowing that. 
A normal student represents themselves. Other than that, here, just being part of the team you have to be held to a higher level.

J: You have talked a little bit about your family. Do you find connections between the way you are raised and the way you think about mentoring...good or bad.

R: Just because...most people would look up to their parents as their main mentors, and then being able to have that relationship and being away from the family. Maybe looking for another mentor, finding it in a coach, advisor, whatever.

$\mathrm{J}$ : Is there a difference between formal and informal mentoring?

R: I would describe Ethan as a informal mentor, and Rug as a formal mentor. Both are good, it's great to have both. In a way, being able to talk with coach, Rugler is that straight professional aspect.

$\mathrm{J}$ : What has Ethan done that made you feel like you can have that kind of relationship with him.

R: Well, it all started with the recruiting. When I called and we talked, he was open. As soon as I get down here, we have a retreat. He's had us at his house, we met his family, and really opened his arms and let us in.

J: Are there things that can happen to cause students to be more open to it?

R: I think that it depends on the personality of the student. If it's there, then it has to be the student who takes them up on it. The school can't rope them in on it.
Alex
Graduated May 2010
Nursing major
Interview: August 4, 2010 
J: Highlights for you while you were at Point Loma. People, places, high points for you?

A: significant hesitation. One of the first things...my roommate. That first year, we clicked. We were best friends and most people hated that first year, but I loved it. J: did you know each other before you came in?

A: No, we just came in, met and talked. That made it...we started off right. Even though, we were roommates for two years, and then went separate ways. Became friends with new people, we still became close. And it made it so much fun. I know a lot of people who left because roommates were awful. I feel like there are so many little things. Definitely India. After my sophomore year. Not the leaders, but bonding with the girls. I had been to Africa the summer before my senior year of high school. $\mathrm{J}$ : What about the whole Nursing major for you?

A: That in and of itself was crazy. First year, I have never cried so much. Never been more disappointed in myself. Nursing is completely different. I would study for days and still get a 78 on a test. I felt like I didn't know anything. It was hard, but in Nursing you make friends, they understand what you are going through. Good or bad, they know what you are going through.

Nursing school makes you realize how much you know and learn over these years. Even though I feel like I still don't know much, it's all in there. Graduation was really fun. I didn't dwell on it, but it was a fun time. We had Nursing pinning, graduation, family, it was so fun to have family there. I feel ready for life, ready for work and I didn't feel that way when I graduated. But, now that I am in it and working, I feel ok with it. I don't know what I would be doing with my life if I wasn't nursing. Nothing else really entertains my mind. But, it's good. 
J: A little more specific. DO you feel like you had mentors during your time?

A: I don't feel like I had mentors. Trish and Leanne...I could go and talk to her about anything. I had her as a teacher and maybe that turned into a mentor type thing. During my junior year. I could go in and talk to her about a class, or a professor. She would help me get through that stuff.

J: Was she your academic advisor?

A: No, she had been a professor and I just trusted her

J: So I am curious what she did that gave you permission. You would go to her office I assume? What did she do that gave you permission to go and talk with her?

A: She was always open. A lot of professors say that, but with her you go and stop in after classes. We would drop in and just say hey, and end up talking for 45 minutes. J: Would she keep her door open?

A: No, it would be closed. You would just knock. She would drop everything. I would ask her, "do you have time to talk right now?" I don't know what she did. She's also a very Type B personality...very calm and she laughs things off. If something goes wrong, she'll say, ok go and fix it. And I think especially in nursing, we needed that, her personality.

She could always understand where you were coming from. There wasn't one thing that made her more attractive than another person. She was nice and fun.

J: Did you ever talk to her about personal stuff?

A: Ummm...I would talk to her about my job search. My classes, what I was feeling about them. But not the rest of my life.

J: Did you have any adults that you would talk to about boys, roommates, stuff like that? 
A: No. Not really. With Chris, it would come out once in a while. Not someone that I could say, what do I do about this or where do I go from here?

$\mathrm{J}$ : Have you ever had that kind of adult in your life?

A: Yes, when I was freshman or soph in high school at out church A group came and they started small groups at our church and I think she was 24 at the time. And I was at that time, going through hard stuff at home with my mom that I didn't want to talk to anyone about. Her name was Leslie and she as always so open to me talking. We still talk. I would consider her my mentor, my older sister. That was a long time ago. J: How would you define a mentor?

A: Umm. I think first someone who is not my parents. Someone I can, I guess it depends on your parents. But I can tell my mom something, but she always has to give me advice or tell me what to do with it. What to think about it. Sometimes I just want to share my feelings with you, and you say that is really hard. For me with a mentor it is someone who will listen to you and give you feedback, and maybe share an experience that they had. Just to remind you that you are not on your own. College is all about finding who you are.

Your beliefs and realizing your life and I think that would be good in a mentor. Someone to bounce questions and ideas off of. And I don't know if you need to hang out with them necessarily, maybe more of a professional friend. I think you can share more with someone you are not super close to.

J: Do you look back and feel like you missed out because you didn't have that here? Or do you feel like your experience was full and rich and you did the work you needed to do here?

A: I think it was a good experience. I think there are definitely times I wish I could have 
had someone to talk to. Other than my roommates. Which we talked all the time. My friends or parents. Just someone older that maybe, I was stupid and wasn't involved, and they had mentors set up in nursing. Seniors would mentor sophomores. Be their senior students, but I don't think I realized how hard it would be. You can talk about it with your friends all you want, but it's not someone older to tell you that you are going to get through this. I had one professor when I got a low grade on a test and I went to her and just cried and she said, don't worry about it, it won't matter when you graduate. It may matter now, and it hurts and it's awful, but your not going to care about it in a few weeks, and when you graduate. It's not going to matter and when I look back on it, she's righ. So I could tell my parents, but they couldn't relate to it, or understand what I was feeling about it. I guess that means to me that it would be good to have someone that understands what you are going through. Especially in college, someone who knows your field of study. But, it's hard, you can't, be open.

Another good quality in a mentor is to be open, maybe with their own life. As a mentee you are more nervous about what your mentor thinks of you.

J: So the openness would be with personal failure or success, but to be approachable. And I have read that many students are attracted to the informal mentoring you are describing, not so much a formal system.

A: In my new job, they have a mentorship there. And at first I was like, I really don't want to have to meet with someone every week...you just don't want to do that sometimes. The lady heading it up came and talked to us about it. You get paid, to meet with your mentor. You have to meet at least once a month. And you get paid for an hour. They don't just assign a mentor to you, you write down hobbies, things you like to do, what kind o people you like and you give it back to them. She goes around and gives 
you a lists. It's been really, really successful. I know some that go surfing together, runs together, and it's different for every person, though. Sometimes you become friends with them, others you just meet for coffee. She tells them, the manager, to keep it concise. An hour or hour $1 / 2$ and just be open, attentive.

I guess their rates for turnover with nurses has dropped. I think it's cool, it's formal but not really. If you write down what you want, you can choose and they really want you to be a part of it. But just about everyone has. They know what you are going through is hard, and they know that you will be happier if you do. I want to do it, I still have to fill out the paperwork. You have to share your life, and it's hard but so good once it's done with, once your hour has passed.

J: Any suggestions around mentoring to PLNU?

A: I could see how people would be hesitant to being assigned to a mentor. Have someone...even a group once a month. School is hard, enjoy, get stuff out there. Talk to someone. It's like when you have a question in class and you don't want to ask it because you think no one else has the same question but everyone does. And I think it's the same thing with just going throughout college and figuring out your life. It's so good to have people there. Even me being able to go to Trish to get help writing a resume, applying for a job, I don't know what to do and I need help. And she sent me a copy of her stuff, and help me and tell me you need to be good at this. To have someone ther and enforce what you are doing and that you are doing a really good job at it. For you to know that it's good and you are doing a good job at it.

J: Some of the easiest inroads or connections would be technical or professional development and if natural relationships evolve out of those, 
A: My advisor was ok, butI never wanted to meet with her other than that. It's hard, when you sit and think about it. I don't know what it is that makes you open to sit and talk with some people and to go to them and talk with them and seek advice. Maybe it's just the connection you have.

$\mathrm{J}$ : Why do certain students come here and find people and what is in between these two worlds of those who find mentors and those who don't?

\section{A: I don't know.}

J: Do you think most students, once they are in the relationship, would want and value it or do they want to navigate it on their own? Did you want an adult in that space, or did you want to do that on your own?

A: More on my own. I have always been with my parents, everything has always been their way. They are the parents. As far as dating and personal development, I think it might be good to have an older person there, but as long as you have a friend there. With my roommates, we would share our thoughts and ideas about it and that helps you put it all together. I think that developing myself professionally, in classes and stuff, it is good to have people there. I guess I think one of the things that was huge for me, and Kesley and Tara, we hung out with our professors all the time. They have offered for us to come to their house, and have taken us to dinner. I don't know why they liked "us" taking initiative to talk to them and finding out that they are more than a professors and finding out they have a normal life. I think that is one of the big things that draws you to an older person. Those are the people I was closest to, one who was younger than them, but not just their students. The out of the classroom time.

$\mathrm{J}$ : When you do those times, more hanging out and being together?

A: They would share nursing experiences with us, spending time together and it was so 
fun to be like the professors favorites and enjoy it. I didn't come away from PLNU with tons of friends or that I had a lot of older people over me, but with the few professors they want to hang out, go to dinner, and here how we are doing. That transition, you need that in your life.

Interview with "Mark"

Graduating May 2011 Senior Theology major August 30, 2010

$\mathrm{J}$ : When you look back on the last three years, highlights, significant times, people, things. What have been some of the big ones for you?

M: Obvious Jennifer and Smiths. Jennifer the biggest life change and Smith the biggest influence.

J: How did you and Tim meet?

M: I started going to church and his first Sunday was like my third and so the first Sunday he just sat in our Sunday school and watched what happened. Karen thought I was an arrogant soccer player, which was really funny. I do not play soccer. And, then just kept going. I introduced myself the second week. I'm Mark ...I will be here.

$\mathrm{J}$ : That was your freshman year?

M: Week four. I went to dinner at his house that week, and then I probably went two or three more times to their house. And then Tim pretty much after that pursued me. We'd get breakfast once a week, at least, and even if I wouldn't show up or if I would forget, he would still come back the next week. He was really persistent on meeting with me. Then Jennifer and I started dating and they were central figures at the beginning of our relationship. 
J: Sitting in Sunday School. He's in there and you are 18. You introduce yourself to him. What initiated that? Was he introd as the teacher?

M: The next week they were introd as the teacher

$\mathrm{J}$ : From there, just causal having people over at the housel

M: It was usually just me. Rachel and I were the only consistent attenders, and there were 8 that would come in and out.

J: So it was more them starting with who was there

M: Right. And I just happened to be a new student, but they didn't really know that.

$\mathrm{J}$ : So you are hanging out at their house and started connecting. He started to pursue you and or you him?

M: I thought he was cool, and I knew Karen, but not well. I didn't really become friends with Karen until a year of me and Tim being friends. But, that first year we met a least once a week, but it wasn't a friendship yet. It was pretty much felt like a meeting, "I am getting to know you, I need to process some things. It wasn't like I will call you whenever, stop by your house. We would know when we were going to see each other. J: Where would you do it...when...what did those meetings look like?

M: Usually that first year it was breakfast once a week in the caf or burritos somewhere. $\mathrm{J}$ : And it was the casual and getting to know you?

M: Yes, and then my first summer he asked if I would intern for the summer. I couldn't because I had a job at home. And so at that point, it was that "he sees something in me" that's worth developing. Then when I came back from that summer. They moved right next to campus and it was much more accessible and that second year was completely different. It was four times a week I would see him. Then this last year it was maybe once a week that I wouldn't see him. I would see him all the time. 
$\mathrm{J}$ : What about the second year. What did the context of your relationship look like your second year?

M: It felt much more like a disciple. I would follow him, learn from him, ask him about how church would work. I would read with him. It was different in the sense that I felt more freedom to call him. I called him all the time...if Jennifer and I were fighting. He walked through a lot of our fights with us that second. Any year that we got to a place where I had said what I wanted to say, and she had said what she had wanted to say, and were still were screwed and couldn't figure it out, I would call him. And that second year, we strategically planned to have Jennifer and Karen become friends. So, they both liked the Bachelor so we made a TV night and they started watching it. Then they became friends and the four of us started hanging out a lot.

J: Then what did last year look like?

M: Constant. He worked on campus, so I would at least see him once a day. We'd talk on the computer or phone pretty frequently. And last year I moved from disciple to friend and remember that conversation. It was about halfway through the year and I said, I feel like I am your friend. That's weird for me. It was that weird, you are cooler than I am but we're becoming friends. We're becoming colleagues. He said, "we're colleagues, that's what we're becoming, so of course we would would be friends. M: So that's when I started to live in this identity of pastor and friend. Instead of kid who is learning to do everything he does. I started teaching Sunday School every month or two.

$\mathrm{J}$ : would you call them mentor or do you use disciple?

M: Mentor is secular disciple. That's all I feel like disciple is...church version of mentoring. I use them interchangeably when I talk about Karen and Tim. Especially as I 
got to know Karen more, she became a huge resource for me in terms of understanding Jennifer and I eventually would call her if Jennifer and I were fighting. Cause Tim would sometimes be at a loss, or I wouldn't be satisfied with his answer.

$\mathrm{J}$ : This is a very intimate relationship you are describing. What was it in both of you that even enabled this? Were you looking for this when you came? Are you wired this way? Is this a unique pattern for you? I am trying to get at what causes this?

M: He is the first person I have ever had as a mentor/mentee relationship. I feel like there is a bunch of half-ass mentor/mentee where you meet every once in a while but it's not really that important and your not really shaped. He's the first person that I really...people meet us separately and say, "oh you know, you must be friends with, because you guys talk the same way, use your hands the same way I molded to him. And I think that I understood the importance of it, and that's why it was important that he pushed for it even though I didn't. Because my freshman year I really didn't care, it just was like, whatever, because I didn't understand it. I didn't know. If you would have asked me if I needed a mentor, I wouldn't have even known, "What is a mentor going to do for me?" I think he sought it because he knew the benefit it could have in my life. We had this emotional moment recently where I was explaining this relationship I have with this sophomore Sean. I have this weird desire to make sure he's ok, to make sure he doesn't give up on the church, and that he continues to ask these questions, but asks them well. And has good people to ask them with. And Tim was like, "you have your first disciple" and I was like, what the heck, this is full circle, at some point, I learned from Tim what I could. He exhausted his teaching resources and we did become friends and colleagues because he has trained me. I am a mini-Tim now.

$\mathrm{J}$ : At some point he acknowledged that? 
M: I said, he called me a friend and I said that 's weird for me to hear. You calling me a friend. He said, but you are and this is no longer...I am no longer your teacher, I am your friend. And it's weird because he is 29 , and so I feel like my peers that are 20 either don't pursue relationships with people who are older or don't have people who don't understand the importance of pursuing the relationship with those who are younger. And so when people hear me talk about my friend Tim, they expect that he's my age. Then I tell them, no he's married, he's almost 30, wants to have kids. That's foreign to me, because it's not very often that it happens. But it's made me incredibly open. I can call my father-in-law, and say I know you are almost 30 years older than me, but I disagree with the decision you made and I want to talk through that with you or else I can't continue in a healthy relationship with you. And I feel like that is a pretty unique skill for someone in college only because we're not taught how to do it.

J: And you feel like the context of your relationship with Tim and Karen really enabled those skills?

M: Oh ya, it taught me that it's possible and not only possible but necessary if you want to be a resource for people. I won't be a good pastor if I don't know how to confront or how to support. If I can't someone whose 40 , just because she's 40 , then I won't be a good pastor.

$\mathrm{J}$ : To any institution that sees a steady stream of $18-22$ year olds. What do you say to a place like this in regards to mentoring?

M: Your peer isn't your mentor or your borometer. They aren't going to make any better choices than you are. That's dumb. Are you going to ask someone who is in the exact same place in life? There is merit to but when your peer is your advisor, you are setting yourself up for failure. 
$\mathrm{J}$ : Put yourself back in chapel as a freshman, no inclination whatsoever, and we utilize a formal mentoring strategy. Can an institution orchestrate those kinds of relationships? What can an institution do to maybe increase the odds of those kinds of connections, or can they?

M: The answer isn't assignment. If it is assignment, it's unnamed assignments. Adults are assigned students and the adult pursues the students. And clearly that isn't feasible for the whole campus. So, do you just do that with your RAs? Just with leadership? But it often happens freshman year. But even the RD/RA relationship is fabricated, it's not mentorship.

$\mathrm{J}$ : Can it evolve out of those prefabricated relationships?

M: Absolutely. But to say I am going to do this with all my students is foolish... you don't have the capacity for it. But, if an RD can say this is a student I can mentor and then spent time. You have the risk of favorites, but at least you have one who has a good mentor. So you have one who finds a mentor with the RD but 5 who have to look elsewhere.

M: Probably also what compounds Tim and my relationship is that we want to pursue the same thing vocationally. Not only do I want you to be a successful person, but you want to do what I want to do.

$\mathrm{J}$ : Looking for those kinds of vocational alignments.

J: Has there been anyone else while you are here that you would identify as a mentor?

M: On a much lesser level the faculty in the religion and literature. I want to teach and so I want to learn from them. I am probably more proactive and tell them I want to do what you do. 
$\mathrm{J}$ : Do they invite that in class?

M: They say that they have office hours and are available if you have questions. But it's not like they say if you want professional advice, I will mentor you. But the other one is Spiritual Development...Mary, Mark and Syl. Especially Syl. Those are more situational resources. (WEB) If I am in a situation that calls for advice on applying to school, I will stop by the faculty or if I am questioning the seasons and don't know why epiphany I will go to syl, mark mary but it's not a holistic mentor that knows Jennifer and knows my family and the music I like. It's more on demand mentoring.

$\mathrm{J}$ : And yet, you feel comfortable going to them

M: Yes, but I don't know if that is something unique about my personality or if that is just what happens when you spend time with them.

J: Did you feel that way before you knew them? Is there an air that they give off of accessibility or is that something that has been cultivated because of situations and being together

M: But again, I am not. Jennifer is very different from me. She would meet a professor that she really like and never say a word. And I think that's dumb. She thinks that's awkward, it would work, she doesn't have time. And I think you would be surprised...at how willing people are at least here.

$\mathrm{J}$ : What do you see as the fundamental practices of mentoring?

M: persistence, frequency of interaction. The ability to listen only because the most impressive things Tim has said to me have come after some statement I have made about whatever. But he can't respond to me unless he has listened. So it's not a prescribed this is what I need to teach you, but what has been so powerful about Tim is that it has been tied to certain situation moments in my life that the lesson isn't divorced from my life. 
So 1 learned how to listen that night that Jennifer said she was going to dump me because I wasn't giving her enough time. I called Tim and explained that to him and he said, "it's not that you're not giving her time it's that when you are with her, the time you are giving her isn't valuable. $\mathrm{H}$

I would add accessibility and ability to listen. Deep trust, if that's not there, you aren't going to get anywhere. Maybe a better way to say persistent is to say being committed. Out of your commitment comes persistence. If you are talking about organic mentoring, it has to start with the mentor committing to the mentee even before they know it. I am going to hope that someone who is 30 has better perceptive skills than I do, to say that someone who has been in a career or a church or whatever for 10 years longer than I have can meet me and in the first month say I see some things that are good but they need to be grown and at that point say, whether this person likes it or not, I am committed. And maybe it flops and in two months you get to know the person down the road and it's not what you thought. But if there isn't an initial commitment on the side of the mentor, then you can't expect someone who has never been mentored to know what to ask for. But now I can ask for things, I know what to ask for.

Interview with "Anna"

Graduating May 2011

Social Work Major

Interview date: September $9^{\text {th }}, 2010$

$\mathrm{J}$ : This is your $4^{\text {th }}$ year here. As you look back, what have been significant highlights and lowlights for you?

A: Freshman year, I came in and was placed with my roommates and we got along really well. And then, we just kind of got scooped up in this group of friends. And I don't 
know how. It happens every year, there is this freshman group of girls who usually live in Nease, and somehow they always get scooped up by these upperclassmen boys, and somehow I got put into that group. And so that was significant because that was the group I surrounded myself with and that affected ultimately all four years here because that is who I spent all my time with until I got back from Study Abroad. And that's when I stopped hanging out with them. I study abroad the spring of my sophomore year. I hung out with that group freshman, beginning of sophomore year I didn't want to be in that group as much anymore, but it was too hard to pull away. That was all my friends. I still hung out with them, and then I studied abroad. And then when I came back, it just wasn't the same so I stopped hanging out with them.

$\mathrm{J}$ : Your major is Social Work and minor is Spanish.

A: Because I had been planning to go to culinary school before I came to PL. So I was in the interview at California Culinary when the lady put a packet down on the table, and it said what is your passion? And that was when God was like, "not this" J: Had you heard about SCU?

A: I had heard of it because of my church and there where a few people that had come here. After that interview at California Culinary and I realized that was what I supposed to be doing, then I knew that working with the inner city and working with my kids is what I wanted to do. And so I looked at Biola, SCU, Vanguard and Azusa. And I picked SCU because of the campus and they didn't have a specifically inner city work major, so I picked social work because it kind of fit what I wanted to do.

$\mathrm{J}$ : So, what you just described is a very smart, responsible decision making process. Then to come here and start partying doesn't seem to jive with who you are. What happened? Did you party in high school? 
A: In high school I never partied. I was against it, I thought it was wrong. Especially since I was in a leadership position in Neighborhood Ministries and we taught our kids not to drink and not to do these things. That was another reason I didn't and I just thought it was stupid. But then I came here, and it supposed to be a Christian university. So if everyone else is doing it, then I didn't have to be an example for anyone. In high school I went to a public high school, and so for me, everyone knew I was a Christian and so I was being the example. But then to come to a Christian school, then in my mind I didn't have to be the example for anyone. Because everyone was supposed to be Christian, and the first weekend I was here my roommate took me to SDSU because her brother was in a frat. And I started dating a senior my freshman year and that was all they would do on the weekends is party. All the same group of people that party. So I didn't have my best friend Chelsea, who is usually the voice of reason in my head, and I just didn't have a ministry anymore to be an example to anyone. And if all these people are Christians, then I didn't have to be an example to anyone. For me, I didn't think about it happening, and it happened and I got swept up into it. That's just what we did every single weekend. That was our friends. The upper classmen guys are usually the ones that finds that group of freshman girls and they bring them up. And you can watch it every single year and they usually live in Nease. There are about 10 or 12 girls. It's always junior senior boys. That's what got me into it. J: So you did LAS in Costa Rica, Cuba and Nicaragua.

A: I wanted to go to Spain, but my parents told me I couldn't study abroad unless I did a Christian program. Which made me mad because I didn't want to, but part of me also didn't want to party the whole time I was abroad because that would be pointless. Part of me was running away from things, and I just didn't want to be here anymore, so I really 
did want to study abroad. And my sister study abroad with best semester in Uganda, she went to Biola. I didn't really know anything about LASP, but I applied for it, and their program is a lot harder to get into to. They only take 50 students, you have to write three essays, and have recommendation letters. And for most of the other SA programs, you just go. And so I got accepted to that, and decided to go, but I wasn't really prepared. I didn't know what it was, which I guess was better. Because I wasn't expecting anything. And so, going LASP was a lot different. I had a lot of friends that SA in but didn't really do anything. I was in Costa Rica for most of the time. We lived with a family in the campo of Nicaragua for two weeks, no running water, no electricity, and then we did Cuba for two weeks at the end.

A: And I didn't speak any Spanish when I went. And in my mind, I thought well they won't put me with a family who doesn't speak any English, why would they do that to you? But, my professors, most of them didn't speak any English, my family didn't speak any English. All of our classes were in Spanish. I had had summer school Spanish and then a semester here that I had barely passed. So I went, and I don't like doing things on my own, but with LASP, there theme is "in doing we learn" and do if I asked a professor, they would say, "you'll figure it out" or you need to be on this bus to meet this person, so figure it out. On the first day, they met us in San Jose. They gave us money, and said, "ok figure out how to get to school" and we had to figure out the bus system. J: So you get back here, totally jacked theologically, socially, emotionally. A: Their purpose is to make you think, to have you know why you believe the way you do. It pushes you a lot, and sometimes that pushes kids off because that is confusing and then you don't really know why you believe what you believe. J: did you go home that summer? 
A: Yes, but I interned at Neighborhood Ministries and so living in a community that is $98 \%$ Hispanic and being at a place...the neighborhood is my other home and we speak Spanish all the time. I had been part of neighborhood for two years and then when I came to PL I kind of drifted and didn't keep in contact with anyone, until that summer I came back from LASP and got involved there and that was ok for me. I didn't have a hard time, to be in the Mexican culture, and it's different from Costa Rican culture, but it's still not, to be working with my kids.

Then I came back to PL, and then to have a place that is majority Caucasian, and I didn't want to go back and party anymore, and so, I went out one night when I got back to see everyone. And everyone was completely drunk, and I just sat there and thought "I don't want to do this anymore" so I just stopped going.

J: How did your friends respond?

A: Well with that group, I wasn't really close with anyone and I had friends, but I didn't really consider them my friends. So it was they noticed that I wasn't there, but that was about it. There was no effort. I would see them on campus, and they would say, "we went out last weekend" and that was all. And I couldn't even function, I hated it hear, I didn't have any friends. I was lonely for a long time. I wanted to go to a bi-lingual church and I been going to The Rock, and I don't like it. It's too big, there is no community there. And I had been going because that is where everyone goes. And so I wanted to find a bi-lingual church. That's how I found Harbor Mid-City. And I still hate doing things by myself but I went by myself and I met Tucker who had studied with LASP and went here. And I met Nicole and had done Best Semester in Uganda the semester I had. Somehow one day she was sitting behind me in church. She had been emailing me, but I didn't know who she was and then we met at church. She was one of 
the people I got connected with and she felt the same way I did. Which was good, but I still didn't have a group of people. So I started going there, and I started going to Baggage Claim. And that did help, but I was still alone and that was only an hour a week. For me, I had no one. Then I met Tucker, and she had talked to me about her student assistant couldn't work anymore because he was busy with Bio-Chem. The job was very detailed and she needed someone who knew the system, I came up here and asked if she needed an assistant. I didn't know anything about IM or Tucker, and so I interviewed with her and got the job.

And I started doing Bread of Life and getting connected but I still felt very along. J: As you look back, do you have anyone you would say has been a mentor?

A: Tucker.

$\mathrm{J}$ : What does that mean for you?

A: For me, finding someone that has the same heart, the way she lives her life. The things that she loves to do are the same things that I love to do. That part was good, and just having someone to listen to me. She understood how I was feeling, taking the time out to pay attention and listen to me. I didn't feel like I could talk to a lot of people about it, because it doesn't register. To my old friends, talking about my SA experience has no meaning, because they have never really experienced anything and they don't really care. But for Tucker, having her be there for me and seeing the way she lives is somehow, that is how I want to be.

J: How has your relationship grown? What has been the progression of growth for you two? 
A: Going on all the Ministry in Mexco trips and SALT and getting to actually experience thinigs with people.

J: Do you two have regular times set up or is it more casual?

A: We don't specific times, but I know if I need to talk to her, then I can go to her.

J: Do you talk to her about personal stuff?

A: Yes, she's the one person I talk to about that stuff. She's the one person at SCU I can talk to. And especially Tucker because she's just there. And I have a really hard time communicating and I don't like to share, if I chose to I can. It's hard for me. If something is bothering me and I don't really share it. I try to share with Tucker. $\mathrm{J}$ : Could we have found you earlier?

A: If I would have found a way to get involved earlier. I didn't really pay attention. Cause I also didn't know anything about IM or LoveWorks even fr/so year. I sat in the back of chapel I didn't every pay attention, I hadn't ever heard of any of this. No one was involved with anything and so I didn't get involved. And I wanted to. Having done neighborhood ministries, it was my passion and to have lost that for so long, I feel like if I would have gotten involved in something and gotten to know other people. I don't know if I could have gone by myself. I hate being by myself.

Sometime know, I have amazing roommates, I have Rico and Tucker and all of his family. Still sometimes I feel really alone. I just think that PL reminds me of being alone. I don't have great memories here. That part is hard for me sometimes. I don't have great memories until last year.

I didn't know anyone else. Either it was that group that partied, or they had viewed everyone else as these like super Christians and these prude people who don't know anything. So, I didn't know anyone and part of my view was that, so I was alone. I 
didn't know and pay attention to the ministries. Maybe if I would have gotten involved or connected.

J: Do you feel like you belong here?

A: Not really. I don't feel like I have ever felt. I think even fr/sop year when I was in that party group, I didn't feel like I belonged there. I knew I wasn't supposed to be there. And I never felt like I have true friends, and didn't feel like I belonged there. And especially when I got back from SA, I didn't feel like I belonged at all. I felt so different, and isolated. And knowing Casey and Nicole helped. My upper level SW classes and everyone with the same passions, I do feel like I belong there. But I didn't really talk to those people. I remember Leanne was in most of my classes, but I didn't talk to get to know anyone.

J: How do we help student's find their Tucker?

A: Getting involved. You can choose where you want to me, what you want to do, what you are good at.

$\mathrm{J}$ : So the peer to peer invitations are important. Because people are going to get swept up into something.

A: If you are in a group that doesn't pay attention in chapel or goes to school events, then you are stuck in a smaller place, a smaller bubble, you see people they are too Christian, they'll judge me. So even now in my old group of friends, I am known for being involved in ministry and people will come to me and the come to me to want to go. Being able to be that, even my old roommate... "I see how you are and you don't hang out with anyone and I wish I could do that, but I can't"

$\mathrm{J}$ : Is that a courage issue?

A: Yes, since you have been with those people for three years it is hard to walk away. 
Interview with "Henry"

Graduating May 2011

Senior Philosophy/Theology Major

Interview date: September 14, 2010

J: Looking back on college, what were highlights for you?

H: Ivan was this guy, I met him, we became friends instantly, I met Assul, I met Lorena, Edna, and all these people we were just friends that brought us together without having to try. So that was a sweet deal. This was at the end of my freshman year. I met Ivan probably halfway through spring semester. What brought it together for me was finals week, we were hanging out and from then on, I feel like I fit now. That was a huge point in my life. And then going on YouthWorks was another great experience for me, I met other great people. But the only person I really got close to on that trip was Urbano, that is who I became friends with after that. We lived in the same dorm on the same floor, never really talked to each other until three or four months after.

J: When did you do YouthWorks

H: Sophomore year. Summer 2008. I knew Bano and we talked, started hanging out more. We kind of are/aren't we don't talk a lot but it's one of those friendships. And I have experienced this with all Latinos, not just anybody else, and all of the sudden the first time you see them again, it's like time didn't go by. It's a bond, somehow, I feel welcome within this people. There is a sense, something you can't see, I am welcome here, these people like me. I don't have to try and do anything, I can be myself and be accepted the way I am. Which was hard for me to do at the beginning, because people just have to. I didn't connect with any of my roommates, so I am not saying...but we didn't connect. Different sense of humor. The first time I watched The Office, I thought 
it was the stupidest thing I had ever seen. People watch this, get together and have parties around this? I learned to tolderate it, and I learned to start laughing at it, but it was something that wasn't in me. But to me it was so stupid. This is nonsense, I could be doing something more useful. I hate being that kind of person, I'd rather be out doing something that sit around and watch this show. Ivan was a huge part of my first year. I tried ALAS my first year, and there was 5 people there. The guy in charge of it was kind of like, not really excited for it. So then, the following year, Myra started doing it, and I decided to be involved and the first meeting I was there. I was going to be a part of this, and I was going to help out however I could. And I did. Myra was president and I was her assistant. Whatever she told me to do, I did. Fundraising, publicity, all this other stuff and we brought the club back up. Perhaps I could continue that. And so I became the club president, and this is my second year of being president. So it's like, last year was a lot. We had a bunch of people at the beginning, they became friends and got close then the meeting attendance died but you could see these pockets of people still hanging out, which is the purpose of it, this is what I wanted. I don't care if you don't come to the meetings, I know people are busy, I know they have a life, this what I wanted. To create a community, to have the initial spot where people could come and meet, people that are possible having the same experience that I had. This huge culture shock, but they come together in this place, where it's like people a lot like you, people that speak your language, understand where you are coming from and are part the minority of this big campus. And connect and be friends and I still see these pockets of people hanging out, and that's what drives me. ALAS president has done a lot for me, I really enjoy it, and I really enjoy being the person that people that the new students look to, to tell them this is a huge deal, it's not just you. If you need someone, you are here. That's what I feel like 
I didn't get when I was here, "if you need someone I am here" because I didn't connect with anybody.

$\mathrm{J}$ : Do you feel you have anyone here you would call a mentor?

H: definitely after doing Youthworks, Tucker. I knew Tucker prior to coming here. If I was ever lonely, she was the person I would come talk to and tell her, "this sucks, I have no friends" I would talk to her, she was my getaway for a few minutes, we had long conversations, and she would tell me, "stay in there" and I am here and I feel like there is a reason for me being here, but I don't see it. Like New Student Orientation was good, I won't deny that. I just didn't get involved with it either, though I went to the little service. When I was there, I felt very welcome. This is where I am supposed to be, it just felt right. But then, the stuff after, if I feel like I am supposed to be here, but it's not I just don't see why I am supposed to be here. I couldn't see why. It was confirmed by that service, but the stuff that came afterwards, was like this sucks, I really don't want to be here but I feel like this is where I am supposed to be.

J: How did Tucker fit into that? Why would you call her a mentor, what did she do?

H: Just to hear from somebody else that yes, I know it's hard. Just having someone to talk to...I didn't feel like I had someone to talk to. I am very expressive person, if something wrong, let's work it out. I feel like I need to bring it up. I don't want to speak when I am angry. Sometimes I like to think about it and take some time to think about it. So, you and I are having a good conversations, I work through my emotions. Going to Tucker was a good thing, she definitely understood and I would explain to her what was happening to me. And I was looking forward to YouthWorks, and this is a segway into getting friends. We're going to be together for a whole week, preparing before we go, 
doing things. My idea was to come in and make friends that will last. That was my investment to it.

$\mathrm{J}$ : Would you have done it if she hadn't of been the leader? What was it that attracted you to that.

H: What got me interested was that Tucker did it. But the more I thought about it, the more time I spent here, I felt I wanted to be a missionary somewhere. This would be a good way to experience that. And then I talked to Tucker about it and she said, "ya" So we had good conversations and she was always the person I would come to for any advice and I still do. She's been a mentor and a person that I look to for guidance. That's what I would define it as... a person you look to for guidance. $\mathrm{J}$ : it sounds like you have tried to take on that mentoring role yourself with the club H: yes, with the ministry and stuff, I feel like I can contribute a lot. I was in the foster care system and I can somewhat relate to them. It's different, and it is my culture. So coming back from YouthWorks, and I told Tucker I have been praying about it and this is something I am supposed to help, I feel like I could help out. You work in Mexico, I am from Mexico, I could help there is culture barriers, and no matter how experienced you are in the culture, there will always be this collapse somewhere. So I am fluent in Spanish, I can connect with a lot of Mexicans, it feels natural.

J: Did you feel like you had other faculty or staff reach out to you to be that guiding voice in your life?

H: No, I came with a high expectation. Always heard it's a small school and you can have good relationships, and I heard people made good relationships with their professors. When I was here, I didn't feel that or see anybody. Class, out of class. It was powerful when a professor prayed in class, but it never went beyond that. I never 
really had...it didn't feel like anyone had an interest. I understand that they have a busy life, but it was disappointing. You hear about people doing dinner at their houses and stuff, where are all these great professors I was hearing about? A lot of my friends from last year have that, I feel like they put the effort into talking to professors and I feel like that is probably my fault.

$\mathrm{J}$ : Is there cultural stuff in that?

H: I don't know what it is. Last year I got a little close to the professor that I was working with because I spent so much time. If it hadn't been for the group effort, I would not have made it through those classes. And last year was my best year by far in terms of connecting, outside of the Latino community. Being within my major with students.

J: If you could give advice to faculty and staff on mentoring students, what kind of advice would you have?

H: It's hard for me to comment on that. What I needed was just for someone to say, "How's it goin?" But really mean it. If you need anything, come to my office and talk." Everyone hands out the syllabus and says come to my office if you have any questions, but that is what any professor says. If someone would have taken a personal interest, it would have been a bit different. It's not just Tucker, I have someone. I did have one professor, and I went to him with some issues I was dealing with freshman year, and told him some things. I talked with him a few times, and that was good, but I never saw him again.

Everytime I talk to someone in the club, I try to mean what I say. Not let it become a habit, when you have been teaching for so long, it becomes a habit. Here is the syllabus, any questions come to my office." It happens to all of us, not that you aren't interested in 
students, but it has to be renewed. Somehow, having professors rethinking why they are teaching, to really take interest in students. A lot of it feels like it is just class, and a lot of it is just class, because that is what they are interested in. At least in the science department you see it a lot, perhaps saying if you ever need anything and really mean it. That is what I would like to see, to see that building of relationships in and outside of the class. I have done it, especially with the professors who speak Spanish, but not others, maybe the language is a big deal.

\section{Interview with "Erin"}

Graduating May 2011

Social Work Major

Interview date: September 16, 2010

$\mathrm{J}$ : What have been significant highlights for you during your time at SCU?

E: There are so many things. I have tried to be involved and do stuff that matters. You know, student ministries, tutoring, stuff like that. And, for me it's been my relationships with my faculty. For some reason, I just have really hit it off with several of them. Maybe it's my major, or maybe it's just luck, or both but I am close to a lot of them. My friends have been significant, too.

$\mathrm{J}$ : Would you call any of them mentors?

E: I don't know. That's a funny word, I am not sure what it means. I feel like you have to want a mentor. It has to be mutual. If you are curious enough, enough willingness to open up, then you will seek that person out. And I guess how it develops. I get images, if it's a professor, then you are interested in what she or he has to say, so it's conversations after class or things like that. You have to have the curiosity to take that one step further. 
$\mathrm{J}$ : Have you found anyone?

E: I don't think I have one specific that we meet on a weekly basis. But I have always had the desire for that. I have wanted that before. I think I have had snippets of it before. Conversations with Sam Telson. One picture. And I just finished Tuesdays with Morrie today, so my image is of that. Janet Nelson is a friend, too. Someone I knew before I came. Good conversations. In my major of Social Work, good conversations with Kevin but I don't have one specific person. But if that was there, I feel like it would be a huge gift. It's definitely an interest and has been on my mind.

J: Have you ever had it, maybe before you came here?

E: In high school, a young life leader, and in middle school a youth leader as well. I have an image of an older person, someone to get stories from. I feel like I have snippets.

Even looking at the week, not a mentor, but we had Bob Soff over at a friend's house. There is a community living house and I don't know him, but that was significant. This week we've been helping a woman move her husband in a house and listening to her talk. So finishing that book, and then having that I feel like I try to find avenues which is a different thing than I guess a mentor relationship when you meet one on one once a week, but feel like still getting snippets of wisdom by interacting with people who are older than me and through interacting through hearing stories.

J: When I say mentoring, people bring up Tuesday's With Morrey a lot.

E: I think a lot of it is the gift of being heard or understood. To be acknowledged by someone who is older. Sometimes that is more necessary than a list full of what you need to do with your life. Even when Bob Goff was talking to us the other night, and Matt, he said that Bob doesn't always tell him what to do. Bob will tell a story, and he won't give a package, so therefore go and do this... he sort of says, this is my story and then you 
have let it sit with you. Just to be able to share a story and talk back and forth without an agenda of this is how you should live.

$\mathrm{J}$ : Any advise for SCU on helping students to find mentors?

E: Not really...it's such an organic thing and hard to force on anyone. I think students need to look for faculty who show they care and reach beyond normal interactions.

\section{Interview with "Justin"}

Graduating May 2011

Media Communications major

Interview date: October 12, 2010

$\mathrm{J}$ : As you look back over your time at Loma, what have been the most significant times or people for you?

$\mathrm{J}$ : A significant point for me is coming back and sitting in your office. I came from a public school all growing up. I went to a junior college that was pretty liberal and open...do what you want. Lived my life a certain way and I thought morally I was on the right track. I came here and really struggled. My first semester here, it was like it wasn't what I thought, it was overwhelming. I felt like I was constantly in trouble, I couldn't be me. In the classroom, on the baseball field, with everything. I was almost to the point where I thought this was too much, and then I got in trouble. And I cam in here and I sat down with you and Ethan Hamilton and Coach Blather, and they kind of pushed me toward Coach Filmore as well and they started to make me realize everything that I had to lose, and everything I had done to get to this point, and really just the fact that they didn't give up on me right when I had got in trouble and we spun that whole thing so that it had been the worst thing that has happened to me, and it probably the best thing that could have happened to me. 
It opened my eyes and the way they handled it, and the way they stuck with me. I have built relationships with Coach Blather, and Coach Filmore. I still talk to Coach Filmore maybe once or twice a week. Ethan Hamilton, everytime I see him, those are three men that were unreal in turning my life around and it wasn't just because "you're my pitcher and we need you" it was more because they were invested in who I am as an individual and I can tell because now my baseball career is over, and I still talk to those guys as if I was still playing baseball and if nothing has changed. So my relationship with them I guess would have never happened had I not gotten in trouble. I kind of look at that as a God thing, I guess.

Totally turned everything around, I don't know if you want to call it scared straight or just surrounded by the right people or what, but it was pretty major. It was two years ago this Christmas break and was a complete 180.

And now I love this place. The place I was cussing out and cursing, you know, now if anyone ever asks me about SCU, whenever Blather has a recruit in to talk about, or if they have question marks, he sends them to me, because I bought into the fact that it's a process.

$\mathrm{J}$ : Do you have people that have been mentors to you?

J: Ya. Definitely those three. Ethan Hamilton, especially when I was coming into this whole situation, it was right when Coach Land was stepping down and Coach Land was stepping up into the $\mathrm{AD}$ role. He has so much on his plate to begin with, that the mercy and the patience and the way he was with me, and he had so much going on that he didn't have to be that way.

With Coach Blather, it was that you invested all this money to bring me here on scholarship and I am just throwing it in your face. Messing up all the time. Coach 
Filmore, I had never met Coach Filmore and I got introduced to Coach Filmore as here is this kid who needs help and he's screwing up all the time. Instread of looking at me with these preconceived notions, all three of them disregarded the reasons we were here, the reasons we were talking, and the reason we were interacting and started off like it was a fresh book or something. I guess you could say our relationship was based off of me getting in trouble, but that is definitely not what they are now. These are three guys that when I need something, I can go to. When I have a problem, I can go to Coach Filmore. Like I told Coach Blather, I got the itch, I don't know what to do without baseball. He said come on out, come help us.

They are always looking to help me. If I don't call them, they call me. Even more so than people in my family. They keep tabs on me and stuff, and being an hour and a half away from where I live, my parents are doing their own thing. It's good to have people keep tabs on you. When things are bad, to know people are still thinking about you. They have been great.

J: Have one or two of them taken a more intentional role with you?

$\mathrm{J}$ : Coach Blather because he was my head coach and everything. But, I don't know if it is because of his youth, his experiences, or because he saw something in me. He was defiantly one of those guys who was an open book. I could go and talk to him about stuff that I don't think I would be able to talk to other people about. And I don't know if that is because he has this aura about him, or he's super soothing, you know he's this calm guy, or that I can relate to him because he has been there. He's been a baseball player at this school, he was a transfer student at this school, so there is a lot of stuff that we have similar ties and I can relate to with him. And then Coach Filmore, he's got this infectious energy about him. Like I said, if I don't contact them, they contact me. I am 
not kidding, I'll be thinking to myself, "I haven't talked to Art Filmore in a while, I wonder how he is doing." And my phone will ring and it will be Coach Filmore. We have this thing where I feel like we're on the same page about hings. Whenever I am thinking about him or wondering about him, it seems like he is doing the same. So, they both have got me into things and opened my eyes to things that I would never see myself doing before I came to this school. If it's mentoring other little kids, or helping out with that Rockin' at the Point event, where I helped him set that all up. Just the stuff that I am involved in and the things that I have done through them and then things that I have accomplished because of them is just I just step back and if you would have asked me two years ago if I would be doing this, I would laugh. There's no way I would be serving my community, or going to church, or praying with another person. It was really heavy at first, but it's been great.

$\mathrm{J}$ : Tell me about some of those things you talked about that surprised you.

J: First, just the faith aspect. I was always curious about faith and Christianity but it was one of those things I wasn't raised a Christian, my grandparents were Christian, my mom kind of dabbled with it. My dad is an atheist, so I had this real diverse background coming to PL. And, my final two schools I chose between were here and Chico State. Polar opposites. I went on my trip to Chico State and it's like, this is it, this is awesome, this is going to be so much fun. Then on my trip to Loma. So I come down here, went from being dead set in Chico State to dead set in about 5 minutes. And I don't know what it was. I had been here before, so it wasn't like I was awestruck by the beauty. I showed up and PL lost that day. I can't explain what it was, but there was this longing to be here and be a part of this. And I had no idea why. Once I got in trouble, I started exploring that and I was dating a girl, went to Christian schools all growing up, so that it 
peaked my curiosity even more. And then I just had a sequence of things I couldn't chalk up to coincidence anymore. I have to seek this out. And I had to meet with Shaeffer once a week, because it was required. And I would talk to him on a real level. And he said, Art Filmore is a great outlet, you should go talk to him, and I would go and sit with Filmore and I would tell him I am super curious about my faith right now there is so much going on in my life right now, it's time for me to find that. He sat me right down, and showed me what to read.

It can be overwhelming, do I just open to Genesis and start? Do this, do this, and read this and when you do that you will know where to go from there. And I remember thinking you are crazy. Trying to write and sure enough I read and I thought, I don't have any questions, I know what to do now. The more that happened, the more I started to buy into that and into what they were saying. And then on the field, off the field, in life I took off. All of the sudden, the stuff I thought was impossible and the stuff that I would pray for would happen. I'd go on this run, and then the next thing you know I am a member of my church, I go to church every week. I do community service through The Rock with my church, I coach little kids and mentor them through a Christian baseball camp all summer. I help. Personally, I think SCU has done a great job with second chances. For me, I am one of those people who will give someone a second chance, and I like that mercy shown on me. I have never been one to need a third or fourth or more chance. For me, it's hard for me to say..you want to put faith in kids, to give them a second chance, when they get in trouble, prevent them from getting in trouble, so much of that is being in a new environment and its inevitable.

Once you do get in trouble, I was provided with resources to fix it. And SCU gives you an opportunity to fix it. And if it's getting you off of drugs, getting you eligible, 
providing you with tutors, mentors, PL does that. PL is a tool, but you have to use it. For me, I learned my lesson, you didn't have to tell me twice, I don't want to lose this and I was able to fix it. So if I had advice for new students, it would be to take advantage of the resources that you have. Everybody is human, you are going to mess up, if you do mess up, that's not it but it needs to be eye opening. It could be it. A lot of it falls on them and they feel like the victim sometimes, and your not. You are not getting screwed over right now. From a resource, I was given everything I needed to turn my life around and it worked.

\section{Interview with "Haley"}

Graduated spring 2010

Social Work major Interview date: October 13, 2010

$\mathrm{H}$ : I am working at the International Rescue Committee (IRC). I know, it is so great. I am in their security and community health department. They have food and farming programs. We run a food pantry and different farer training programs for the new immigrants that are coming in from already agricultural areas. Mostly my job is doing an afterschool garden program at Crawford High. It's with AmeriCorps. I'll be there for one year. I am learning so much.

$\mathrm{J}$ : What were the significant parts of your time at SCU?

H: My involvement with Student Ministries. Definitely was very significant. And through that a lot of mentoring the way the program is set up. And getting to know Tami. There were a couple of classes I took as electives that I ended up loving them:

Globalization with Dr. Green and Sustainability with Dr. Smith. Those were two classes that I find are extremely applicable in my life right now, which is so good because I 
learned all this stuff in class and I am actually living it out right now and it is amazing to see so many of the things I learned in my classes and talked about in discussions, and are so real right now. I have been very grateful for my education lately. It's been really cool to see how it ties together. And mainly because of the professors involvement. The content of the class was definitely interesting, but it was how the professors connect to things, encourage dialogue outside of class, and different projects. And, so the professors were pretty much the driving force of my interest and involvement.

J: What Student Ministiries were you in?

H: I was involved in the Homeless Outreach Group. For three years. Those were definitely highlights. Academically, I was a commuter my last year, but living on campus was a good experience. The mentorship that I got from Tami was the most impacting probably. Because of the type of work we're involved in. Because of the type of person Tami is and the way she approaches her position, she's so open, and going out to breakfast or lunch with her to talk about issues you are having in your ministry, or different community issues, a better understanding of that was very helpful.

$\mathrm{J}$ : You would call her a mentor?

H: Definitely. I guess I was mentored in other areas, by different professors. Definitely, when I did my honors project the advisors I had were Dr. Green and Dr. Faily and I got a lot of really good guidance from them. And then it's encouraging because even being graduated, the mentorship really does continue in a lot of always. Like I have been working on a project with Jamie Gates, on some sort of advocacy video, so I am able to continue a lot of that kind of work and that kind of relationship now that I am no longer in classes.

I Have talked to other friends who have gone to other schools and they tell me, I don't 
know my professors, I don't go to lunch with my professors, and I am "wow, I really do have something special" That's really cool to see how SCU has developed that kind of community.

$\mathrm{J}$ : Who would you put on your list of mentors while you were here?

H: Tami, Dr. Smith, maybe some others more informally.

$\mathrm{J}$ : Why do you call them mentors?

H: For me a mentor is someone who provides guidance. And is also a friendship as well, so I don't feel like I Have had an "official" mentor but their mentoring has come alongside the friendship that has developed through the involvements. So I consider Tami a mentor because of her willingness to talk through issues, or also offer her perspective from her experiences which has been very helpful. She's experiences pretty much everything we're encountering in our ministries. She offers that developed perspective. And, a mentor offers perspective, has the time to invest in you and what you are doing. Is aware of where you are at and that more checking in here and there.

J: What about Dr. Smith?

H: I think I related to him as a professor because his approach to thinigs. Both Dr. Smith and Tami are really good at listening. Not jumping to conclusions and then offering their advice or not even really

$\mathrm{J}$ : How is that faculty relationship different than your time with Tami?

H: With Kevin, he gets me to think about different issues. He more has the power of suggestion, in what he is talking about. Think about these things, or in different. Like the project we're working on now, it's to advocate to redesign friendship park at the border. And so in working on that project and hearing his perspectives on immigration issues and my just beginning knowledge of everything, too and coming along and just 
learning from him and his work and his passion. When I think of a good mentor, I think of someone who exemplifies a life of passion, dedication to what they are involved in or what they are saying in class is reflected in their life. Like he's on sabbatical right now, and he's working on this project. It's cool see that side of it.

J: Busy, working, students are surprised when someone takes the time ...idea

H: It was an added. I was surprised. I didn't expect her to take so much time. She's busy, all over the place, family, school, And I don't know how she does it. So definitely felt like a privilege to have that kind of guidance. I think it's expected from professors, but many of them come and take the time with students outside the classroom, not even about school stuff, just what's going on in your life kind of stuff. That's incredible to experience.

J: You would not have initiated had they not invited you to them?

H: Ya, a lot of the guidance I have sought out. I don't know. I think I defiantly initiated it, but with Tami let's plan a time to sit and talk in a 1/1.

One thing I have noticed about Dr. Smith is that since the subject matter we cover in class can be really heavy material, he's really good at getting your personal response to a world issue and having you explore what a personal response is and what to do with all these things that you feel, and every class ends with what is our theological, spiritual response look like? What is our calling and he takes it to the next level.

So in my African Cultures and History Class I took with him, the class ended with what is the church's response to a lot of these issues? We read a book about the missionary efforts in Africa and how awful all of that was, and so I think that was important because we're at an institution where you can do that and that kind of response to the next level. 
There is that aspect of spiritual guidance, too not just academic or an emotional mentor, but a very full experience.

\section{Interview with "Kate" \\ Graduated May 2010 \\ Math major \\ Interview date: October 13, 2010}

$\mathrm{J}$ : What were the significant things of your time at PLNU?

$\mathrm{K}$ : Coming here from the home environment I did was really rough. Immediately I was in culture shock, a lot of shock, because I had never been in a faith environment, and because nothing was wrong, and I was even more confused because I was expecting it to be, and therefore it was weird. Why is everyone so nice? They are either fake, or crazy. How are you not pissed at the world? I hated it. I came into school with still a serious cutting problem. And, so I would say that my first experience with mentoring was my RA that year. I don't think she had every handled anything that big. I think that was the first attempt someone made at mentoring me, and I was quickly angered and off completely. You don't know me, don't understand me. Now my RA doesn't know what to say to me, and it's awkward. Looking back, I was fresh out of crazy, more drama with my roommate who left. Another roommate came and left. I was working with Paula Jones all year and bummed at the way she handled it. I guess it hurt me, but they made me feel like I was the problem, I felt even more alone.

Now, I love Kelsey and Paula.

I went on LoveWorks to Dominica. It worked out because of my leaders on that trip, Shelly and John. John told me straight up he was scarred for me to go on the trip because I was young and he thought I might get crazy. Looking back, I love that he was 
that honest with me, but then through that trip, instead of saying your crazy, they listened and that was something I never had in my life. John and Shelly simply listened to my life and told me it wasn't my fault and nothing I had every heard. It was freeing. I was shocked, sitting on the beach where the Caribbean meets the Atlantic, and Shelly said, "It's not your fault" and I said, no, my mom tells me every day that it's my fault. So that was so freeing. The next week, John asked me to preach. I'll work with you. I did it and he said it's the best preaching anyone did that trip, including the pastor and him. And long story short, that relationship, Shelly being older and wiser, and being a psych major, and living and working in the city where I grew up, it felt God given to me. The first time I felt like God had a role of bringing someone into my life in that sense...mentorship, is what it is.

Came home, ended up started to going to church with them in Southeast (San Diego) where I am now. John and Shelly were my first mentors in college and in life. John told Pastor Steve that I was a preacher and I started preaching at random things, and found out I loved it and maybe God did shape my heart for ministry. Because I had always thought about it before, but all my pastors had advised me not to think about it because women weren't allowed in ministry in that tradition. So someone saw something good in me, and thought I was good enough, and maybe God gave me some sort of gifts that were good. The mentorship, of listening, changed my life. Shelly listened, lots of one on one time, constant affirmation, helped me to grasp and hope that maybe I can do this, maybe I can graduate college, maybe I can have a future. On that trip I turned 18 and for some reason I never thought I would live to be 18 , my entire life, I had never thought about what I wanted to be or major in, I am not the girl 
who thought about her wedding day, because I never thought I would get married. So now there is future, and that was never a possibility for me and Shelly was the one to cultivate that. They were mentors to me for a couple of years, and although it wasn't a consistent "I meet with you every other Tuesday" the moments that we had from the initial few months, and really just the people they were became the biggest message to me. And although they are now in Hawaii, Shelly will call and email and she sees me as someone of value, and I guess although I am sure other people do, because she communicated that to me and the way she knew I never heard it, it meant the world. And even though they are gone, I still consider them mentors. They spoke wisdom into my life, and I didn't understand then. As I am growing up and living it, I see now so even now that they are gone, what they have said and who they were, are ministering to me in a very present way.

Coming off that trip and finally admitting to everyone that I had been abused and had a hard life. Because in the neighborhood I am in, this is the norm. I have friends now that are willing to listen. And they suggest the Wellness Center, and so I go in. They gave me Caye Whitlock. And she asked me opening stories. And I learned that there is freedom to feel what I am feeling. I liked her, and I am seeing her to this day. Four months into it. It was so good, and I believe that she's the reason I am who I am today. I am so thankful for her more than anybody. If anybody ahs journeyed with me through the weekly things, when I was alone in Hawaii as an intern.

My junior year, she was the only voice saying if you want to teach, it's ok. Because half the people think I should go be a preacher or missionary and half the people think I need 
to go to grad school and save the world through engineering or something. And, she's the only one saying your heart is for teaching and you are good at it. And I affirm that in you if you are at peace with that.

Any professor in the math departments. I still have this sense, I just thought I worked hard and didn't think I was smart, but they took me. I wasn't getting A's, I was failing Calculus. And Dr. Smith sat down, and instead of saying, what don't you get, how can I help. Said, What is going on? What are you doing this Christmas break. I don't know. And she asked, are you scarred about it? And somehow without knowing it, I didn't know it then, pretty sure that the reason I could succeed in math was because I had way too many other stresses going on. And for him to not count me as stupid, and to see the way my brain worked in class, and my performance on tests, I am so thankful that he saw the correlation, truly sat down and said, what's going on at home because this is affecting you.

And, for a professor to sit down and let me share that ya, I am paying half my mom's mortgage, and paying for my schooling, and these little things. And then all of a sudden I got math scholarships, and wasn't worried about school. So now I work 10 hours a week instead of 30 and that's something so small and it was the world to me. I didn't know anyone had money to do that, and he didn't I don't know where it came from. That was the moment where I thought, these people believe in me, and it made me want to work, not to gain approval and appreciation like I always did with my mom and it never came but because I felt like I could be something. That started then.

A lot about the he saw me through Calculus. B that's a really good grade, especially for your circumstances. And I said, screw my circumstances, I don't want to be special. But 
he said, it's not a choice, you are special and that's a beautiful thing. It's not a bad thing, it's not special bad. You are supporting two kids who are far away and made that more tangible. This is your situation, it's real life, it's hard, but he was a motivator. Mentor.

And something happened to me, the middle of my sophomore year, in Physics. I had been going to counseling for five months, and everything was good with friends. I can't explain what happened. I was sitting at a Physics test and had serious test anxiety. I knew how to do it, but couldn't prove it, and get angry and freeze up and freak out. But I was looking at the Physics test and just pretended that it was just a homework problem, I looked at it and said, it doesn't matter, this doesn't matter, in the scope of all things, it's just a test. The weight was gone, and I just started laughing, straight up lauging, and I said, "it doesn't matter" worked it out. The week before I got a 60 on the test, 9 days later, turned it in. Dr. Sanders emailed me the next day and said, your test is better than my answer key, how did you think if this? You got $102 \%$. That same semester, after Dr.Smith saying these things to me, I started getting As on my midterms, stats, probability. He said, “I don't know what happened to you, but you caught fire and no one can contain you, maybe not even yourself so be careful" I am just letting you know, you caught fire, and I think it's going to stay, and he shook my hand and said, good job, I am proud of you. And then, inviting us over to their home, and to see parents who love their kids, huge mentorship in professors inviting us to their home. 


\section{Interview with "Matt"}

Graduating May 2011

Philosophy Theology

Interview date: October 14, 2010

$\mathrm{J}$ : What has been significant for you since you came?

M: People have always been very open to work with you. Not just students, but the staff. I have always felt like I have connections with them. I think there is a difference between male and female professors. I think that is normal. I feel more connected with male professors. I wrote about this in class the other day and a few women agreed with me. I think that is pretty valid, and you are trying to find someone to model after. Especially for me, philosophy is kind of it's own niche, its own thing, and so there are only two philosophy professors. So there are two kinds of molds. That's a trend in philosophy as well, where women will go to ethics of feminism, and social philosophy and men will study metaphisics or epistemology. That's a big, that is what embodied here. A lot of role modeling was after the male philosophy prof. Which has been good and bad in different ways, because he's a human being. I have taken other classes to balance, and to get an idea of expectations.

$\mathrm{J}$ : Outside the classroom stuff you have been involved with or that has been significant for you?

M: When I first transferred as a sophomore, I did student congress. That was really good. I was VP for Academic Affairs. Basically, I met once a week and we talked about changes and proposals, so I felt very connected to campus with that. I thought most of those people meant well, and there is a lot of different social drama that goes with that and it was a good stepping stone for me. I got kind of tired of it...ready to move on. I think its great for someone going to managerial stuff, but for me I want to do theoretical 
academic work, so I just want to hang out in the library. It was a big distraction, but it was a good way to meet people.

I did debate for a semester, and that was meaningful. And, interesting talking about mentoring with that. The coach was not a very good mentor. He had people helping him out, but it turned into more of a student led aristocracy. Debate kids which is bad because they all kind of have complexes of combativeness and achievement, and so it was sponsorships. He was very hands off, so it gave the students a lot of power, somedays it felt like Lord of the Flies. I was actually promised scholarship the next semester, and I went and worked on debate files over Christmas break, and I was doing all these things. I was trying to do everything, but you can't. And with my partner, we won. He said he'd give me money if I stuck with it. I came back and he said, "someone told me you weren't coming back" and thought someone else told you? It was handled poorly. He wasn't a very approachable guy. So that has a big impact on you, my parents can attest. That break, trying to find identity, my sophomore year, especially the new school, find identity, J: Do you have people you consider mentors?

M: I do. I'd say different types. I don't think I have one ideal mentor that I could go talk to that really understands me. But, that's probably asking too much to have one professor that you just really click with. There are definitely professors I can go to if I wanted to do different areas of study, grad school, I know I could go and talk with them and they would help me. Or they would meet with me.

J: Who would you put on that list and why?

M: John , because he is the Philosophy guy. When I first transferred here, he took me under his wing. Because he knows my dad, and they used to teach together at NNU. So 
it was cool, but it also lead to problems because he has this preconception of me as this kid who he once knew. And I am trying to find my own way. Many times, he'd belittle what I was trying to do. I'd say, I want to do this project, and he'd say, "Are you sure you can handle it" Kind of skeptical at times, and it really bothered me somedays. Because, it's your mentor, you trust him. Even if it was, if it was someone I wasn't so attached to, I think they would have been required to be optimistic. But, I guess he felt more connected, so he felt like he could be more honest. Which, I don't know if it was good or bad. Some days, I didn't like it at all, and once I went a whole semester without talking to him..

It's weird how you fluctuate out. Maybe it was a whole year, all last year I didn't talk to him as much and I treated him more like a professor, not like a friend. Maybe philosophy and theology are special like that, you are used to it, you want to build togetherness, but you are trying to be colleagues and trying to be intellectual. I think that line it blurred and it's an interesting hurdle.

Other mentors...hmmm, in Psychology it would be like Dr. Pfeffel. I know I can go talk to him. Doing an independent study with him right now. And, I talk to Dr. Barrs about my honors project. And he's been giving me input, and Dr. Wright I just met but he volunteered to be my actual mentor for my honors project. Which is interesting because I don't even know him.

It's kind of that atmosphere, people are willing to do things. But, I would have appreciated something kind of like Dr. Wright at the beginning, someone that is like, I am one of those people that if you give me something, I will keep doing it. I'll keep going. All you have to do is encourage me, and I'll keep going. But when they don't return your email like 8 in a row because they don't check their email, not very good. 
$\mathrm{J}$ : Is that a case of intentionality vs lack of intentionality?

M: I think it's more of a personality thing, it's not just me. He's not just like that.

J: How do you define mentoring?

M: Good question. Mentoring is the intentionality, making a point, to know that I believe in you or I am looking out for your best interest. Which, I have never felt in the philosophy department. Because I think they are too lax about a lot of things. And then they change grading policies.

I don't think my parents understand where I am at in my life, they say they do, but I think it's a big thing that a lot kids experience. They honestly do associate more with a certain professor, which is why it's important to have a mentor. Because parents just can't or don't get it, with the differences in our generation and the stress and people want to go to grad school and social life.

J: Thanks. Any other suggestions or thoughts you have?

M: No, not really.

\section{Interview with "Casey"}

Graduated May 2010

Piano Performance and Music Education

Interview date: October 19, 2010

$\mathrm{J}$ : What were some significant aspects of your college career?

C: Overall my experience, I was very involved with the music department. Pretty much my life while I was here. All my experiences with concert choir, actually, as a huge thing. Going on tour, those are very powerful experiences. And I was on the Bangladesh team a few years ago. That was life changing. Those were...Bangladesh was one of the biggest highlights. It was right around then that I changed my major to music. A lot of 
music, as music major, they tend to rehearsing all the time with other people, you get really close, really fast. A lot of good things

J: Did you do concert choir all your years here?

C: Yes

J: What happened with the major change?

C: Every since I was a kid, I planned to grow up and go to med school. And I had it all figured out. And then, I think just I had always done music since I was 5 and it was something that meant a lot to me. It was one of the first classes I took with Jim Swanlon, it was Intro to Listening and it's just one of the "every freshman has to take it" as a music major, and he was so philosophical about it, what music is, why you do it, and how it affects people. So that just really changed my perspective on music. And so, it was through that course that I did change my mind, it was mostly just seeing that my reasons for wanting to go to medical school were the same, I could accomplish all that with music, I wouldn't have to give anything up except for science. That was an intense decision and change.

J: So, do you have people that you would consider mentors or who mentored you while you were here?

C: Dr. Plenyon. I studied private piano with him while I was here. Musically, it's always been..a musical mentor. And then there were some big family situations that happened my junior year that he, I had to tell him about. I explained it to him. He, never tried to step in and fix anything, or be anything to me that I might have needed, he made it very clear that I was ok. It's ok to still if practicing doesn't work the way you want it to, it's ok, and he was very encouraging through that whole thing. Even if he didn't know all the details or anything, it was just he knew something big going on, and he was 
there to support it.

He's been very good through all of that. Just in general, maybe I felt like I made the wrong decision, with being in music, or I am not good enough, he'd always come back with these life coaching speeches, why it is important, how it is a spiritual thing as well, so he was one. And then I did an honors project my senior year, and Joe Clemmens was my mentor for that. She her it was more work, I guess, or more academic, but at the same time she would always throw in these things of like, about life in general, more than just the project.

J: Anyone else? Any faculty or staff you bore you soul to?

C: Not really. I went and saw a therapist in the wellness center a lot, with her, I would share stuff with. Beyond that, I didn't.

J: How do you define mentoring?

C: Whenever I think of mentoring, I think of a person who is older and wiser that you can learn about life from. A person or two, not a therapist, they are there with you through it, through everything, whether they help you in specific things you need help in or not, you learn from them about more than just academics. I don't even know, but I picture older and wiser.

J: Did you feel like your relationship with Paul and Joe had aspects of that in it? C: Yes, I have learned a lot about the career I want to go into, from Dr. Plenyon especially, and observing how he does all of it, what works, what doesn't work, and I try the things he says don't work, and he ends up being right. He's taught me a lot about that. Joe was always more the "you are great just the way you are" person always encouraging me in that way. Where as Dr. Plenyon, you can be better, push yourself, a 
lot of times I need that, I like having a challenge to get better at something. So that worked, from him. 


\section{Project Continuation \\ Expedited Review \\ \# 745}

\section{April 28, 2010 \\ PI: Jeff Bolster \\ USD Sponsor: Cheryl Getz \\ Title: College as a Mentoring Experience}

The research proposal was reviewed and verified as an Expedited Proposal and has been approved in accordance with PLNU's IRB and federal requirements pertaining to human subjects protections within the Federal Law 45 CFR $46.101 \mathrm{~b}$. Your project will be subject to approval for one year from the April 28, 2010 date of approval. After completion of data collection or not later than April 28, 2011, you must submit a summary of your project or a request for continuation to the IRB. If any changes to your study are planned or you require additional time to complete your project, please notify the IRB chair.

For questions related to this correspondence, please contact the IRB Chair, Leon M. Kugler, Ph.D., at the contact information below. To access the IRB to request a review for a modification or renewal of your protocol, or to access relevant policies and guidelines related to the involvement of human subjects in research, please visit the PLNU IRB web site.

Best wishes on your study,

Leon M. Kugler Ph.D., ATC

Director, Exercise Science

Advisor, Pre-Physical Therapy

Chair, IRB

Point Loma Nazarene University

3900 Lomaland Dr.

San Diego, CA 92106

619.849.2376

lkugler@pointloma.edu 